\title{
A Historical Review of the Benefits and Hypothetical Risks of Disinfecting Drinking Water by Chlorination
}

\author{
Philip C.W. Cheung \\ Department of Chemical Engineering, Imperial College, London SW7 2AZ, United \\ Kingdom \\ E-mail: philip.cheung@imperial.ac.uk
}

Received: Dec. 11, 2016 Accepted: Dec. 17, 2016 Published: June 4, 2017

doi:10.5296/jee.v8i1.11338ＵRL: https://doi.org/10.5296/jee.v8i1.11338

\begin{abstract}
This review examines the benefits and alleged risks associated with the disinfection of drinking water by chlorination, through critical appraisal of the historical saga of chloroform as the main disinfection by-product (DBP). The author maintains that the provision of clean drinking water is a survival issue for humankind and supports unreservedly the recommendation by the World Health Organization (WHO) of the United Nations to disinfect by chlorination, for the reasons stated herein. The author aims to lead water professionals to a deeper understanding of the public health issues concerning chloroform and how the corpus of knowledge was attained by colossal multi-disciplinary effort on a global scale.

Origins of the alleged risks of chlorination are traced and the assumptions behind these allegations are questioned. The author welcomes and encourages innovations for improved methods of water treatment insofar that the standards of potability set out by the WHO are met in the very least, but argues that the commencement point of research into new techniques should be an acknowledgment of the development of disinfection up to contemporary times, on the part of water engineers and policy makers. There must be a clear recognition of the horrific consequences of failure to eliminate pathogens and toxic substances. To this effect, landmark tragedies are described to emphasize the point.
\end{abstract}

Significantly, this work addresses topics which are sine quo non to the debate over chlorination but which are often lacking in public discourse, namely: differences in the way cytochrome P450 enzymes oxidize carbon tetrachloride which is not normally a product of chlorination, and chloroform, which is a disinfection by-product; the role of free radical scavengers in protecting the human body; the difficulties of extrapolating experimental results from rodents to humans; the awareness of the complex relationship between 
governments, chemical industries, special interest groups and the public. Also introduced are the aetiologies of some cancers (e.g., Hepatitis $\mathrm{B}$ and $\mathrm{C}$ viruses as the instigators for hepatocellular carcinoma) to juxtapose claims that chloroform in drinking water is the sole culprit responsible for liver, bladder, colorectal cancers and birth defects etc. Other well known human carcinogens and a few inorganic compounds known to cause harm are also depicted. Lastly, a structured approach towards integrating the overarching concepts in the analysis of alleged carcinogenicity is applied to chloroform and the inferences discussed.

The literature reviewed spanned the years $1848-2017$.

Keywords: Chlorination, Drinking water, Cholera, Cytochrome P450, Chloroform, Free radical scavengers, Lipid membrane repair and replacement, Disinfection by-products, Risk-benefit analysis, Cancers, Birth defects, No-threshold assumption, Post-modern deconstructionism, Walkerton, WHO guidelines 


\section{Macrothink}

\section{Rationale for Chlorination.}

\subsection{The Benefits, Alleged Risks, Real Risks and Costs of Chlorination of Water}

\subsubsection{The Paramount Importance of Providing Potable Water}

Air, clean water, nutritious food and adequate energy are essential to life. While $70 \%$ of this planet's freshwater is for use in irrigated agriculture, $15 \%$ in energy and $4 \%$ in large scale industries including manufacturing, only about $10 \%$ is for domestic consumption [1,2]. The systematic and continuous production of potable water is a survival issue for humankind. Water is essential to the complex chemical processes in living cells. The principal objective of treating water for drinking, cooking, bathing and cleaning (10\% of global freshwater use) is to disinfect public water supplies, killing pathogens that cause serious illnesses and death.

A country's water supply is determined by rain and snow. For countries that enjoy a rainy season as part of their annual climatic conditions, the supply of freshwater is not a major problem as long as there are adequate facilities to collect, to process and to distribute water. The sources of freshwater are rivers, lakes and springs, but most of the water is actually underground. In countries where rainfall is very sparse, governments must constantly seek ways to increase supplies of this precious resource. As of 2014, the UN predicts that the world's population is expected to grow by 80 million per annum with an accompanying increment in global freshwater demand of $6.4 \times 10^{10} \mathrm{~m}^{3} / \mathrm{yr}$ [3]. Water, farmland, energy sources, and the expertise to manage and conserve them in a sustainable manner, will become the most precious and most contentious resources in the near future.

\subsubsection{The Earth Summit in Johannesburg 2002}

The UN defines "Improved Drinking Water Sources" as one which, by the nature of its construction and when properly used, adequately protects the source from outside contamination, particularly faecal matter. An "improved" sanitation facility is one that hygienically separates human excreta from human contact, and this may include any of the following categories:

- piped water to yard/plot

- public tap or standpipe

- tubewell or borehole

- protected dug well

- protected spring

- rainwater

An "Unimproved Drinking Water Source" may mean any one of the following:

- $\quad$ unprotected spring

- $\quad$ unprotected dug well

- $\quad$ cart with small tank/drum

- tanker-truck

- $\quad$ surface water

- bottled water 


\section{Macrothink}

The good news is that within the two decades 1990 to 2010, an extra 2.3 billion people got access to these improved sources. The bad news is that, at the turn of the millennium, the shortage of clean water and the inadequacy of sanitation leading to waterborne diseases was (and is still) an acute problem in many developing countries. Towards the end of 2015, some 663 million people worldwide are still using the "unimproved drinking water resources" [4], see Figure 1. The sad news is that, the UN estimated 1.8 billion people to be consuming water contaminated with faecal matter, around the year 2014 [5].

Dealing with water issues was the top priority at the Earth Summit in Johannesburg, South Africa, in August/September 2002. The UN has designated March 22 every year as "World Water Day" with a special theme related to this urgency to mark the annual event. Statistics from the March 2007 conference revealed that, "There are still more than one billion people in the world who lack access to a safe supply of water and instead have to drink from contaminated sources. As a result they face the prospect of illness and even death. 5000 children die every day as a result of drinking dirty water [6]." In 2010, the main theme of the event was "Water Quality". In 2016 the central importance of clean water to achieving sustainable economies, thereby providing jobs all over the world, was highlighted. On $22^{\text {nd }}$ March 2017, the UN reported that 663 million people worldwide lack a safe water supply close to their homes (places of abode). The main theme of the 2017 World Water Day is: "Why Waste Water?". Readers of this paper may be surprised that "Globally, the vast majority of all the wastewater from our homes, cities, industry and agriculture flows back to nature without being treated or reused - polluting drinking and bathing and irrigation and losing valuable nutrients and other recoverable materials. [223]". The call to action is therefore one of treating and reusing wastewater.

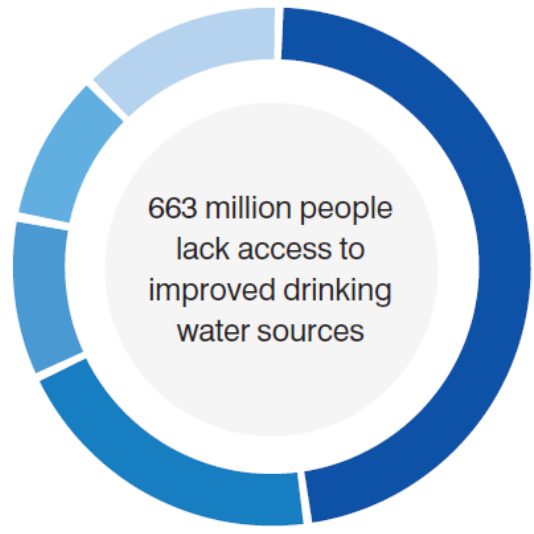

SUB-SAHARAN AFRICA, 319 SOUTH-EASTERN ASIA, 6 SOUTHERN ASIA, 134 OTHER REGIONS, 84 EASTERN ASIA, 65

Figure 1. Geographical regions with no access to improved drinking water by 2015 [4] 


\subsubsection{Failure to Disinfect Water Costs Lives}

One of many known waterborne diseases that are still not eliminated globally is cholera, transmitted through contaminated water and food. The latest outbreak of cholera happened in the United Republic of Tanzania in 2016. As of $20^{\text {th }}$ April 2016, a total of 24,108 cases, including 378 deaths, were recorded [7]. Cholera is an acute infection of the small intestine caused by the waterborne Vibrio cholerae, a genus of bacteria. The disease is manifested as torrential diarrhoea and vomiting. Death can occur as quickly as a few hours after the onset of these symptoms. The disease probably afflicted ancient civilisations but was not often distinguished from other diarrheal illness in ancient medical writings. Longmate (1966) reported speculations of a "virulent form" of the disease in India as long ago as 400 B.C [8]. Epidemiologists now believe that cholera evolved in the Ganges Delta before modern times.

The main strain of Vibrio cholerae in the $20^{\text {th }}$ century is called "El Tor", first isolated from Mecca pilgrims at the El Tor quarantine camp in 1905. "El Tor" is called the "classical 01 serotype", but in 1992 a new strain, the "0139 Bengal serotype", was identified in Calcutta and spread to all cholera-endemic areas in India, demonstrating resistance to cotrimoxazole, neomycin, and streptomycin [9]. The "0139 Bengal" strain had the ability to produce disease in persons who gained immunity by exposure to the old serotype. The 1992-8 cholera epidemic witnessed 200,000 cases in India [10]. In August 2007, cholera killed 115 people in Orissa in India too [11]. Seven cholera pandemics attacked the world in the past two centuries [12] and the seventh has been "affecting much of the world since the 1960s. The disease is still endemic in some 80 countries" [13]. It was once feared that the 1992-8 cholera epidemic in India just mentioned would become the $8^{\text {th }}$ pandemic. With harrowing symptoms and its ability to kill people in their prime, cholera caused more terror than any other disease in European history except the Black Death, the most infamous bubonic plague.

\subsubsection{The Spread of Cholera and Its Immediate Effects}

Typically during cholera epidemics, the infection is spread by a large number of vibrio that enters water sources from the voluminous liquid "stools" (faeces). This occurs particularly in areas of extreme poverty where plumbing and waste disposal systems are primitive or non-existent. The deleterious effects of cholera are due to profuse water loss (20-30 litres/day) and acid-base imbalance in body fluids, and the mortality rate is high in untreated cases (40-60\%). An immediate administration of clean water and electrolytes would save the vast majority of sufferers, were these to be available. Vaccination can also prevent cholera.

\subsubsection{The Alleged Risks of Chlorination.}

The most common form of disinfection of drinking water is by chlorination. The disinfection action of chlorine results from a chemical reaction between hypochlorous acid $\mathrm{HOCl}$ and the microbial cell structure, halting metabolic processes required to sustain microbial life. The reaction of chlorine in aqueous solution with humic acids (complex and gigantic "molecular" networks) which are ubiquitous in natural bodies of water can result in the formation of trihalomethanes, primarily chloroform. The alleged carcinogenicity and other adverse health effects of haloalkanes in drinking water have been the subject of extensive biochemical, 
medical and epidemiological studies, and frequently shape the development of public health policies and legislative matters. The subject demands an integrated approach with all relevant professional disciplines contributing to the debate. The challenge is about how to meet global, perpetual and increasing demands for clean and inexpensive water, while minimising risks to human health, from the many chemical compounds contained in water. Some of these compounds, such as those of the metalloid element arsenic, are of natural origins. A global epidemic of arsenic poisoning spanning seventeen countries and affecting millions has been experienced, due to its presence in water-wells [14]. The fruits of such research must be considered in decisions of public health management.

\subsubsection{The Overarching Philosophy of Public Health Management}

The governance of public health practices rests on the fundamental doctrines of beneficence and non-malfeasance. The first is the obligation to provide benefits to the population and balance benefits against risks. The second is to avoid causing harm. Risks are the probabilities that some harmful effect will occur and lends itself to a combination of risk-benefit and cost-benefit analysis on both the individual and social levels. The former analysis balances the risk involved in some action or event against the benefit to be derived. The latter analysis examines the cost of some action, such as the mitigation or elimination of a risk, in relation to the benefit achieved.

\subsubsection{Halogenated Organic Compounds and the Environment.}

The meticulous attention devoted to the chlorination of drinking water over the last 40 years might lead one to expect that a complete analysis of its benefits, risks and costs to society had already been completed. Water quality issues, unfortunately, have been engulfed in a wider conflict of interest between the chemical industry and the "green revolution" over the use of halogens as feedstock for manufacturing, which may or may not result in products containing halogens, although waste streams will contain them. One notable example was the unpredicted result of using "chloro-fluoro carbons" (CFCs), which depleted ozone in the stratosphere. In 1988, twenty-four countries signed the Montreal Protocol banning the emission of CFCs in developed countries by 2000 and developing countries by 2010. A complete phase-out of CFCs is on schedule. Chloroform was not on the list of haloalkanes to be banned when the Montreal Protocol was signed. In 1999, two Canadian federal agencies jointly published their research in a 118-page report on the behaviour of chloroform in the atmosphere [16], stating that "Chloroform is not an effective agent of stratospheric ozone depletion, since net chlorine loading in the stratosphere from the substance itself and its degradation products is small. Chloroform does not contribute significantly to climate change or to ground-level ozone formation".

Actually, there are many naturally occurring halogenated compounds in the environment. Neidleman \& Geigert (1986) wrote, "Nature has synthesized a dazzling array of halogenated natural products, referred to as halometabolites, broadly differing in their chemical structures and properties. The very diversity of these compounds, both in their chemistry and their sources, suggests that halometabolites have biochemical importance to living creatures far beyond that which our present, sketchy understanding offers" [16]. In the Journal of 
Chemical Education, Gribble (1994) also asserted that there are many more "natural organohalogens" than one knows. He wrote, "Quite astonishingly, the organohalogens dioxin, PCBs, chlorophenols, chloroform, methyl iodide, and CFCs, once thought to result only from the actions of humans - have been found to occur naturally!" The paper is educational and refreshing to read [17].

The best researched (i.e., quantitatively informative, balanced, unbiased and covering all the key environmental concerns) paper describing chloroform from its sources to sinks was written by McCulloch (2003). The paper allays unfounded fears of ecotoxicological and health effects of chloroform [18]. The main points were:

- Anthropogenic sources of $\mathrm{CHCl}_{3}$ contribute only $10 \%$ of the total chloroform flux in the natural environment.

- Over $99 \%$ of $\mathrm{CHCl}_{3}$ present in the environment is in the air (and the mole fraction is $1.85 \times 10^{-11} \mathrm{~mol}$ per mol of air).

- Rate of emission of $\mathrm{CHCl}_{3}$ from identified sources is balanced by the rate of removal of $\mathrm{CHCl}_{3}$ by atmospheric oxidation to form $\mathrm{HCl}$ and $\mathrm{CO}_{2}$.

- " $\mathrm{CHCl}_{3}$ is also widely dispersed in the tissue of living creatures and in foodstuffs but there is little evidence of bioaccumulation and the quantities in foodstuffs and drinking water are not problematical for human ingestion at the highest concentrations found (direct quotation)".

- "Definitive studies have shown that current environmental concentrations of chloroform do not present an ecotoxicological risk, even to fish at the embryonic and larval stages when they are most susceptible (direct quotation)."

- "By virtue of the very small amounts that actually become transported to the stratosphere, chloroform does not deplete ozone materially, nor is it a photochemically active volatile organic compound (direct quotation)."

- "Chloroform has a global warming potential that is less than that of the photochemically active Volatile Organic Carbons and is not classed as a greenhouse gas (direct quotation)."

\subsubsection{Governments, Industry, Special Interest Groups and the Public}

"Characterizing the risk-benefit relationship is critical to setting rational and appropriate public policy. Any discussion of the role of science in this endeavor is inadequately served without discussing these important relationships (Schwartz 2014, [214])." For much of the latter half of the $20^{\text {th }}$ century, national governments all over the world become steadfastly involved in complex relationships between commercial businesses, special interest groups and the general public. Unfortunately, these multi-partite politics often lead to the polarization of views rather than to a thorough benefit-cost-risk analysis. In many "review boards" and "working committees" carrying out "environmental impact analyses", disagreements about the environmental behaviour of a particular chemical compound often tends to proceed by the avoidance of principled debate; for example, refusal to accept scientific facts or theories that do not fit into certain policies or deeply entrenched opinions. Rhetoric is routinely praised as wise judgment; equivocation in the construction of 
compromised formulae seems to be second nature to these "multi-disciplinary" proceedings. Unfortunately, determination of the overall benefits, costs and risks to society is not always top priority for discussion. Often, the stakes are high because every participant is eager to have one's own "values" affirmed and embraced by the rest of society. It has become obvious, with regards to policy-making and decisions about public issues, that professional, scientific and engineering skills, factual knowledge, concrete experience and robust leadership are less important than questions about "values".

While it is true that the social role of Science is to invoke disputable theories of the functioning of modern society and the problems it faces such as pollution of air, water and land, it is unfortunate that the norms of "objectivity" and "impartiality" in research methodology may be lost when scientists support special interests of any sort; they can be tendentiously biased. The genteel culture which is the staple of peer-reviewed literature is sometimes relinquished for self-promoting press releases.

Some groups tend to manoeuvre rapidly to stake out their space in the media, encouraging (otherwise objective) newspapers to announce unsubstantiated research and embellish it into health "scares", revelling in populistic and unprincipled vapidity. This is a serious issue. The masses still believes in the power of Science and they rely on the word of an accredited expert "in a white lab coat". Actually, experts do disagree with each other (sometimes vehemently) and the polemics generated is not easily followed by anyone who is not a veteran in a specialized field. Sometimes, heated debates within the scientific community spill over into the public domain and citizens suddenly become flummoxed at the lack of consensus, not knowing what to believe, but this is hardly the fault of the ordinary folk. The example par excellence is the discredited theory of the MMR (measles, mumps and rubella, also called German measles) vaccine causing autism in children. (The World Health Organization had hoped measles could be eradicated in Europe by 2015.)

Many useful chemical compounds are vulnerable to being banned when governments and law-making bodies are petitioned to eliminate them. Chemical processes that produce haloalkanes as by-products, of which chlorination of drinking water is but one, also come under scrutiny. All too often legislation is enacted that accedes to the wishes of politically astute groups more skilled at attracting public attention to emotionally charged subjects (such as cancer) than the scientific establishment, at the expense of the majority of the public.

At the other end of the spectrum, there are heart-wrenching stories such as those of asbestos and thalidomide. The asbestos industry carried out research in the 1930s into the high death toll of its workers but nevertheless suppressed their findings until the weight of the evidence of fatalities could not be ignored. The truth about the carcinogenicity of asbestos started to emerge. The health-and-safety issues concerning asbestos took decades for formal recognition and many thousands paid the ultimate price in the meantime [196]. Thalidomide wrote an inglorious page in the history of the pharmaceutical industry itself. In the 1960s pictures of horrific birth defects in children began to appear in the news. These defects were soon linked to thalidomide, prescribed worldwide to pregnant women to combat morning sickness. The U.S.A. was spared this horror thanks to Dr. Frances Oldham Kelsey of the Food 
and Drug Administration, who was alarmed at the lack of evidence of the benignity of the drug, although it seemed to be performing well with Europeans. Kelsey pressed the pharmaceutical company for more research, and bought time to attain a deeper understanding of any cause-and-effect relationship. Eventually, thalidomide was taken off the shelves, but not after 10,000 children had been adversely affected [197].

Governments should be the ultimate bastion of truth for the people but lobbying from both the industrial sector and special interest groups can lead to bad decisions with the public being the victim. Science is about seeking epistemological truths. At the kernel of science is the advocation of the high art of gnoseology (i.e., inquiry into the origin, nature, validity and limitations of knowledge). Independent and fundamental research should be funded by governments in the interests of the people, and the battles between lobbyists are no substitution for hard science and cold logic.

The key questions for the public are: Who paid for the research? Why was it commissioned? Was there a political dimension, e.g. who lobbied and why? Transparency is cardinal here. Schwartz (2014) is emphatic on this point, "When using science to inform policy, transparency is critical. However, this transparency should include not only financial ties to industry but also ties to advocacy organizations and other strongly held points of view [214]." Loyalties to professional bodies, college alumni associations and political parties also come to mind. Notwithstanding these human complications, had there been no research and development of chemicals to fight illness and disease, we would not have had safe water, penicillin or antibiotics. Should we eliminate pharmaceutical drugs which have proven to be efficacious medicines, but which contain halogens? Should we stop using non-stick frying pans made of Teflon? Should we replace a disinfectant as effective and affordable as sodium hypochlorite in existing water treatment plants and in households?

\subsubsection{Consequences of Populist Pressures}

Chemical and related industries will face considerable technological problems if they were to give in to the demands of sentimentality. Alternatives to replace existing, functioning halogenated compounds are not always easily identified, or developed rapidly enough to satisfy conflicting demands, and the "environmental-friendliness" of proposed substitutional materials is not always readily demonstrated.

A good example of this is the case of polyvinyl chloride (PVC). An exceedingly rare type of liver tumor called "angiosarcoma" was identified in the USA. Around 1974, there were 25 cases in the entire country per year. Between 1963 and 1974 there were four cases of angiosarcoma reported from a single PVC manufacturing plant in Kentucky [198], and this is the origin of suspicions of PVC being a carcinogen. The hypothesis of PVC being a causative agent for liver cancer is still being investigated in MIT [199]. At the turn of the millennium, the tripartite relationship between government, business and "green" pressure was well documented by an article in the journal Chemistry \& Industry (2001). It cited the publicised intention of the retail chain Marks and Spencer (UK) to eliminate PVC from all its packaging on "anticipated customer demands". The (then) U.K. Department of Environment, Transport and the Regions (DETR) carried out its own research on PVC and "for the first time 
[included] risk assessment and economic analysis [with] conventional life-cycle analysis of the product". The study concluded that "the environmental impact of PVC is not excessive compared with alternative materials, and differences between PVC's impact and that of alternative materials are marginal", and that "PVC was the best for packaging" based on considerations of "wider sustainability issues [200]."

The whole issue of packaging was raised by the European Union (EU) and resulted in a directive about the use of plastics in close proximity to food. Cling film was one of them that raised the issue. This resulted in the "Material and Articles in Contact with Food Stuffs Regulations" in Britain. The worry was about the possible transfer of carcinogens in plastics onto food. Market retailers often take pre-emptive action with the precautionary principle ("erring on the side of caution") before science can reveal otherwise. This is understandable, considering the potential loss of market share and the increasing propensity of a litigious populace.

During the same week of penning addenda to this paper, British Prime Minister Teresa May has just triggered the process for Brexit by invoking "Article 50" on 29 th March 2017. The Brexit divorce has yet to materialize, but in the meantime the UK Government has announced that it will repeal the 1972 European Communities Act that will end the legislation that gives European Union law supremacy in Britain. The "Great Repeal Bill" will be proposed which will put legislative power back into the hands of both Houses of Parliament while Brexit negotiations continue. The Brexit activities also highlighted the importance of King Henry VIII's "Statute of Proclamations" (dating back to 1539), which bestowed the monarch power to legislate by decree alone. Today, these "Henry VIII clauses" give the U.K. Government powers to change old laws already passed by Parliament, therefore allowing the Prime Minister to modify existing laws without Parliament's full approval. Ministers insist that these powers are necessary for the U.K. to "correct" European laws that refer to EU bodies likely to be defunct subsequent to Brexit. It is not known whether the foodstuffs regulations, or any other water and environmental protection regulations will be repealed or replaced. The author of this paper urges such decisions to be made based on sound science.

\subsubsection{Impediment of Genuine Dialogue by "Deconstructionism”.}

Rhetoric from some quarters of the academe reflects an effete yet pervasive intellectual liberalism that resembles a form of literary criticism called "postmodern deconstructionism." Deconstructionists are sceptical about the stability and determinacy of language. To them no method of textual analysis can claim absolute authority over the interpretation of a text. On the contrary, they claim that any text can be read as saying something quite different from what the author appears to be saying, and that the text may actually have multiple meanings. They also suggest that the language of any discourse is at variance with itself, which may lead to an endless regression of dialectical interpretations. In other words, deconstructionists hold that the meaning of language is constantly shifting and cast doubt on the possibility of ever identifying or communicating objective truth. But exactly what deconstructionists understand by "objective truth" or any type of "truth" is not crystal clear because, by applying their "logic", the meanings of those words can be in a state of flux and changeable. 
If they believe (and want others to believe) that no such entity as "absolute truth" exists, then eventually they have to ask themselves what indeed is "human existence"? Is it a true fact that humans exist on this planet? Or is Earth really a Planet of the Apes? Or is it just a matter of semantics? Is "chlorine" an "element"? And what indeed is the difference between the Periodic Table and a coffee table? Well, then, is "deconstruction" no more than just another polemical form of grand narrative, or is it a subtle form of anti-intellectualism?

The Scientific Method provides humanity with a body of knowledge that is useful for solving a large variety of problems. A competent scientist always challenges his/her own assumptions and is ready to revise current thinking in the light of new evidence and new theories. Respectful argumentation and debate are the hallmarks of an intellectually healthy and progressive research institution. Unfortunately, some tend to "cherry-pick" only the information which supports their own views. In addition, deconstructionists may consider the premises of the Scientific Method a mere collection of ambiguous "texts", questioning the usefulness of the pedagogy, boundaries and coherence of the Scientific Method and its dictum (i.e., the formal language expressing, proposing and conferring its operability), attempting to render the adequacy and validity of scientific practices doubtful. Moreover, accepted metaphysical and sociological notions about the nature of knowledge run the risk of becoming "irrelevant" when they are "deconstructed". Taken to the extreme, nothing has meaning because the word "meaning" has no meaning after all, and dialogue soon dilapidates into oblivion.

Fortunately, this has not happened because the format, meaning, purpose and legitimacy of the multi-faceted, multi-perspective and multi-levelled analytical inquiry called "deconstructionism" are fiercely debated by mainstream Critical Theorists in literary fields without remorse. To illustrate the destructive nature and implications of deconstructionism, one could apply its sceptical claims by asking what is meant by "format", "meaning" and "purpose", and by questioning whether "deconstructionism" itself can be ascribed the same characteristics at all. Carried to the extreme, linguistics (the scientific study of languages) will cease to exist as an academic discipline.

Academics and writers have been engaged in critical appraisals of literary "deconstruction". The degree to which "deconstructionism" can contribute to scientific discourse has been gauged and questioned by Professor Mairéad Hanrahan of the Department of French at University College London (2010), in a lecture which she reviewed the contemporary academic status of "deconstructionism" [216]. Professor Noam Chomsky at the Massachusetts Institute of Technology (Linguistics and Philosophy) is no fan of postmodern deconstructionism and forthrightly labelled it as "illiterate gibberish". His polemics has been critiqued by Turner in 2007 [217]. In his book "What Science Knows and How it Knows It" [19], Franklin (2010) lamented that post-modernists do not fight fair, nor do they seek a listening dialogue, because they believe that any discussion would legitimise the "other side" - theologians and scientists (both trying to understand the mysteries of the universe and not totally disagreeing with one another, despite fierce debates erupting between them at every encounter) whom postmodernists spend much time and effort contradicting, aiming to dismantle tradition and science. With candour, Franklin (2010) ridicules postmodern 
"thinkers" such as Jacques Derrida and Michel Foucault who are infamous for their difficult styles of "language" [19]. Indeed, earlier in 1992, philosophers have protested the award of an honorary doctorate to Derrida by the University of Cambridge. Interestingly, in eulogizing Derrida at the time of his passing away in 2004, President Jacques Chirac said, "France has given the world one of its greatest contemporary philosophers, one of the major intellectual figures of our time [218]." Consider this the staunchest rebuttal to all the critics of Derrida.

The act of deconstruction is usually closely followed by undue polemics. Addresses on public health affairs in open forums such as international conferences are necessarily discursive so that a range of important and relevant issues are covered, highlighted and interwoven in an orderly way. Occasionally, random and haphazard polemics surface during the exchange of otherwise valuable ideas. The role, stance and image of scientists in society are scrutinised when presented with a plethora of non-technical, pithily expressed matters for instant comment, and their so-called "expert" opinions are gauged, often for public consumption. Befuddling pseudo-scientific expeditions generate abundant factoids and complicate the picture even further. As demands are made on governments for decisions on urgent health matters, different ethical standards can lead to additional uncertainties and complexities. In other words, there are problems for which no immediate solution can satisfy all parties because their objectives may be diametrically opposed.

\subsubsection{The Need for Fundamental Ecological Research}

It must be emphasised that fundamental research is vital to our understanding of the natural environmental. A deep understanding of the way our planet functions can help us make the difficult choices of how we use natural resources today, and safeguard them tomorrow. Without systematic approaches based on raw field data and critical thinking there can be no strategy on the management of this planet on which workable policies can be based. Therefore academics must become involved directly and decisively in this endeavour. On that front, there are ample opportunities for universities and governments to collaborate in research. First both parties must agree on the relevance of the research area. On fruition, the full significance of research results must be explained clearly and disseminated to the key policy-makers who funded the research. Communication between academics and policy-makers must continue after reports are delivered, and the usefulness of the research gauged over a period of time. Scientists who are sincere about making the world a better place must continue to build public confidence, because the loss of confidence may have calamitous health consequences around the world.

\subsubsection{Summary of the Benefits and Risks of Chlorination}

Chlorination of drinking water is an excellent example in which there are risk-benefit and cost-benefit considerations relevant to the individual and to society. The benefit rendered to the public by disinfection of drinking water is the continuation of Life. This benefit has been linked to a "hypothetical" risk, the proposed existence of which has not been demonstrated unequivocally. The hypothetical risk of chlorination is an increment of the probability of cancer development in the population. However, projected increments of cancer may not actually appear, because there may not actually be a cause-effect relationship between a 
chemical species and its alleged toxicity at the dosages received. Avoiding the perceived risk of chlorination by withdrawing the known benefits of this practice, without supplying alternative methods of disinfection, incurs the real risk of the occurrence of mass outbreaks of waterborne diseases such as cholera, leading to unacceptable loss of individual lives.

\subsubsection{Chlorination is Recommended by the World Health Organization.}

The World Health Organisation (WHO) of the United Nations understands that the real threat of cancer is not to be taken lightly. The Organisation's approach is: gather the data, analyze and interpret it, then build an international consensus on actions to follow, and sets norms and standards. WHO considers the benefits of chlorination far outweighs the perceived risks of cancer, and unreservedly recommends chlorination as the best method of disinfection [20]. As water treatment agents, sodium hypochlorite solutions have the advantage of a residual disinfection effect, and are the only technique so far that assures disinfection from the water treatment plant right up to the tap, which global citizens need and welcome. To the credit of the U.S. Environmental Protection Agency (EPA), it recommends the use of boiling water and granular calcium hypochlorite dissolved in water for disinfection in case of emergencies, e.g., hurricanes and floods [21].

Alternative water disinfection techniques deploy chlorine dioxide, ultraviolet radiation, ozone and ultrafiltration for disinfection and separation of microbes. They are all effective technologies when applied properly. None of these techniques produces chlorinated compounds except the first (but less than that produced by $\mathrm{NaOCl}$ ), but the technologies are more complex and the total costs are higher. Moreover, there is nothing "unnatural" about hypochlorite. Hazell et al. (1996) and Hazen et al. (1996) reported that human white blood cells use their haloperoxidase enzymes to catalyse the oxidation of $\mathrm{Cl}^{-}$to $\mathrm{OCl}^{-}$[22,23], i.e., the human body manufactures its own disinfectant. The hypochlorite ion then attacks invading microbes of the human body and render them harmless.

\subsubsection{Costs to the Individual}

Many individual members of the public are willing to meet the cost of avoiding alleged health risks by purchasing bottled water from supermarkets, or by installing small water treatment facilities at home. However, bottled waters from supermarkets are not necessarily chloroform-free. Gibbons \& Laha (1999) reported that waters which were not chlorinated, such as well-water and bottled mineral water, had been shown to contain naturally occurring chloroform at approximately 4000 nanograms/litre $\left(3.3 \times 10^{-8} \mathrm{~mol} \mathrm{dm}^{-3}\right)$ [24]. The Wisconsin Department of Health Services (2010) instituted an upper limit of $6 \mathrm{ppb}$ of chloroform in groundwater and $100 \mathrm{ppb}$ of total trihalomethanes in drinking water [25]. (c.f., $300 \mathrm{ppb}$ of chloroform and $560 \mathrm{ppm}$ of total trihalomethanes recommended by WHO, 2005, [26]). Lowering the concentrations of all chemical species in public water supplies can be realized by more stringent legislations and novel separation processes, but this inevitably means higher prices for everybody and therefore the consumer pays more. It must be noted that extra safety cannot be purchased in the absence of real risks. 


\subsubsection{Limitations of Chlorination}

Protozoans with their chlorine-resistant spores or cysts have become a clear and present danger to public health. Cryptosporidium parvum and Giardia lambia are responsible for the most recognizable outbreaks in waterborne disease. Ozone is found to be an effective primary disinfectant against them, but ozone does not protect water from other pathogens right up to the tap. Discussion of this topic is beyond the scope of this work but the reader is urged to read the article: Threats to Sources of Drinking Water and Aquatic Ecosystem Health in Canada [215].

\subsection{Disinfection from the mid-19 $9^{\text {th }}$ to late $20^{\text {th }}$ century: a Historical Narrative}

\subsubsection{Dr. John Snow Pioneers Epidemiology}

Discussion of the history of aquatically transmitted diseases and disinfection must commence by paying tribute to the legendary Dr. John Snow (1813-1858) [27]. Born in York, England, he took medical apprenticeship in Newcastle-upon-Tyne, where he was first exposed to an epidemiological crisis. As part of the pandemic that started in India in 1826, cholera advanced relentlessly westward across Europe in the early 1830s, hitting Newcastle in 1831 and Paris in 1832. Snow was sent to provide medical assistance in Killingworth where the miners from the local colliery and their families were victims of a cholera outbreak. He witnessed the illnesses and the ways in which the coal-mining society was affected. Later, he studied in London to obtain professional qualifications in medicine and in May 1838 passed examinations to become a Member of the Royal College of Surgeons (MRCS), permitting him to practice general medicine. Dr. Snow devoted much of the rest of his short life monitoring the transmission of waterborne diseases [28]. In Britain, cholera broke out four times between 1831 and 1854 with a total mortality of 90,000. There were no efforts to investigate its root causes nor to prevent resurgence, and the disease rampaged through the industrial cities that helplessly awaited its arrival. The year 1853 saw outbreaks in Newcastle and Gateshead as well as London, where a total of 10,675 people died of the disease [29].

During the August-September 1854 cholera epidemic in London with a death toll of 616, Dr. John Snow mapped out the location of each cholera death and traced the water source from which each victim's household fetched its water [30]. (Historical timeline: the "Charge of the Light Brigade" during the Battle of Balaklava in the Crimean War took place just a month later, on October 25, 1854.) He then requested the parish Board of Guardians to remove the handle from an ill-fated water pump close to the junction of Broad Street and Cambridge Street, from which all victims had drawn their water. The pump delivered water contaminated by a leaking sewer nearby, and it so happened that the sewer carried wastewater from a home where someone had already contracted cholera. The users of the Broad Street pump came from various neighbourhoods because they preferred the taste of the water. This was some of the earliest evidence that taste and clarity are no indication of water safety. Snow was 41 at the time of the Broad Street epidemic. He had already propounded his theory of promulgation of diseases through water, at conferences in 1849 and again in 1853, but the medical establishment was unconvinced at the time [31]. Even if his theory had been accepted, it would have been almost impossible to locate the exact location of the origin of an epidemic. 
Meanwhile Florence Nightingale, the "Lady with the Lamp", was on leave from the Crimean War and volunteered to nurse the victims of cholera in Middlesex Hospital in London, but half of the admitted patients died [32]. The historian and biographer of the Victorian epoch, Cecil Blanche Woodham-Smith OBE (1896 - 1977) wrote in her first book Florence Nightingale [33], "In the summer of 1854 cholera broke out in London, particularly in the miserable un-drained slums round St. Giles, to the West of Drury Lane. The hospitals were overcrowded; many nurses died; many, afraid of infection, ran away. In August, Miss Nightingale volunteered at the Middlesex Hospital 'to superintend the nursing of cholera patients'. Such is the scenario: the authorities of the hospital were obliged to send out their usual patients in order to take in the patients brought in every half-hour from the Soho district, Broad Street, chiefly fallen women of the district. The prostitutes came in perpetually, poor creatures staggering off their beat. It took hold of them worse than any, and Miss Nightingale was up day and night, undressing them. The women were filthy and drunken, crazed with terror and panic."

By the time Dr. John Snow removed the pump-handle on Broad Street, residents had already fled from the life-threatening scenario in Soho. This reduced the number of deaths in the immediate affected area and the cholera bacteria did not seem to spread beyond it [34]. The story of the Broad Street pump became folklore. More important was the implication of Snow's approach to monitoring an epidemic. He and his assistant John York were convinced that contaminated drinking water was the cause of the outbreak [30]. They showed that the mortality from cholera in persons happening at the time to have clean "up-river" water was lower (i.e., some prevention was achieved) than in a similar population drinking a "down-river" contaminated supply - mortalities from cholera in the four weeks ending August 5, 1854 were 14 in Lambeth and 286 in Southwark and Vauxhall. The cumulative effect of the data that Snow gathered meticulously, relating locations of significant morbidities and mortalities to their sources of water supply, laid the foundation of what is now called "community epidemiology". This discipline emphasises the surveillance of diseases and their occurrences, and the implementation of community-based interventions by officials. The exemplary work of John Snow signalled the defeat of cholera in Britain.

\subsubsection{Filippo Pacini Discovers the Cholera Bacteria}

Meanwhile, the parallel "Asiatic Cholera Pandemic" of 1846-63 (part of the second global cholera pandemic that hit New York in 1851) ravaged India and China. Cholera also exploded spasmodically all over Europe in 1848, during the lifetime of John Snow and his famous contemporaries, the French chemist Louis Pasteur and the German Nobel laureate Robert Koch. It is helpful to look at the political development of Europe at this juncture in order to understand the cholera epidemics in its proper perspective.

The year 1848 is known as Europe's Year of Revolution. Violence began in France and spread, although Holland, Russia and Scandinavia were amongst a handful of countries unafflicted. The causative factors of the upheaval were many and complex: rampant urban poverty; appalling living conditions including those in France and Germany; a population explosion promoting the spread of diseases; continual economic decline; crop failure; sweeping 
technological innovations which inevitably changed individuals' lives; and sharp, clear lines of social, political and financial demarcation between the privileged oligarchy and the masses. All culminated in acute unrest when the European peoples felt they had suffered enough. European countries were not welfare states as they are now in the European Union.

The 1848 revolution did not happen overnight. The toxic brew of negative social factors had been fermenting for more than a decade. The horrors of Parisian slums in the first half of the $19^{\text {th }}$ century were a prime example. The historian Mike Rapport [35] wrote in 1848:Year of Revolution, "Miserable lodgings, a contaminated water supply and open sewers running down the middle of narrow streets provided the unsanitary conditions in which a ghastly new disease, cholera, made its first appearance in western Europe in 1832". Note that cholera also hit Dundee in Scotland, in 1832.

The "Revolution" was eventually quashed but continued to have a tremendous impact until the early $20^{\text {th }}$ century; following 1848 , many European countries developed social reforms and constitutional changes. Cholera's contribution to the revolutionary fervour was debatable, but it certainly added confusion, fear and death to the existing miseries since no formal cure was known at the time. (John Snow did not remove the pump on Broad Street until 1854. The existence of bacteria was just beginning to be suspected in the same year).

Britain escaped the mayhem of the European revolution of 1848 due to the pacification of the middle class by enfranchisement in the Reform Act 1832, and the Chartist (labour) movement. The repeal of the protectionist agricultural tariffs (the so-called "Corn Laws") in 1846 had defused some proletarian tension. In the meantime, British-ruled Ireland suffered horrendously during the Potato Famine in 1845. Widespread deaths in Ireland led to the Young Irelander Rebellion of 1848 in the name of democracy, but collapsed without leading to any immediate social reform.

Parts of mid- $19^{\text {th }}$ century Victorian London provided the perfect setting for a Charles Dickens novel. Living conditions were so bad that a "Sanitary Reform" began to gather momentum in 1848. In his survey of sanitary facilities and public health in an area in Bethnal Green (now geographically in the London Borough of Tower Hamlets, East London), Hector Gavin M.D. (Fellow of the Royal College of Surgeons, Edinburgh) wrote the following report [36] in 1848: "This district (District No. 4) exceeds all those which have gone before it in filth, disease, mortality, poverty, and wretchedness; it abounds with the most foul courts, and is characterised by the prevalence of the greatest nuisances, and perennial foulness. Unlike the last district (District No. 3), there are several gardens in it resembling those already described, but infinitely surpassing them in everything degrading to our civilization.

For many years this district has been notorious as the hot-bed of epidemics. This is easily explained, when the foulness of the streets, the dense crowding in some parts, and the nearly total absence of drainage and house-cleansing, are considered. The drainage, in fact, is characteristic of primitive barbarism; the drains are very near the surface, and some of the houses are built over them; the streets are perpetually covered with the most offensive foetid mud; the population is very dense, as many as 30 persons residing in a single house - 57 houses had a population of 580 persons. In about half a mile square of these houses and 
streets 30,000 persons are congregated; the houses are generally of the worst class, and four-roomed, but great numbers resemble, in many respects, those in the worst parts of the Old Town of Edinburgh - a class of houses common to the French, and which they were the cause of introducing into both places. The houses built by the French refugees are all several storied, and have large rooms on each floor, with a common staircase; the houses are, without exception, let out in rooms; each room contains a family, with a bed common to all; generally it is a work-room as well as a dwelling-room. Ventilation in these rooms is in the most defective state; the atmosphere is most oppressive, and loaded with unhealthy emanations; it is a common practice to retain the foecal remains in the rooms, in order to avoid exposure, and the perfect nastiness of, the common privies. The parochial medical officer has not seen, and does not know of, one water- closet in the whole district.

All the tenements in Greengate-gardens are unfit for human habitation; they are much under the level of the neighbouring road, and are very damp; they smell most offensively. There are great numbers of low public-houses and beer-shops in this district; all these are crowded with lodgers, and thus become great nuisances, and sources of disease and immorality.

Since several streets have been pulled down by the Railway Company, there has been much overcrowding; so much so, that not a habitation or lodging can be had in the neighbourhood, and some persons are, even now, in opposition to the law, residing in cellars, because they can find no place else to reside. The poor inhabitants generally prefer any kind of abode to the workhouse. The occupations of the inhabitants are chiefly weaving and shoe-making; hawkers, toy-makers, and cabinet-makers, abound here, and the women wind silk and cotton. Those small manufactures which are carried on here are chiefly prepared in the prospect of being sold to the ready-money shops, or on speculation.

The earnings of the population of this district are very low and precarious, their habits most irregular, and generally intemperate-ta-day an unexpected "stroke of luck" supplies them with means to indulge their appetites with dainties and abundance-tomorrow sees them deprived of the most inferior kinds of sustenance. No prudence or forethought prevents them from living on the best, when they can, or restrains their ill-regulated appetites. Their common food consists of potatoes and bread, and butcher's meat of a very inferior quality. Numerous chandlers' shops are in the habit of supplying this inferior kind of food, and of receiving goods as pledges for its payment; these pledges are sold at the end of a month, if unredeemed.

Moral debasement and physical decay, naturally enough, accompany the utter defiance of all the laws of health, and the complete disregard of all the characteristics of civilization."

Cholera also visited Florence (Italy) in 1854, the same year it hit Broad Street in London. The Italian physician Filippo Pacini (1812-83) was quite fascinated by this "new" disease phenomenon. Immediately after the death of a cholera patient, he scrutinised the intestinal mucosa. He discovered a comma-shaped bacillus in the same year, calling it a Vibrio [37].

\subsubsection{Ignaz Semmelweis Demonstrates the Efficacy of Chlorine as a Bacteriocide}

One of the earliest and clearest demonstrations of the antiseptic properties of chlorine was made in 1847 by the Hungarian-born obstetrician Dr. Ignaz Phillip Semmelweis (1818-1865) 
in Austria [38]. In the Allgemeines Krankenhaus, a hospital in Vienna, Semmelweis noted that between 1841-6 the average mortality rate from postpartum fever was three times higher in the maternity ward staffed by medical students than the one looked after by midwives. This particular kind of fever begins as a vaginal infection and eventually causes blood poisoning and death. At the time it was not known that the common cause of this maternal fatality after childbirth was bacterial infection, especially by the streptococcus and staphylococcus bacteria, since the existence of the microorganisms had not yet been discovered. To Semmelweis, it was obvious that an epidemic had developed in the hospital: there were 2,700 deaths out of a total of about 40,000 patients from the two wards in the time period mentioned [39]. This is equivalent to 6 deaths per 100 births, unheard of in today's developed countries. Before Semmelweis came to work in the ward where medical students were trained, $30 \%$ of mothers died in that ward. "Today, the disease affects less than $0.0001 \%(1$ in 10,000) of women who give birth [40]."

As part of their training in that particular hospital, medical students performed autopsies in a morgue, while midwives were forbidden the task, therefore eliminating the possibility of cross-contamination between them and obstetrical patients. Semmelweis hypothesized that the fever was a contagious disease spread by hands contaminated with materials from corpses, and that washing hands could stop the transmission of lethal agents to pregnant women. Henceforth medical students were told to soak their hands in chlorinated lime after autopsies. When he also associated the spread of puerperal fever with necrotic (i.e., dead cells and tissues) discharges from living patients, he required students to wash their hands between examinations of patients. The results of his intervention were dramatic. In the year 1848 in which chlorine disinfection was practiced for all 12 months of the year, the mortality rate of women delivered by students fell slightly below that of midwives. In some months there were no deaths. What is now technically called "nosocomial" (hospital acquired) infection had been substantially reduced. Alarmingly, under the title "Hand washing: the Semmelweis lesson forgotten?" Jarvis (1994) exclaimed in the Lancet, "Hospital-acquired infection is still a major cause of morbidity and mortality throughout the world [41]." Is MRSA still killing people in hospitals?

It was most unfortunate that the life of Semmelweis was plagued by difficulties not of his own making. During his lifetime, Hungarian nationalism was ignited and efforts to sever ties with Austria resulted in the "Hungarian Revolution of 1848" (part of the events in the Year of Revolution). Soon after his success with disinfection by chlorine, he and his brothers had to join the Hungarian army and fight the Austrians, a conflict that did not advance his career in Vienna. (The revolution resulted in the Dual Monarchy of the Austro-Hungarian Empire. It was not until 1920 that Hungary truly became a sovereign country.) Also, many of his peers would not accept that disease could originate from their own hands. Physicians and midwives alike soon stopped washing their hands with chlorine water, and the number of deaths increased again. Even so, the medical establishment resisted Semmelweis' attempts to institute changes in hygiene. To add to his woes, academics were critical of the style of presentation of his one and only treatise on puerperal fever, published in 1861, when he was aged 42 . 
Defending his clinical observations and beliefs against open criticism, Semmelweis himself wrote in the Medical Times and Gazette (1862), "After the introduction of washing with chlorine, both mother and child remained healthy [42]". He went on to quote comforting words from a colleague, Dr. Beduar, then First Physician of the Foundling Hospital of Vienna, "The sepsis of blood in new-born children has now become a great rarity, which we attribute to the happy discovery of Dr. Semmelweis, formerly Assistant-Physician of the Lying-in Hospital at Vienna, who has successfully discovered the cause and the means of preventing puerperal fever, formerly so destructive among women and children [42]".

Friends believed that, frustrated by so many unhappy developments, Semmelweis developed mental illness. They took him to a lunatic asylum in Vienna where he died at 47. But a post-mortem showed that he died of septicaemia (i.e., blood poisoning; fatality rates for septicaemia are high, it is a medical emergency and needs urgent treatment) incurred from an injured finger [43]. In an interesting article, Best \& Neuhauser (2004) discussed whether Semmelweis was "a hero or a martyr", or both [44]. The author of the present work believes that he was a true scientist determined to save lives, and despite all odds, refused to compromise his scientific integrity. He sought academic freedom in Vienna to substantiate a hypothesis, unfortunately amongst colleagues with closed minds who, incidentally, had nothing concrete to contribute to the prevention of nosocomial deaths at the time.

\subsubsection{Joseph Lister Uses Phenol as Disinfectant}

In Britain a parallel development in the field of antiseptics was pioneered by Sir Joseph Lister (1827-1921), physician to Queen Victoria. He realised that deaths from surgical operations mostly occurred from infection contracted as a result of unclean practices during the operation. He discovered that using phenol to maintain aseptic conditions during operations significantly reduced fatalities. Like Semmelweis he initially encountered peer opposition. Nonetheless, application of his methods by the Prussian army during the Franco-Prussian War of 1870 (which resulted in the defeat of France and the Unification of Germany in 1871) provided his major career breakthrough, although the war unleashed a terrible epidemic of typhoid in Europe. Over the next decade, the practice of aseptic surgery was gradually accepted. Substituted phenols are still used today in some modern formulations of domestic household antiseptics even though they are lethal if ingested.

In current practice, doctors and nurses use soap and a solution of skin-persistent "Hibitane" (chlorhexidine gluconate) to wash their hands in hospital, and wear sterilized gloves during surgical operations. Historically, the antiseptic was synthesized in a laboratory of Imperial Chemical Incorporation (ICI, Britain) in 1954, and it is still widely used in antiseptic formulations in many countries today.

The struggle to educate the world about personal hygiene and the washing of hands continues into the $21^{\text {st }}$ century. In Imperial College's international affairs journal called Global Village, Professor Alan Fenwick OBE (2010) drew attention to a diverse group of diseases that the WHO in 2003 named "Neglected Tropical Diseases (NTDs)". These diseases are "highly prevalent in rural areas where piped water does not exist and hygiene and sanitary conditions are poor. This promotes hand-to-mouth and water borne infections with insect breeding 
leading to vector borne diseases". Fenwick (2010) graphically described, as an example of parasitic worms affecting humans, "Three species of intestinal worms infect the 'bottom billion' - those people who live in poverty in the poorest areas of the poorest countries in the world. They are hookworm (Necator and Ancylostoma spp), whipworm (Trichuris) and the roundworm (Ascaris lumbrichoides). These worms inhabit the human gut and live off our ingested food while their eggs are passed out in our faeces. They have no intermediate hosts; in poor hygienic conditions the last two (types of worms) are ingested, while hookworm undergoes a free-living stage before reinvading a human host through the skin [45]”.

\subsubsection{Pathogenesis of Cholera}

The general sequence of events in the bacterial disease mechanism of cholera is well known and is described here. After entering the human host by contaminated water or food, the facultative anaerobic, gram-negative, shaped like a curved rod (Figure 2), and highly mobile bacteria Vibrio cholerae (sp., predominantly of the serotype 01 and 0139) must swim and attach themselves to microvilli of the brush border of epithelial cells of jejunum crypts and multiply to the extent that colonization from jejunum to colon is possible. (A bacterium that can be stained blue is called "gram positive". A bacterium that cannot be stained blue because the cell wall stops the penetration of the blue dye is called gram-negative. Also, the antigens and antibodies in body fluids and tissues identify bacteria because these indicate what type, or "serotype", these bacteria may be.) For healthy individuals, ingestion of a large amount of the bacteria is necessary to overcome the acid defence of the gastrointestinal system, e.g., by deliberate consumption of a meal of raw (uncooked) seafood, before cholera can develop.

Vibrio cholera does not actually damage the intestinal mucosa physically, but the exotoxin (i.e., excreted toxin) they produce is a two-unit protein of molecular weight 84,000 that attaches to the glycolipid ganglioside (complex carbohydrates) $\mathbf{G}_{\mathbf{M 1}}$, which is a receptor on the intestinal mucosal cells [46]. ( $\mathbf{G}_{\mathbf{M} 1}$ is the IUPAC nomenclature for these complex lipids whereby the alphabet ' $G$ ' means 'ganglioside'. The subscript 'M1' means that it contains a

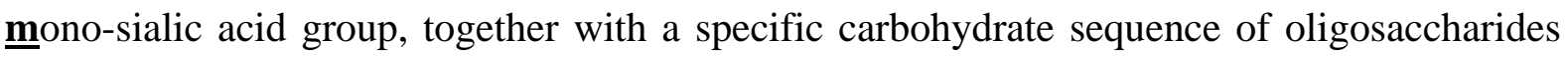
given the number code ' 1 ', the sequence being Gal-GalNac-Gal-Glc-ceramide).

The two protein units in the single polar flagellum (tail-like structures, Fig. 2) of the Vibrio Cholerae, known in literature as A (2 peptides linked by a disulfide bridge, MW 28,000) and B (5 identical peptides), are bound non-covalently (for the gram-negative cholera bacteria; for gram-positive bacteria the 2 subunits are covalently linked) to form a unique macromolecular toxin unit. Unit $\mathbf{B}$ contains the binding site to $\mathbf{G}_{\mathbf{M} 1}$ while subunit $\mathbf{A}_{\mathbf{1}}$ of Unit $\mathbf{A}$ enters the host cell by translocation, subsequent to reduction of the disulfide bridge which binds it to subunit $\mathbf{A}_{\mathbf{2}}$ [47]. $\mathbf{A}_{\mathbf{1}}$ is effectively an enzyme belonging to a group of enzymes called ADP-ribosyltransferases, i.e., $\mathbf{A}_{\mathbf{1}}$ catalyse ADP-ribosylation of a guanine nucleotide protein, designated here as $G_{\mathrm{s} \alpha}$, which regulates the function of the adenylate cyclase (AC) enzyme system by attaching to it (stimulation) and detaching (inactivation). ADP-ribosylation is a post-translational modification of proteins that involves the addition of ADP-ribose (Figure 3) to $\mathrm{G}_{\mathrm{s \alpha}}$.

Once ADPR has attached itself to $G_{s \alpha}$, the newly combined structure then binds to the 


\section{Macrothink}

inactive form of adenylate cyclase in the cytoplasm of the mucosal cells and stimulate it to function, but ADPR locks $G_{\mathrm{s} \alpha}$ to $A C$ in such a way that $G_{\mathrm{s} \alpha}$ cannot dissociate itself from $A C$, and as a result, "cAMP" is continuously synthesised and accumulates at the intestinal cell membrane. This increase in the level of intracellular cAMP, will activate protein kinase and $\mathrm{Ca}^{2+}$, which act on the apical membrane leading to inhibition of $\mathrm{Na}^{+}$and $\mathrm{Cl}^{-}$absorption by villus cells, but stimulation of the transport (secretion) of $\mathrm{HCO}_{3}{ }^{-}$and $\mathrm{Cl}^{-}$ions by secreting cells in the Crypts of Lieberkühn (intestinal glands found in the epithelial lining of the small intestine and colon) into the small bowel lumen of the gut, causing ionic imbalance and the most dramatic watery diarrhoea known which, if untreated, is often fatal due to dehydration [51]. See Figure 4 for the schematic representation of the mechanism of cholera pathogenesis. The WHO recommended the following "Oral Rehydration Salts" (aqueous solution) to reduce mortality from cholera, Table 1.

Table 1. Aqueous solution of three salts and glucose to drink, for rehydration $[52,53]$.

\begin{tabular}{|c|c|}
\hline Ingredients & Conc. (g/litre) \\
\hline Sodium chloride & 2.6 \\
\hline Potassium chloride & 1.5 \\
\hline Trisodium citrate & 2.9 \\
\hline $\begin{array}{c}\text { Glucose } \\
\text { (anhydrous) }\end{array}$ & 13.5 \\
\hline
\end{tabular}

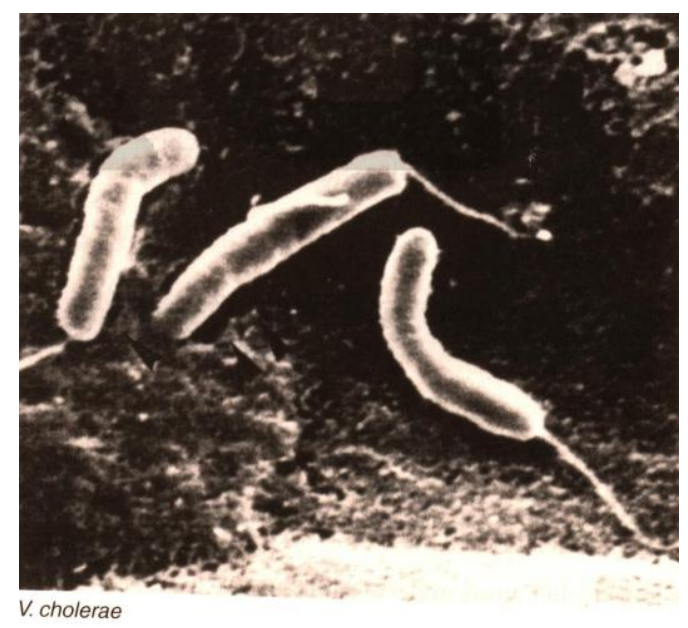

Figure 2. Scanning electron micrograph of Vibrio Cholerae [48].

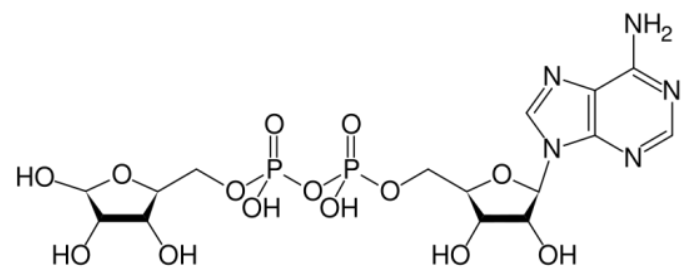

Figure 3. Molecular structure of ADP-ribose [49]. 


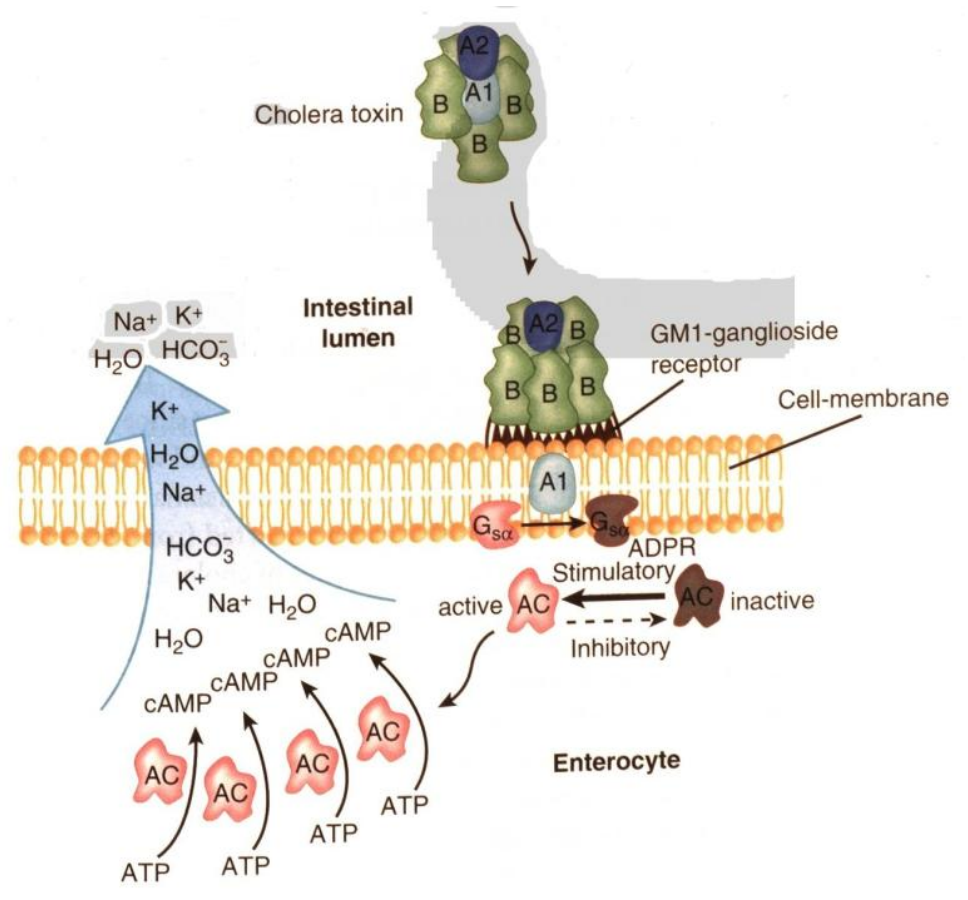

Figure 4. Action of cholera toxin [50].

Gangliosides (sialic acid-containing glycosphingolipids) are a family of membrane-spanning glycolipids. They are continuously released (a process called cell surface shedding) from the outer plasma membrane of all cells to extracellular space. In disease conditions, this process accelerates. In humans, the concentration is highest in the brain. Brain gangliosides are shed into the extracellular space and therefore found in cerebrospinal fluid (CSF). They are markers of degenerative diseases affecting neuronal membranes. Four major brain gangliosides are present in the CSF: GM1, GD1a, GD1b, whereas GM3 and GD3 dominates in serum. GM1 is known to bind calcium, thereby exhibiting a neuroprotective function against ischemia damages (restriction in blood supply) in the retina. During ischemia or exposure to neurotoxins, excessive calcium influx to neurons becomes neurotoxic. GM1 has been shown to couple with nerve growth factor (NGF) receptors to regulate signal transduction. Gangliosides are known to participate in memory and learning. Biochemistry and immunology research has discovered other gangliosides such as GM2, GD2 and GT1. Abbreviations found in literature in the nomenclature of gangliosides are as follows:

$\mathbf{M}=$ mono-sialic

$\mathbf{D}=$ di-sialic

$\mathbf{T}=$ tri-sialic

$\mathbf{Q}=$ tetra-sialic

$\mathbf{1} \equiv$ Gal-GalNac-Gal-Glc-ceramide

$\mathbf{2} \equiv$ GalNac-Gal-Glc-ceramide 
$\mathbf{3} \equiv$ Gal-Glc-ceramide

\subsubsection{Louis Pasteur and Cholera Epidemics in France.}

The research work of Louis Pasteur (1822-1895) on infectious diseases is well known. Pasteur was no stranger to personal tragedy caused by waterborne diseases, since three of his five children died of typhoid. He also witnessed outbreaks of deadly diseases in mid-nineteenth century Europe including cholera, "French Military Fever", smallpox and influenza. Pasteur was only ten years old when cholera hit Paris in 1832. This was to be followed by outbreaks in 1848-9, 1853-4 (coinciding with the London and Florence epidemics in 1854 mentioned above), and 1865-66, while less severe episodes occurred in 1873, 1884 and 1892. Most of the research of Louis Pasteur on the vaccination against the diseases cholera, anthrax and swine erysipelas converged to fruition by about 1881, applying his methodologies to the study of infectious diseases (with microbes as causative agents), their prevention (asepsis) and prophylaxis by immunization (vaccination). He synthesised chicken cholera vaccines from attenuated cultures of the cholera bacteria and demonstrated that inoculating the chickens could prevent the disease. Pasteurian bacteriology opened up the vision of biological agents used to destroy bacteria, echoing the studies of the English physician Edward Jenner (1749-1823) who had conferred on human immunity to smallpox by vaccinating individuals with a mild form of cowpox [54].

\subsubsection{Robert Koch Rediscovers the Cholera Bacteria and Proposes Chlorination}

In 1875 a rival contemporary of Pasteur, the German physician Robert Koch (1843-1910) became the first German doctor known to have successfully grown a pure culture of the bacterium causing anthrax, paving the way for modern bacteriology. It is possible Koch was unaware of Pacini's work at the University of Florence thirty years earlier, he nonetheless rediscovered the cholera bacillus in the faeces of those who died of cholera (but not of other diseases), in the 1883 epidemic in Egypt. In agreement with Pasteur's work carried out from 1879 to 1881 , he correctly linked the bacteria to cholera.

In 1881, Koch showed that pure cultures of bacteria were killed by hypochlorite solutions [55]. The pathogenic organisms of cholera and typhoid were also grown in culture in 1883 and 1884 respectively, allowing the action of disinfectants to be studied quantitatively. This work was recognised as an important step in the development of public health in Germany. In the midst of the 1892 cholera outbreak in Hamburg, he attributed the low incidence of cholera in Altona, located downstream on the Elbe River from cholera-infested Hamburg, to sand filtration practiced in Altona. He denounced the Hamburg authorities for not disinfecting wastewaters before discharge into the River Elbe, from whence drinking water was extracted without subsequent purification [56].

In 1902, in a stroke of ingenuity, Koch correctly explained the reason behind continued outbreaks of typhoid fever, after the contamination in a water supply had been eliminated, as being due to human "carriers". People who were infected with the bacteria could infect others but remain healthy themselves. The necessity to eliminate at all times all pathogens in potable water supplies from the treatment plant right up to the point of consumption (e.g., taps) 
became firmly established. Chlorination of drinking water was finally introduced in Germany in 1910 (the year that Koch passed away) after Koch convinced the country that sand filtration was insufficient technology for the disinfection of drinking water. He demonstrated the effectiveness of utilising a combination of disinfection by hypochlorite and the application of slow sand filters for removing waterborne pathogens [57]. Koch received the Nobel Prize in 1905 for his research in tuberculosis.

\subsubsection{Sir Sims Woodhead Applies Hypochlorous Acid to Disinfect Water.}

In England, sporadic chlorination of water supplies during and after episodes of public health emergency had been practiced since the time of the Broad Street epidemic. For example, the typhoid outbreak that lasted from September 1897 to January 1898 in Maidstone (Kent, England, 143 deaths) was a well documented case whereby chlorine was applied to disinfect water. Sir German Sims Woodhead KBE (1855-1921, knighted 1919) used aqueous solutions of hypochlorous acid to sterilize potable water distribution mains, and hypochlorous acid gained official acknowledgement as a disinfectant [58].

\subsubsection{The Western World Begins to Chlorinate Water}

Queen Victoria passed away on $22^{\text {nd }}$ January 1901. Edward VII ascended the throne. The population of London stood at an impressive 4.5 million. Londoners greeted the new century with the latest water treatment technology. Race (1918) reviewed The Royal Commission $5^{\text {th }}$ Report on Sewage Disposal (published by HMSO in 1908). The review stated that, "the credit for the first systematic use of chlorine in water disinfection is due to A.C. Houston with whom McGowan was associated in the work carried out at Lincoln in 1904-1905. Owing to flood conditions, the reservoirs, filters and distribution system became infected with typhoid bacilli, which caused a severe epidemic amongst the consumers. The storage and purifications works were thoroughly treated with a solution of 'chloros' (sodium hypochlorite containing approximately $10 \%$ of available chlorine) and that the bacteriological results were entirely satisfactory [59]." (Nowadays, many commercially available disinfectants still carry the brand name "Chloros", sodium hypochlorite is just one of them.) London had begun to chlorinate part of its public water supply in 1916 and during the following year, the entire supply. Continuous chlorination of drinking water in Britain has taken shape in earnest, sharply reducing deaths due to cholera and typhoid.

In the United States of America, the history of water purification is also well documented. In $1900,10 \%$ of all deaths in the U.S. resulted from water-transmitted diseases. In 1908, Jersey City (New Jersey) successfully pioneered the installation of hypochlorite treatment facilities for the disinfection of its Boonton public water supply, and was soon followed by the rest of the country [60]. By 1940, nearly $100 \%$ of all households had clean water supplies and by $1967,75 \%$ of all households had proper sewage facilities. By 1967, only $0.25 \%$ of all deaths were caused by waterborne diseases (c.f., about $2 \%$ of all deaths was caused by car accidents in the same period [61]). Hunter et al. (2001) reported a figure of 127 drinking water outbreaks in the U.S. from 1990 to 1998 , claiming that the number of such outbreaks have declined in the last two decades of the $20^{\text {th }}$ century [62]. 
On the $150^{\text {th }}$ anniversary of the Broad Street epidemic, Triggle (2004) reminisced, "The disease still remains a killer in the developing world. The world has been fighting the seventh cholera epidemic since it was identified in Indonesia in 1961. It soon spread across Asia, Russia and the Middle East and Africa with cholera cases topping 140,000, including 4,500 deaths, in 2002, according to World Health Organisation figures [31].”

\subsubsection{WHO Warns of Existing Health Risks from Polluted Water}

Faecal contamination and untreated or inadequately treated water supplies remain the greatest threat to public health, especially amongst the poor in developing countries, where substantial proportions of the population use and drink contaminated water [63]. Diarrhoea remains a major killer in these countries. Diseases such as cholera, typhoid and chronic dysentery are endemic and claim the lives of young and old alike. Annually, there are $4 \times 10^{9}$ cases of diarrhoea (including dysentery) resulting in $2.5 \times 10^{6}$ deaths, most under 5 years of age, and "this is equivalent to one child dying every 15 seconds, or 20 jumbo jets crashing every day! These deaths represent approximately $15 \%$ of all child deaths under the age of five in developing countries. $2 \times 10^{9}$ people are at risk of malaria, with $10^{8}$ affected at any one time, causing 1 to $2 \times 10^{6}$ deaths each year. Water, sanitation, and hygiene interventions reduce diarrhoea on average by between one-quarter and one-third [64]".

Unfortunately, the availability of safe drinking water in many areas is practically nonexistent, due to poverty, poor understanding of water contamination, and lack of treatment facilities. The UN also estimated that three billion people could be facing little or no access to clean water by the year 2025, unless the world takes urgent action, and urgent action is being taken. It must also be noted that most of these developing countries do not provide basic health care.

Weiss (2002) further commented on the severity of the problem: "At highest risk are the 1.1 billion people (in the world) lacking access to safe drinking water and the 2.4 billion without adequate sanitation facilities. Cholera, an acute diarrheal disease, claims more than 5,000 lives a year. In fact, in the 5-year period between 1996 and 2001, the average number of reported cholera deaths per annum in the world is 7,527. Over $90 \%$ of these deaths happened in Africa, for every year [65]."

\subsubsection{The Earth Summit (2002) Revisited}

In Aug/Sept 2002, the nations of the world held an Earth Summit at Johannesburg (South Africa), a city plagued by water and sewage problems, to identify the worst environmental issues facing planet Earth. It was decided that the combined lack of clean drinking water and lack of adequate sanitary facilities is the most desperate issue and must be tackled. The fact that cholera and other waterborne diseases are preventable by the continuous availability of clean, potable water was emphasised throughout the summit proceedings.

\subsubsection{Case Studies from Peru, Finland and Canada}

This section describes episodes of waterborne diseases in three countries during the last decade of the $20^{\text {th }}$ century. The tragic consequences of these incidents compellingly illustrate the importance of good governance and practice in the provision of potable water. 


\section{Case 1: The Peruvian experience}

Outbreaks of cholera began in Chancay, a small village 40 miles north of Lima, the capital city of Peru, on January 23, 1991. Illness was characterised by diarrhoea, vomiting and severe muscle cramping. The disease spread quickly up the Pacific coast, and then to Ecuador, Columbia and Brazil. Eight months after appearing in Peru, it reached Bolivia. By the end of 1992, virtually all of South and Central America reported confirmed cases. From the onset of the epidemic in 1991 to June 15, 1995, the Americas reported 1,075,372 cases and 10,098 deaths [66]. This relentless five-year epidemic of cholera was the first in the hemisphere in the $20^{\text {th }}$ century.

Whatever the sources of the cholera bacteria, it is now widely accepted that the root cause of this epidemic was the failure to disinfect the entire water supply in Peru. The official stance of the then Lima government was based on its response to the alleged carcinogenicity of trihalomethanes (THMs), which are by-products of water disinfection, reported by the U.S. EPA in the 1970s. Activists have long campaigned against the use of chlorinated organic compounds and by the late 1980s they were trying to convince water authorities around the world of "cancer risks" posed by chlorination by-products [67].

The tragedy in Peru motivated Anderson (1991) to publish in Nature, alerting the world to a "Cholera Epidemic Traced to Risk Miscalculation". He wrote, "During the 1980s local water officials, citing the (US) EPA studies of chlorine's cancer potential, decided to stop chlorinating many of Lima's wells. This has now raised serious questions about both EPA's risk assessment and the way it has been communicated to the rest of the world. Given the uncertainties of risk assessment and the difficulties in balancing microbial and cancer risks, researchers asked whether EPA should have given more emphasis to the disaster potential of not disinfecting water supplies." He went further, "This sobering case of risk assessment gone wrong is forcing US and international health officials to come to grips with the flaws in what most agree is a haphazard process of balancing real and theoretical public health risks." In the same article, some practical and economic difficulties of chlorination were quoted as the more probable causes of minimising the application of disinfectants, to the point of withdrawal, and that cancer risk was a pretext to abstain from chlorination [68]. Observing domestic household habits in Peru, scientists of the U.S. Centers for Disease Control and Prevention (CDC) discovered that cholera was associated with drinking unboiled water. They shared their findings in the Lancet in 1992 [69]. John Snow's theory of the propagation of cholera epidemics via the agency of water is fully vindicated. While water is not the only mode of transmission of pathogens, it has great potential for causing widespread infection, as cholera epidemics can now testify.

A cholera outbreak returned to haunt Peru in the first four weeks of 1998, during which a total of 2,863 cases with 16 deaths were reported. Storms and floods were the purported causes of the episode and documented in a "Disease Outbreak Report" published by the WHO in 1998 [70].

\section{Case 2: The Finnish experience}


Acute gastrointestinal illnesses resulting from failure to properly disinfect and decontaminate drinking water are not confined to developing countries. In Finland, 24 outbreaks of waterborne related diseases were reported between 1980 and 1992. In 1995, the Helsinki government published an analysis of these events, without naming the geographical locations in which they took place, as some of them were military sites. For example, it was stated in a 1995 paper that 5,000 people, $85 \%$ of the population of some communities, were affected by disease [71]. Also documented were two separate episodes in the summer of 1990 and in the autumn of 1991, caused by "inadequate" disinfection by the same water treatment plant. In both cases, bacterial and viral counts in the water were high, and chlorine was depleted. These incidents were precipitated "owing to customer complaints and active debate in public on the high amounts of organic chlorine compounds produced in disinfection of surface water with chlorine, (and subsequently) the treatment plant had reduced the chlorine dosage to a level at which free chlorine concentration in distributed water was $0.05 \mathrm{mg} / \mathrm{litre}$ ". The authors of the paper [71] directly linked the risk aversion culture prevalent at the time to real health problems. It is also very interesting to note that the Peruvian epidemic described above commenced in January 1991, between the Finnish episodes.

\section{Case 3: $\quad$ The Canadian experience}

The last millennium ended with yet another unnecessary tragedy due to insufficient or no chlorination of water intended for human consumption. The most serious case of water contamination in recent Canadian history happened in May 2000. The drinking water system in the small farming town of Walkerton in the southern part of the province of Ontario in Canada was polluted with the bacteria Escherichia coli 0157:H7 and Campylobacter jejuni. Seven people died and 1,300 cases of illnesses were verified in that town with a population of only 4,800, with children and the elderly, i.e., the most vulnerable, taking the brunt of the calamity. The Ontario government launched the "Walkerton Inquiry" and concluded that the unhappy episode could have been prevented by proper chlorination of drinking water [72].

In Walkerton, the water system was supplied by groundwater sources known locally as "wells" (this is not colloquialism, they are actually wells). The water from each well was treated with chlorine before it entered the distribution system for use by residents. The Ontario government requires a water system such as Walkerton's to apply adequate chlorine to disinfect the raw water, and to sustain a chlorine residual level of $0.5 \mathrm{mg} /$ litre $(0.5 \mathrm{ppm})$ of water after 15 minutes of contact time. Hypothetically, the absence of any residual chlorine means that all of it is already utilised in disinfection and immediately suggests the possibility of invasion by pathogens. Therefore residual chlorine is needed to ensure disinfection throughout the distribution system.

Even though it might seem desirable, a direct determination for microorganisms is not routinely performed on water supplies. Indirect methods are used instead because pathogens are likely to enter water only sporadically, and once in the water they do not survive for long periods. Consequently, the practice of routine sampling may miss their presence. Laboratory procedures may fail to detect pathogens in very small numbers, and it takes 24 hours to obtain results from a laboratory examination. If deadly pathogens were present, water 
authorities would not respond for at least a day. By then, many people would have already used the water and would be subject to infection.

From May 8 to May 12 of 2000, heavy rainfall washed manure from a nearby farm into one of the wells, providing the source of the bacteria. On May 13, operators who routinely measure residual chlorine unfortunately did not perform the task on the particular well that was contaminated with the pathogenic bacteria contained in the manure. The overwhelming increase in risk to public health was unnoticed and therefore unreported, while residents continued to consume the water contaminated with bacteria. The current view is that, had the chlorine level been maintained at the prescribed level of $0.5 \mathrm{ppm}$ throughout the month of May, well over $99 \%$ of all bacteria would have been killed and the incident avoided. Justice Dennis O'Connor documented the horrific health effects experienced by some individuals in Walkerton as a reminder of the community's suffering [72]. The narratives are not for the faint-hearted.

It may be possible to draw an analogy between the Walkerton debacle and a dysfunctional system of electronic controls in chemical engineering. A process plant was designed to manufacture a product (potable water) of precise specification $(0.5 \mathrm{mg}$ residual chlorine/litre of water). A step change occurred due to an externally injected perturbation (influx of bacteria). The measurement system installed (operators) failed to register the deviation from specification and/or operating conditions, and so no signal (alarm) was sent to trigger an appropriate response (addition of corresponding amounts of chlorine) by the system to realign the process to prescribed conditions. The result was that a product of the wrong specification was made, with tragic results.

Canada continues to disinfect its water supplies by chlorination and has not entertained ideas of halting the practice. In 2001, the year after the Walkerton disaster, two Canadian federal agencies (Environment Canada \& Health Canada) jointly published their authoritative research in a 118-page report on the behaviour of chloroform in the natural environment, based on all available data up to the time of publication [80]. The report concluded that chloroform is not entering the environment in a quantity or concentration or under conditions:

- that have or may have an immediate or long term harmful effect on the environment or its biological diversity;

- that constitute or may constitute a danger to the environment on which life depends;

- that constitute or may constitute a danger in Canada to human life or health.

The Walkerton incident shows that proper disinfection should never be deferred to considerations of alleged carcinogenicity of THMs.

\subsection{Toxicology of Haloalkanes in Rodents; Difficulties in Extrapolation to Humans}

Toxicology of many haloalkanes including disinfection by-products is carried out by experimentation on rodents. For example, mice are usually fed much higher doses of disinfection products than humans ingest. Positive turmourigenicity in the liver, kidney and large intestines of mice is believed to be induced by a host of halogenated organic compounds, including chloroform. The mechanism appears largely non-genotoxic, and most cells were 
damaged or killed by these high doses of halogenated compounds before any genotoxicity has an opportunity to manifest itself. It should be noted that the natural defence mechanisms of a healthy mammal can be overcome by the administration of an acute and severely large dose of xenobiotics through the pulmonary or oral routes. It is the dose that makes the poison. For example, liver damage was a significant problem in humans exposed to excessive carbon tetrachloride or chloroform and several deaths resulted due to liver failure in the early days of anaesthesia. Also, hepatic necrosis has been reported in humans following ingestion of pharmaceutical preparations containing $16.5 \%$ by weight (an extremely high dose) of $\mathrm{CHCl}_{3}$ [73].

\subsubsection{The U.S. EPA Assumed a "no-threshold” Level for Carcinogenicity}

The publication of Silent Spring in 1962, authored by none other than the quintessential doyenne of the global Green Revolution herself, Rachel Carson, changed the tripartite relationship between federal government, the chemical industry and the public forever. Carson alluded to the ecotoxicity of pesticides which led to the ban of the insecticide DDT in the USA in 1972. These events inspired the creation of the U.S. Environmental Protection Agency (EPA). To be fair to the Swiss chemist Paul Hermann Müller who was awarded the Nobel Prize in 1948 for his "discovery of the high efficiency of DDT as a contact poison against several arthropods", he had the best interests of humankind at heart. The application of DDT from World War II onwards reduced malarial morbidity and mortality substantially, but its biochemical properties as an endocrine disruptor and as a human carcinogen soon became apparent. Müller could not have foreseen that.

Nowadays, whenever disinfection by chlorination is practiced, the trihalomethanes (THMs) of which chloroform is the chief component, are the most likely disinfection by-products (DBPs) to be encountered, together with some halogenated acetic acids (HAAs). By the time Silent Spring was published, great extensions in the capabilities of instrumental methods of chemical analysis were made. Gas chromatographs fitted with electron capture detectors managed to discover and identify contaminants in environmental samples at very low concentrations. Then, news broke in 1974 that chloroform and related compounds were found in drinking water and the world was alarmed.

Traditionally, the U.S. EPA assumed that there is no lower limit of exposure under which cancer will not develop. This is equivalent to saying that even a single molecule of an alleged carcinogen poses a cancer risk, because that single molecule may attack DNA directly and trigger carcinogenesis. This approach to regulate alleged carcinogens according to implied rather than demonstrable molecular mechanisms has generated much controversy.

\subsubsection{A landmark Legal Case: U.S. Court of Appeal Rules against the EPA (1998), [74].}

The U.S. Safe Drinking Water Act (SDWA) demands that the EPA deploys the best science known at any present moment to set standards and regulations for water quality. In December 1998, the EPA opted to set the Maximum Contaminant Level Goal (MCLG) to zero for chloroform in drinking water, adhering to its "zero tolerance" policy. In all likelihood, the chlorine industry (which manufactured many chlorine-based disinfectants and is represented 
by the trade organization known as the Chlorine Chemistry Council) predicted that the EPA was unable to demonstrate convincingly the role of chloroform in human carcinogenicity at the time, and took the matter to be resolved in a court of law. To be fair to the EPA, it acknowledged that the best science had pointed to the adoption of a non-zero MCLG, and while awaiting review by a "Science Advisory Board" over the matter, it deemed appropriate to set a zero value as an interim measure.

On $31^{\text {st }}$ March 2000, the U.S. Court of Appeals for the District of Columbia Circuit ruled that the EPA violated the Safe Drinking Water Act by setting such a goal because it failed to use "the best available peer-reviewed science" to set concentrations for contaminants. Judge Stephen Fain Williams found "the agency's December 1998 rule adopting a zero MCLG for chloroform to be arbitrary and capricious and in excess of statutory authority [and therefore] we vacate the rule". (So, "best-available science" does not mean "the best that might be available in the future".) The ruling was hailed by many as a victory for common sense in public health management. On hindsight, had the EPA not reneged on its own sound science and adopted a non-zero MCLG, the lawsuit may not have transpired. This case shows that rejecting the exercise of a benefit-cost-risk analysis and focuses only on the alleged risk of chloroform carcinogenicity (i.e., knowing the benefits of chlorination but choosing to ignore them) is the incorrect approach in charting policy for the provision of clean water.

\subsubsection{No-Threshold Assumption Revised}

The U.S. EPA withdrew the zero MCLG in 2000 and the latest guideline issued in 2006 instituted a concentration of $0.07 \mathrm{ppm}$ (i.e., $0.07 \mathrm{mg} \mathrm{CHCl}_{3}$ per litre of water, or $6 \times 10^{-7} \mathrm{~mol}$ $\mathrm{dm}^{-3}$ ). The concentration has not been lowered since [75]. Essentially, this is a paradigm shift from the "no-threshold" philosophy, a conclusion already drawn by WHO in 1993. The latest EPA update on the hazardous nature of chloroform was issued on $5^{\text {th }}$ December, 2016. The EPA continued to support its own conclusion reached in 2005, one which asserted that at low exposure concentrations from trihalomethanes (THMs) in drinking water, chloroform is not carcinogenic [205], in plain English. It has also been reported by Bernard (2016) that the EPA's current stance on the issue is one in which chloroform represents "no known or expected risk to health" at present regulatory levels [76].

Closely related to the U.S. EPA court drama of 2000 is a story of mice and men. Soon after chloroform was discovered in drinking water by gas chromatography, the National Cancer Institute (NCI, 1976) used corn oil as a solvent for chloroform and injected this non-aqueous mixture directly into the guts of mice and rats [210]. (The dose of chloroform intended for the experiment was probably so high that the solubility of $\mathrm{CHCl}_{3}$ in $\mathrm{H}_{2} \mathrm{O}$ may have been exceeded, thus the use of organic solvent.) Did anyone even have the slightest inkling that, with very high doses of chloroform being administered, damage to rodents in some fashion would be a conclusion foregone? (Why not inject pure liquid chloroform into a rat to elicit an observable biological response?) It so happened that liver and kidney tumors developed in the rodents in this case. The U.S. Food and Drugs Administration (FDA) then banned the use of chloroform in the manufacturing of many household products the same year. Chloroform in drinking water has been stigmatized ever since. 
The rebuttal of the NCI's work done in 1976 [210] did not appear soon enough. Ten years on, Bull et al. (1986) reported that the chloroform-laden corn oil meals were far too carcinogenic for the results to be useful in interpretating the effects of doses encountered in drinking water [211]. Jorgensen et al. (1985) prepared solutions containing 1.8 grams of $\mathrm{CHCl}_{3}$ per litre of water (i.e., $1800 \mathrm{ppm}$, or 2,571 times higher than the $0.07 \mathrm{ppm}$ prescribed by the EPA in 2000) but no dose-response relationship was observed [212]. Larson et al. $(1994,1995)$ showed that feeding mice with tap water dosed with chloroform in the range 60 to 1,800 ppm, for 3 weeks, did not produce tumours of any sort [77, 213]. Golden et al. (1997) carried out comprehensive research on the subject but found no evidence of mutagenecity [214].

Commenting on these results, Brukner and Warren (2001) wrote, "This suggests that ingestion of $\mathrm{CHCl}_{3}$ in small increments, similar to drinking water patterns of humans, fails to produce a sufficient amount of cytotoxic metabolite(s) per unit time to overwhelm detoxification mechanisms. Currently, the U.S. EPA classifies $\mathrm{CHCl}_{3}$ as a probable human carcinogen (group B2), meaning that there is sufficient evidence for carcinogenicity in animals and inadequate or no evidence in humans. Experimental evidence, such as that of Larson (1994), and the prevailing opinion that $\mathrm{CHCl}_{3}$ is non-genotoxic, indicates that the relationship between $\mathrm{CHCl}_{3}$ dose and tumour formation is nonlinear or threshold, meaning that there is a dose of $\mathrm{CHCl}_{3}$ below which cytotoxicity is insufficient to produce a significant cancer risk [78]."

\subsubsection{Canadians are Exposed to Safe Levels of Disinfection by-Products.}

In Canada, responsibility for safe public drinking water supplies is shared between the provincial/territorial, federal and municipal governments. The day-to-day responsibility generally rests with the provinces and territories. The role of Health Canada is one of leadership, advice and research, and its mandate and expertise lie in protecting the health of all Canadians. Health Canada has developed and maintained, over the past thirty years, a successful relationship with the provinces and territories through its role as technical secretariat to the Federal-Provincial-Territorial Subcommittee on Drinking Water. This partnership develops and publishes the Guidelines for Canadian Drinking Water Quality, which is used by all provinces and territories as the basis for their own enforceable requirements. The guidelines establish maximum limits for microbiological, physical, chemical and radiological parameters in drinking water.

In 2003, Health Canada has established a guideline for total THMs (trihalomethanes, including chloroform) of $0.1 \mathrm{ppm}$, and commented that "the cancer risk at this level over a lifetime is extremely low [79,80]." (The value of $0.1 \mathrm{ppm}$ is still in use in 2013 and has not changed since.) A "DBP-Task Force" within Health Canada is responsible for updating existing health risk estimates for THMs, estimating potential health care costs, examining available water treatment options and costs and identifying additional benefits from improved water treatment. Risk, cost and benefit analyses are continually conducted and recommendations for appropriate health-based THMs guidelines and treatment options are being developed. 


\subsubsection{Research into the Hepatotoxicity of Carbon Tetrachloride}

The original biochemical research into liver damage in mice by haloalkanes focused not on chloroform $\mathrm{CHCl}_{3}$ but on carbon tetrachloride $\mathrm{CCl}_{4}[81,82]$ which is not commonly known to be a by-product of disinfection. Carbon tetrachloride was the first toxin for which it was shown that the injury it produces is largely or entirely mediated by a free-radical mechanism $[83,84]$. It must be emphasised that there is no real evidence that $\mathrm{CHCl}_{3}$ behaves similarly to $\mathrm{CCl}_{4}$ in terms of the biochemical pathways of tissue damage. Therefore, we must examine the issue more closely here by discussing the hepatotoxicity of carbon tetrachloride.

\subsubsection{The Role of Cytochrome P450 in Xenobiotic Metabolism}

Abundant in the liver are families of haem-thiolate proteins with the collective name cytochrome P450.The main role of P450s is the detoxification and metabolism of xenobiotics and certain endogenous substances that required elimination (e.g., steroid hormones). They are crucial to the initial metabolism of the majority of drugs in current clinical use and they are also associated with the toxic activation of procarcinogens and other toxicants, and the generation of reactive oxygenated species (ROS), which damage DNA and other vital biological entities. Since the scientific community objects to direct experimentation on humans, data on the toxicity of chemical compounds are compiled by testing on rodents. Carbon tetrachloride is converted to a highly reactive free radical by cytochrome $\mathrm{P} 450$, through a one-electron transfer reaction:

$$
\mathrm{CCl}_{4}+\text { cytochrome } \mathrm{P} 450\left(\mathrm{Fe}^{2+}\right) \rightarrow \mathrm{Cl}_{3} \mathrm{C}^{\cdot}+\mathrm{Cl}^{-}+\mathrm{P} 450\left(\mathrm{Fe}^{3+}\right) .
$$

In aerobic environments, the following conversion can also occur:

$$
\mathrm{Cl}_{3} \mathrm{C}^{\cdot}+\mathrm{O}_{2} \rightarrow \mathrm{Cl}_{3}-\mathrm{C}-\mathrm{O}-\mathrm{O}^{\bullet}
$$

Whether or not the addition of $\mathrm{O}_{2}$ to $\mathrm{Cl}_{3} \mathrm{C}^{*}$ occurs on a reactive enzyme site is immaterial, since the free radical $\mathrm{Cl}_{3}-\mathrm{C}-\mathrm{O}-\mathrm{O}^{\circ}$ cannot be metabolised further by the cytochrome $\mathrm{P} 450$ system once detached from it. Instead, it initiates chain reactions in the polyunsaturated lipids of the endoplasmic reticulum of the cell, a phenomenon known as lipid peroxidation. These reactions can spread into the plasma membrane and to proteins, eventually resulting in cell swelling, lipid accumulation and hepatocellular necrosis. Therefore, $\mathrm{CCl}_{4}$ seems to be the causative agent for lipid peroxidation insofar as the $R O S \mathrm{Cl}_{3}-\mathrm{C}-\mathrm{O}-\mathrm{O}^{\circ}$ is formed in aerobic conditions. Yet, Yamamoto et al. (1988) expressed doubts over alleged roles that $\mathrm{Cl}_{3}-\mathrm{C}-\mathrm{O}-\mathrm{O}$ ' play in $\mathrm{CCl}_{4}$ hepatotoxicity [192], while Chamulitrat et al. (1994) recognized that $\mathrm{NO}_{2}$ may contribute to $\mathrm{CCl}_{4}$ damage in rats [193]. The $\mathrm{Cl}_{3} \mathrm{C}^{\circ}$ radical may react further, in the following five ways:

1. Formation of chloroform.

$$
\begin{aligned}
& \mathrm{CCl}_{4}+\mathrm{e}^{-} \rightarrow \mathrm{Cl}_{3} \mathrm{C}^{\bullet}+\mathrm{Cl}^{-} \quad(\mathrm{P} 450 \text { catalyzed }) \\
& \mathrm{Cl}_{3} \mathrm{C}^{\cdot}+\mathrm{R}-\mathrm{H} \rightarrow \mathrm{CHCl}_{3} \text { (chloroform) }+\mathrm{R}^{\cdot}(\mathrm{H} \text {-abstraction by free radicals }), \\
& \mathrm{R}^{\bullet}+\mathrm{HOH} \rightarrow \mathrm{R}-\mathrm{H}+\mathrm{HO}^{\bullet} .
\end{aligned}
$$




\section{Macrothink}

The $\mathrm{HO}^{\circ}$ radical has a half-life of only $10^{-9}$ second due to its extreme reactivity and the great number of species it can react with. Chain-terminating steps include:

(a) $\mathrm{HO}^{\circ}+{ }^{\circ} \mathrm{OH} \rightarrow \mathrm{H}_{2} \mathrm{O}_{2}$

(b) $\mathrm{HO}^{\circ}+\mathrm{e}^{-} \rightarrow \mathrm{OH}^{-}$

(c) $\mathrm{R}-\mathrm{CH}=\mathrm{CH}-\mathrm{R}+{ }^{\circ} \mathrm{OH} \rightarrow \mathrm{R}-\mathrm{CH}(\mathrm{OH}) \mathrm{CH}_{2}-\mathrm{R}$, see [194].

2. Formation of hexachloroethane.

$2 \mathrm{Cl}_{3} \mathrm{C}^{\cdot} \rightarrow \mathrm{Cl}_{3} \mathrm{C}-\mathrm{CCl}_{3}$.

3. Formation of $\mathrm{Cl}_{2} \mathrm{C}$ : (dichlorocarbene).

$\mathrm{Cl}_{3} \mathrm{C}^{\bullet}+\mathrm{e}^{-} \rightarrow \mathrm{Cl}_{2} \mathrm{C}:+\mathrm{Cl}^{-} \quad(\mathrm{P} 450$ catalyzed $)$

$2 \mathrm{Cl}_{2} \mathrm{C}: \quad+\mathrm{H}_{2} \mathrm{O} \rightarrow \mathrm{CO}+2 \mathrm{HCl}$.

4. A "kamikazi" reaction (the author's own terminology). The $\mathrm{Cl}_{3} \mathrm{C}^{\circ}$ radical plants itself onto a meso-carbon of the prosthetic group of a cytochrome P450 enzyme (an irreversible reaction), thereby removing itself from further metabolism, but concomitantly renders the enzyme dysfunctional permanently. See articles [195] and [196].

5. Encounters with free radical scavengers such as vitamin $E$ (and this also applies to $\left.\mathrm{Cl}_{3}-\mathrm{C}-\mathrm{O}-\mathrm{O}^{\circ}\right)$.

Besides free radical scavenging, there are two other mechanisms that protect and ensure the proper functioning of membranes in the human body, namely, lipid repair and lipid replacement.

It must be emphasized that the metabolism of $\mathrm{CHCl}_{3}$ in the liver is different to that of $\mathrm{CCl}_{4}$. Slater \& Sawyer (1971) reported that $\mathrm{CHCl}_{3}$ is much less damaging to the liver than $\mathrm{CCl}_{4}$, consistent with the observation that it induces lipid peroxidation in isolated rat liver microsomes at a much lower rate. The rate of lipid peroxidation induced by $\mathrm{CHCl}_{3}$ was only $7 \%$ that of $\mathrm{CCl}_{4}$ on an equilmolar basis [81], partly because the energy required to produce the free radical $\mathrm{Cl}_{3} \mathrm{C}^{\circ}$ from $\mathrm{CHCl}_{3}$ is much higher than that from $\mathrm{CCl}_{4}$, Table 2. The data in Table 2 has not changed since 1971. In fact, Halliwell \& Gutteridge (2015) is still teaching this medical biochemistry [85] while paying tribute to the late Professor Trevor Slater who produced these results in 1971 [81]. Addressing the suspicion of whether $\mathrm{Cl}_{3} \mathrm{C}^{\circ}$ can do harm in organs other than the liver, Halliwell \& Gutteridge (2015) stated that the radical "may only persist to do damage in hypoxic (i.e., oxygen deprived) regions of the liver; like most $\mathrm{C}^{\bullet}$ radicals, it rapidly reacts with $\mathrm{O}_{2}$ to give an extremely reactive peroxyl radical (an oxidizing agent more powerful than most other peroxyl radicals): $\mathrm{Cl}_{3} \mathrm{C}^{*}+\mathrm{O}_{2} \rightarrow \mathrm{Cl}_{3}$-C-O-O , which reacts rapidly with arachidonic, linolenic acids, thiol compounds and the tysosine and tryptophan residues of proteins [85].” 
Table 2. Relative importance of haloalkane-induced lipid perixodation [81].

\begin{tabular}{|c|c|c|}
\hline $\begin{array}{c}\text { Photolysis of alkyl } \\
\text { halides }\end{array}$ & $\begin{array}{c}\text { Energy required for } \\
\text { homolytic bond fission }(\mathrm{kJ} \\
\left.\mathrm{mol}^{-1}\right)\end{array}$ & $\begin{array}{c}\text { Relative rate of lipid } \\
\text { peroxidation (\%) }\end{array}$ \\
\hline $\mathrm{CCl}_{4} \rightarrow \mathrm{Cl}^{\bullet}+\mathrm{Cl}_{3} \mathrm{C}^{\bullet}$ & 284 & 100 \\
\hline $\mathrm{CHCl}_{3} \rightarrow \mathrm{H}^{\bullet}+\mathrm{Cl}_{3} \mathrm{C}^{\bullet}$ & 376 & 7 \\
\hline $\mathrm{BrCCl}_{3} \rightarrow \mathrm{Br}^{\bullet}+\mathrm{Cl}_{3} \mathrm{C}^{\bullet}$ & 205 & 3650 \\
\hline
\end{tabular}

In organic chemistry, the stability of a projected "leaving" group (an atom, molecule or ion which leaves the parent compound of which it was a constituent, and is the product of a chemical reaction) often decides whether a chemical reaction proceeds at all. The issue concerns both thermodynamics and kinetics. To illustrate, the hydrolysis of methyl chloride is described here. The overall reaction is:

$$
\mathrm{CH}_{3} \mathrm{Cl}+\mathrm{OH}^{-} \rightarrow\left[\mathrm{HO}^{\delta----}{ }^{\delta+} \mathrm{CH}_{3}---\mathrm{Cl}^{\delta-}\right]_{\text {transition-state }} \rightarrow \mathrm{CH}_{3} \mathrm{OH}+\mathrm{Cl}^{-} .
$$

This is a second order reaction: $d\left[\mathrm{CH}_{3} \mathrm{OH}\right] / d t=k_{2}\left[\mathrm{CH}_{3} \mathrm{Cl}\right]\left[\mathrm{OH}^{-}\right]$. The reaction proceeds through a $\mathrm{S}_{\mathrm{N}} 2$ (bimolecular nucleophilic substitution) mechanism. As the inductive effect between the carbon and chlorine atoms is in effect, the nucleophile is the hydroxyl ion which attacks the carbon centre to produce an intermediate complex, and is the rate-determining step. The intermediate then decomposes to give methanol via a fast step. The leaving group is the chloride ion. However, is it possible for the leaving group to be a negatively charged hydride ion $\mathrm{H}^{-}$? The answer is: not as likely as $\mathrm{Cl}^{-}$. Why not? This is because bond strengths are a matter of critical significance here. At $298 \mathrm{~K}$, the bond dissociation energy of the C-H bond in $\mathrm{H}-\mathrm{CH}_{2} \mathrm{Cl}$ is $419 \mathrm{~kJ} \mathrm{~mol}^{-1}$ [202], and that of the $\mathrm{C}-\mathrm{Cl}$ bond is $357 \mathrm{~kJ} \mathrm{~mol}^{-1}$ [203]. It is easier to break the $\mathrm{C}-\mathrm{Cl}$ single bond than the $\mathrm{C}-\mathrm{H}$.

Now recall the oxidation of $\mathrm{CCl}_{4}$ by cytochrome $\mathrm{P} 450$, but substituting $\mathrm{CCl}_{4}$ by $\mathrm{CHCl}_{3}$. The hypothetical reaction is: $\mathrm{CHCl}_{3}+$ cytochrome $\mathrm{P} 450-\mathrm{Fe}^{2+} \rightarrow \mathrm{Cl}_{3} \mathrm{C}^{\bullet}+\mathrm{H}^{-}+\mathrm{P} 450-\mathrm{Fe}^{3+}$, but does it represent a plausible oxidative pathway? The answer, again, is "unlikely". The $\mathrm{C}-\mathrm{H}$ bond dissociation energy in $\mathrm{H}-\mathrm{CCl}_{3}$ is $392 \mathrm{~kJ} \mathrm{~mol}^{-1}$, and that of the $\mathrm{C}-\mathrm{Cl}$ bond is $338 \mathrm{~kJ} \mathrm{~mol}^{-1}$ [204,205]. Therefore, the argument from the perspective of bond energy alone leads to the same argument that the production of $\mathrm{Cl}_{3} \mathrm{C}^{\circ}$ from $\mathrm{CHCl}_{3}$ in vivo is very difficult because the requirement of the formation of the $\mathrm{H}^{-}$ion as a discrete product entity is thermodynamically unfavourable. The photolysis of $\mathrm{CHCl}_{3}$ to produce $\mathrm{Cl}_{3} \mathrm{C}^{\bullet}$ and a hydrogen atom (Table 2) is a very different reaction to enzyme catalyzed catabolism. An alternative redox reaction was suggested by Garner (2004):

$$
\mathrm{CHCl}_{3}+(\text { cytochrome P450/NADPH/O }) \rightarrow\left[\mathrm{CCl}_{3} \mathrm{OH}\right]_{\text {intermediate }} \rightarrow \mathrm{CCl}_{2}=\mathrm{O}+\mathrm{HCl} \text {. }
$$

The P450 system adds an oxygen atom to the chloroform molecule to give the unstable intermediate trichloromethanol $\mathrm{CCl}_{3} \mathrm{OH}$, which then decomposes to phosgene $\mathrm{CCl}_{2}=\mathrm{O}$ and $\mathrm{HCl}$. While phosgene can be detoxified initially by GSH in the cell, its role in hepatorenal toxicity after the depletion of GSH has been hypothesised [86]. Brukner \& Warren (2001) discussed the toxicity length [87]. This is all fascinating research and should be pursued for 
its own sake.

\subsubsection{Human vs. rodent Cytochrome P450s.}

In a monograph depicting the structure and function of the cytochrome P450 enzyme systems, Lewis (2001) highlighted some of the controversies of using data gathered from mice to predict the behaviour of xenobiotics in humans [88], and in 1998 Lewis et al. wrote, "Human P450s tend to exhibit different substrate selectivities, tissue levels and inducibilities relative to those of experimental animal species, including age and gender differences, mechanisms of regulation and tissue distribution (such as that reported in the rat, for example), thus rendering much animal data conducted in this area, especially in small rodents, to be of little relevance or value for human xenobiotic metabolism studies and risk assessment. However, those compounds which are activated to carcinogenic or reactive intermediates by $\mathrm{P} 450 \mathrm{~s}$ from the CYP1A or CYP2E subfamilies are likely to manifest their toxic effects in both experimental animals and Homo sapiens because these enzymes are highly conserved across mammalian species [89]." While CYP2E1 is responsible for metabolic activation of chloroform at low doses, Pereira \& Grothaus (1997) suggested that pre-exposure to low doses induced resistance to toxicity at higher doses "presumably by suicidal inhibition of P450s responsible for chloroform activation [90]". The process of "inducibility" requires further comment. Inducibility consists of three distinguishable steps:

\section{Identification - a receptor protein will change its structure in response to the presence of a foreign substance.}

\section{Nucleus transport - the receptor then moves across the cell and enters the nucleus.}

\section{Gene activation - the receptor then binds itself to "response elements" (which are} sections of a DNA), thereby activating the genes that produce enzymes to detoxify the foreign substance.

In humans, protein receptors to $\mathrm{CCl}_{4}$ or $\mathrm{CHCl}_{3}$ have yet to be identified, although receptors for phenol barbitone and polychlorinated hydrocarbons are known. One important difference in the cytochrome P450 profile between small mammals and humans is that the CYP2B subfamily in small rodents and rabbits biotransforms some substrates successfully, e.g., CYP2B1/2 were used by Nakajima et al. (1995) in an attempt to metabolise high doses of chloroform [91], but Guengerich (1995) insisted that the human orthologue called CYP2B6 is poorly represented in the human liver and its role in xenobiotic metabolism seems to be limited when compared to these smaller mammals [92]. (An "orthologue" is an enzyme with similar amino acid sequence and perform similar functions, but orthologues are not exactly identical to one another.)

Tumour-causing ability is not widely used as an end point to characterise the toxicity of chloroform because its carcinogenicity has not been demonstrated beyond reasonable doubt at the daily doses received by humans. Usually, during medical diagnosis, other mutagenic agents and/or situations (e.g., genetics) giving rise to malignant tumours is more obvious in patients who must inevitably also consume potable water. Lewis et al. (1998) noted that, "Where differences occur in respect of these chemicals and their P450 activators, one can 
anticipate that they will be due primarily to the significant variation in body weight between small laboratory-bred rodent strains and man, with diet representing an additional factor of relevance to such comparisons [89]."

\subsubsection{Free Radical Scavengers}

Human cells, tissues and organs have at their disposal many defences against toxins. Many reactions involving free radical intermediates are prevented by the presence of anitoxidants and free radical scavengers. For example, Vitamin E and Vitamin A carotenes are very good at preventing lipid peroxidation.

Vitamin $\mathrm{E}$ is the only vitamin whose sole physiological role is to quench free radical reactions. Vitamin $\mathrm{E}$ is hydrophobic and consists of tocopherol structures, with various methyl groups attached, and a phytyl side chain (a long-chained fatty acid, methyl substituted). Among these, $\beta$-tocopherol is the most potent antioxidant. It donates a sterically-uninhibited hydrogen atom from the $-\mathrm{OH}$ group on the aromatic ring to a free radical, forming a covalent bond with the unpaired electron on the radical, changing it to a stable molecule. The Vitamin E free radical thus formed is stabilized by resonance, and has little tendency to extract a hydrogen from another species to produce a new damaging radical. This explains the efficiency of Vitamin $\mathrm{E}$ as a terminator of free radical propagation reactions in membrane lipids. Unlike Vitamin E, Vitamin C is hydrophilic. It scavenges free radicals in aqueous environments best but it can also react with lipophilic radicals. However, its role as a chain-breaking antioxidant is probably to regenerate the reduced form of Vitamin E.

It has also been hypothesized that carotenoids can prevent or slow the progression of cancer and degenerative diseases by acting as chain-breaking antioxidants. Carotenoids are related to $\beta$-carotene in structure, the precursor of Vitamin A. Although much of $\beta$-carotene is converted to Vitamin A in intestinal mucosal cells, carotenoids are also absorbed and circulate in the blood in lipoproteins. Carotenoids may protect lipids against peroxidation by reacting with free radicals.

\subsubsection{Repair and Replacement of Damaged Membranes.}

The action of chain-breaking antioxidants leaves some lipid hydroperoxide in the membrane, the removal of which is necessary to complete the description of defence strategies against lipid peroxidation. Two mechanisms are currently recognised, one is repair and the other is replacement.

Some scientists believe that the enzyme phospholipase $A_{2}$ provides the major repair mechanism for membrane lipids damaged by oxidative free radical reactions [93]. The current view is that arachidonic acid, which is a polyunsaturated fatty acid, can be peroxidatively cleaved in free radical reactions to malondialdehyde and other products. Phospholipase $A_{2}$ recognises the distortion of membrane structure caused by the partially degraded fatty acid, and removes the fatty acid. Acyltransferases then add back a new arachidonic acid molecule. The released fatty acid hydroperoxides might then be metabolised by glutathione peroxidase, reducing them to alcohols (i.e, from the $-\mathrm{O}-\mathrm{OH}$ group to - $\mathrm{OH}$ ). However, the peroxidised fatty acids have to be split from the membrane 
first. A selenium-based enzyme called phospholipid hydroperoxide glutathione peroxidase (abbreviated to PHGPX in biochemical literature) has been described in mammalian tissues [93]. It seems capable of acting upon peroxidised fatty acid side chains within membranes but its metabolic significance remains unclear. Similarly, an intestinal glutathione peroxidase (GPX-GI) has been identified in the lining of the gastrointestinal tract. It may aid the metabolism of peroxides in food lipids as well as those generated during lipid peroxidation in the intestine itself. GPX-GI is also present in the liver.

It should be noted that membrane components in most cells, including peroxidised lipids, are continuously removed and replaced in normal metabolism [94].

\subsection{The Epidemiology and Aetiology of Some Cancers}

1.4.1 The World Health Organization (WHO) Publishes Findings on Disinfection by-products

The difficulties in establishing a biochemically based cause-effect relationship between low doses of chloroform and liver toxicity were discussed above. On the human (population) level, the WHO has also investigated the possible links of cancer of the gastrointestinal tract with disinfection by-products (DBPs) for 25 years, commencing in the mid-1970s. Gastrointestinal cancers (mostly below the stomach) include gastric (stomach) cancers, oesophageal cancers (above the stomach), pancreatic cancers and hepatobiliary cancer (hepatocellular carcinoma, cholangiocarcinoma and hepatoblastoma). WHO published two major reports on its research findings, in 1991 and 2000 [95,96]. Batram (2001) commented on the 1991 report: "The International Agency for Research on Cancer (IARC) published an evaluation of the carcinogenic risks to humans of chlorinated drinking-water based on a number of animal toxicological and epidemiological studies. IARC concluded that because of one or more methodical weaknesses, the epidemiological studies (reviewed) cannot constitute the basis of valid risk assessment [97]."

The epidemiological investigation of the relation between exposure to chlorinated drinking water and cancer occurrence has always been problematic. Any increase in relative risk over people who consumed water that has not been chlorinated is likely to be small. This makes any real increase in risk difficult to detect in epidemiological studies. In all of the studies evaluated by WHO, estimates of exposure were imprecise and surrogates (e.g., surface versus groundwater) do not reflect exposure during the relevant time periods for the aetiology of the cancers in question. Many significant parameters in this consideration, such as smoking habits, dietary practices, alcohol use and genetical pre-disposition are known to affect cancer incidence, but were not taken into account in most studies. Are these inputs synergistic in action with DBPs and with each other?

In its overall evaluation, IARC (1991) concluded that there is "inadequate evidence for the carcinogenicity of chlorinated drinking-water in experimental animals" and that "chlorinated drinking-water is not classifiable as to its carcinogenicity to humans [98]".

In the second report, published in 2000, the summary findings for bladder, colon and rectal cancers are as follows: "Current evidence from epidemiological studies is insufficient to allow a causal relationship between the use of chlorinated drinking water and the incidence of 
bladder cancer to be established. Several studies reported weak to moderate associations of long-duration exposure to chlorinated drinking water and bladder cancer, but risks have differed between smokers and non-smokers in several studies. Inconsistent risks have also been seen when gender and water consumption were considered. For colon cancer, the epidemiological data appear to be equivocal and inconclusive. Also for rectal cancer, insufficient data are available with which to evaluate the moderate associations observed in one study. Similarly, single studies of reported associations of pancreatic, lung, brain and breast provide insufficient data [96]."

The author of this paper would like to supplement the WHO conclusions with the following comments about bladder and colorectal cancer.

\section{Bladder Cancer.}

This cancer occurs most frequently in Caucasian male adults between the age of 50 and 70 , with men three times more likely to develop it than women. The most common type of bladder cancer is "transitional cell carcinoma" (90\% of all cases) which arises from the transitional epithelial cells that line the bladder. The other types of bladder cancer include papillary (i.e., lumpy), squamous (i.e., flat) cell carcinoma and adenocarcinoma. (See Johansson \& Cohen, 1997, for a detailed description of the epidemiology and aetiology of bladder cancer [99]). Bladder cancer develops over many years as a gradual change in bladder cells but the precise causation remains unknown. It is accepted in the medical profession that cigarette smoking may be a common cause in both men and women [99].

Occupational hazards may also contribute to the development of bladder cancer. Carter \& Neville (1978) noted that, "an increased incidence of bladder cancer among workers in the chemical industry was first described in Germany in 1895. Similar observations were subsequently made in workers in other countries and in other industries, notably rubber and cable making, and suspicion focused on a group of chemicals known as aromatic amines". These workers pointed out the strong link between occupational exposure to these amines and the incidents of bladder cancer, and that bladder cancers have long induction periods, namely 15 to 20 years [100]. Robbins et al. (1999) wrote that, "Some dyes have been proposed as a potential causative agent for bladder cancer. A 'Phase I' reaction (addition of a polar functional group to a parent compound) called peroxidase-dependent co-oxidation, conjugated by prostaglandin $\mathrm{H}$ synthase (found in the smooth endoplasmic reticulum in seminal vesicles, kidneys and the urinary bladder) metabolises 2-naphthylamine, a chemical found in dyes associated with bladder cancer [101]." When aromatic amines are absorbed through the skin, they are metabolised as described and excreted in urine. The carcinogens are therefore in prolonged contact with the bladder.

A bladder infection caused by the parasitic flatworm Schistosoma Haematobium increases the risk of squamous cell bladder cancer. (See Mostafa et al., 1999, for the relationship between schistosomiasis and bladder cancer [102]; see Warren et al., 1995, for mutation of the $p 53$ gene [103]). Other urinary infections may also increase the risk of bladder cancer. 


\section{Colorectal cancer.}

The comments made by WHO about the need to distinguish the possible difference in the increment of hypothetical risk of incurring bladder cancer by consumption of chlorinated drinking water applies in similar fashion. Most colorectal cancers are thought to arise in polypoid adenomas, but a hereditary non-polyposis (i.e., not lumpy) colorectal cancer syndrome does exist.

Parker et al. (1996) provided epidemiological data suggesting that colorectal cancer is the most common cause of death from cancer in both non-smoking males and females in the Western world [104], although Goodman et al. (2003) suggests a lag time of at least 35 years for tobacco-induced tumour to develop [105]. The epidemiological question becomes whether or not the consumption of chlorinated drinking water will increase the risk of colorectal cancer in both smokers and non-smokers similarly, or whether there is a synergistic effect between cigarette smoke and disinfection by-products in causing colorectal cancer. These are the problems in methodology in epidemiological research, and are not easily tackled, although McArdle et al. (2000) are confident that "colorectal cancer is one of the forms of cancer most strongly linked to aspects of lifestyle that may be prevented or detected early by individual action. The association with aspects of dietary practices and physical activity is too strong to ignore and needs implementation despite our ignorance of the time lag between implementation and prevention" and that "the aetiology of colorectal cancer is increasingly well understood and there is a strong body of evidence to support the potential of chemoprevention of colorectal cancer [106]".

"Ulcerative Colitis" is a chronic condition of the colon, speculated to have an autoimmune cause. The condition may lead to an increased risk of colon cancer due to stimulated proliferation. The risk varies with duration and extent of the disease, but most studies agree that the cumulative risk is about $0.8-1.0 \%$ per year, i.e., a $10 \%$ risk of cancer after 10 years of ulcerative colitis. This high risk prompted some physicians to advocate prophylactic (preventive) removal of the colon (colectomy), but modern treatment is a more tailored approach to the individual patient.

Continual clinical observations have led medical professionals to make strong associations between chronic inflammations and tumour development in the liver, bladder and colon. (See Jefford \& Irminger-Finger, 2006, for a general review of development of cancers [107].)

\subsubsection{Difficulties in Determining Population Exposures to Disinfection By-Products.}

Epidemiological research can be based on a tool known as a "cohort" study, whereby individuals with different levels of exposure to suspected risk factors are identified and observed over a number of years. The rates of occurrence of the condition of interest are measured and compared in relation to chronic exposure levels. Herein lays one of the greatest challenges to this discipline of research when applied to the suspected carcinogenicity of drinking water. There is much uncertainty in the exposure history of individuals, if the data is obtainable at all.

Nieuwenhuijsen et al. (2000) asserted that, "If we want to use personal exposure estimates, it 
is unlikely that we will ever be able to measure the DBP (disinfection by-products) uptake of every subject in an epidemiological study, given the time and cost involved, although some crude indicator (approximate) may well be within reach of most studies [108]". In addition, many people change their residence from one part of the country to another or from one country to another, and college students who travel to study abroad are one of the best examples; refugees fleeing war-torn countries and settle in geopolitical regions different to their own are another. No doubt the constituents of water that they consumed and the amount of time spent drinking them will also change.

Other assumptions have to be made in order that any expression of carcinogenicity may be ascribed to chloroform alone. The first assumption is that each member of the sample population has not been exposed to chemicals with known and similar carcinogenic activity in humans (which can never be guaranteed in a sample population). The second assumption is that all individuals react to causative factors in the same physiological way, i.e., the increment of cancer risks is indistinguishable between individuals (but this is difficult to demonstrate for any alleged carcinogen, after all, some smokers die of lung cancer at an early age and some life-long smokers do not). Validation of these assumptions is extremely difficult against a backdrop of a multitude of factors within the environment that may influence the disposition and metabolism of xenobiotics. These factors may also interact with one another in complex ways. The research is very expensive to carry out in sufficient detail to obtain meaningful results.

Relationships between chemicals and cancer in humans can be postulated, but they remain hypotheses to be tested. However, given the impossibility of testing the effects of chemicals on people, most evidence of any health risk, not just for a specific carcinogenicity, can be deduced from data of occupational exposure. This has proven difficult in the case of chloroform. Teaf (2000) summarised the experience of practitioners in this field, "Although the toxicity of chloroform and carbon tetrachloride has been ascribed to their solubility in cellular lipid, metabolism appears necessary to explain their toxicity. Since it is unlikely that the chloroform molecule forms a free radical such as ${ }^{\circ} \mathrm{CCl}_{3}$ at human body temperature, it is not expected to be as toxic as carbon tetrachloride. However, the mechanisms and paths of metabolism are still not certain and both enzymatic and non-enzymatic processes may be important. No metabolite has been identified in the blood or urine that can be considered as a useful guide for evaluating occupational chloroform exposure. Chloroform does not appear to induce chromosome breakage or sister-chromatid exchanges in human lymphocytes and failed to produce mutagenic changes in cultures of Chinese hamster lung fibroblast cells [73]."

\subsubsection{Aetiology and Epidemiology of Liver Cancer}

Simonetti et al. (1991) cited the male gender, age, cirrhosis and the presence of the Hepatitis B Surface Antigen (i.e., the coat protein for which the gene has been isolated and abbreviated to HBsAg in literature) as the "major risk factors" for primary liver cancer (hepatocellular carcinoma), [109]. This cancer is now discussed in some detail. The term "metastasis" connotes the spread of malignant tumour cells from a primary neoplasm (abnormal growth) 
to distant parts of the body where they multiply to form new, malignant growths. The phenomenon is a major cause of death from cancer. "Liver metastasis" is cancer that spreads to the liver from other parts of the body. The liver and the lung are the visceral organs that are most often involved in the metastatic spread of cancers. Therefore, the overwhelming majority of hepatic malignancy is metastatic in origin, most commonly from carcinomas of the colon, lung, breast, stomach and pancreas, although any cancer in any site of the body may spread to the liver, including leukemias and lymphomas. In western civilisations, metastases are the most common tumour in the liver, far more than primary carcinoma. However, it is necessary to discuss primary carcinoma because it is the main type of carcinoma for the rest of the world. The fraction of all liver cancers represented by the Western world is much smaller than that of Africa and the Far East added together. Primary cancers that arise in the liver itself are of two main types, but a mixed pattern of both in the same patient is uncommon:

Hepatocellular carcinoma (HCC), which arises from hepatocytes, accounts for more than $90 \%$ of all primary liver cancers globally.

Cholangiocarcinoma, which comprises virtually all of the rest of primary cancer cases, arises from the bile duct epithelium.

Hepatocellular carcinoma (HCC) is one of the world's most common malignancies. Mendelsohn et al. (2001) estimated that, in China alone, there are 500,000 to 1 million cases of HCC annually, about $43 \%$ of all cases in the world [110]. An unusual epidemiologic aspect of liver cancer is its geographical distribution. As already mentioned, primary liver cancer is uncommon in Caucasians in the West, but it is prevalent in S.E. Asia and in the sub-Saharan desert. Cotran et al. (1999) quoted the following figures: "On a global basis, primary liver cancer constitutes the most common visceral malignant tumor (more than 350,000 cases per year) and in some populations is the most common cancer overall. Annual incidence rates for hepatocellular carcinoma of 2 to 4 cases per $10^{5}$ (population) in North and South America, north and central Europe, and Australia compared with intermediate rates of up to 20 cases per $10^{5}$ population in countries bordering the Mediterranean. The highest incidence rates are found in Korea, Taiwan, Mozambique and south-east China, approaching 150 cases per $10^{5}$. Worldwide, there is a clear predominance of males, ranging from 8:1 in countries with a high incidence of hepatocellular carcinoma, with approximately $2: 1$ to $3: 1$ in populations with a low frequency [111]." Males have a higher carriage rate of hepatitis B, see below.

\section{Hepatitis B and C.}

"Hepatitis" is a descriptive term meaning "inflammation of the liver" and has a long list of causes of which viral is probably the most common. Intensive epidemiological studies support a strong correlation between high prevalence of chronic hepatitis B virus (HBV) infection and the high incidence of hepatoma, especially in the Far East and Africa [112]. A very interesting cohort study was performed on Alaskan native persons and it was found that "HCC can occur in persons with chronic hepatitis B who have lost HBsAg, even in the absence of cirrhosis. These persons should still be followed with periodic liver ultrasound to detect HCC early [113].” 
By the turn of the millennium, some 387 million carriers of HBV in the world were counted, and hepatocellular carcinoma will develop in as many as $25 \%$ of them. HBV accounts for as much as $80 \%$ of the cases of hepatocellular carcinoma that will occur with such high frequency in ethnic Chinese and African populations [114]. It would be very useful and important to know whether these Asian and African populations had been consuming water treated to WHO standards with hypochlorite, or not. The assumption that chronic infection with HBV leading to cirrhosis is of major importance in the aetiology of this tumour was validated in large, prospective, epidemiologic studies in Taiwan [115]. Mendelsohn et al. (2001) summed up the current view of pathogenesis, "HBV-induced cellular injury, a consequence of the immune or inflammatory responses to HBV infection, results in liver cell generation that, over time, can lead to cancer. Cellular proliferation in liver regeneration increases the chances for errors in DNA replication leading to mutations that can contribute to the loss of normal cellular growth control. Those cells with an appropriate set of genetic mutations can then undergo clonal expansion and ultimately progress to HCC. [In this indirect model] HBV promotes oncogenesis chiefly by provoking cellular proliferation in response to immune-mediated injury [110].”

In Japan, however, the epidemiology was such that the proportion of HBV-related liver cancer was decreasing, yet the incidence of the cancer has risen significantly since 1970. Soon after the discovery of the hepatitis $\mathrm{C}$ virus and an antibody test developed, it was established that HCC patients who tested negative for the "Hepatitis B Surface Antigen (HBsAg)" were often infected with the hepatitis C virus. Infection of the general population and of hepatoma patients by the $\mathrm{C}$ virus is now established in many countries. While HBV can integrate with genes causing mutation, Cotran et al. (1999) commented, "Although not a DNA virus (a virus which is either a single-stranded or double stranded DNA), hepatitis C virus is also linked to the pathogenesis of hepatocellular carcinoma. As with hepatitis $\mathrm{B}$ virus, the epidemiologic evidence of an association with hepatitis $\mathrm{C}$ virus is compelling. In the case of hepatitis $\mathrm{C}$ virus, the role of this virus in the pathogenesis of liver cancer seems to be limited in its ability to cause chronic liver cell injury and the accompanying regeneration. The mitotically active liver, presumably, provides a fertile soil for mutations [116]." However, Koike \& Moriya (2003) was more confident that Hepatitis C virus was "directly involved in hepatocarcinogenesis". They wrote, "Infection with HCV may be capable of inducing HCC in the absence of a complete set of genetic aberrations. Such a scenario would explain the unusually high incidence and multicentric nature of HCC developing in patients with chronic hepatitis C [117]."

In the preface of the monograph Viruses and Liver Cancer, the editor Edward Tabor (2003) wrote, "Hepatocellular carcinoma (HCC) is the end result of a long and complicated disease process that usually begins at the time of the onset of chronic infection by the hepatitis $\mathrm{B}$ or $\mathrm{C}$ virus. Thus, the 'hepatocellular carcinoma disease process' should be considered a continuum, a process that often begins in early childhood (for cases associated with the hepatiotus B virus) or in mid-life (for cases associated with the hepatitis $\mathrm{C}$ virus) that damages the liver, and that ends as cancer. This continuum usually extends over many decades. Hepatitis B virus (HBV) infections usually must be acquired before, during, or soon after birth in order for 
HBV-associated HCC to develop in adulthood. Patients who acquire HBV infections as adults almost never develop HBV-associated HCC. In contrast, patients who develop hepatitis $\mathrm{C}$ virus (HCV)-associated HCC often acquire those HCV infections after age 40 years, and the HCC often develops 20 or more years thereafter." Tabor then described the development of $\mathrm{HCC}$ in recent years, "In some parts of the world, HCC is one of the most common tumors in adult men. In addition, there is evidence that the incidence of this cancer has doubled in the past 15 to 20 years in many countries, and the incidence has doubled repeatedly every 20 years for the past half century in Japan [118]."

\section{Aflatoxin B1.}

During the autumn of 1960 thousands of turkeys died in poultry farms in southern England. The poison, now known as "aflatoxin B1", was found to be a compound produced by some strains of the mould Aspergillus flavus, which grows on peanuts, a constituent of feed for turkeys. Much research into the toxicity and carcinogenicity of natural toxins including aflatoxins followed the "Turkey X Disease" episode. Wogan (1992) demonstrated that in (global) geographical areas where foodstuffs are extensively contaminated by Aspergillus flavus and their metabolites, there are high incidences of liver cancer [119]. Aflatoxin B1 was also found to be carcinogenic to some animals, especially the rainbow trout [120].

HBV and aflatoxin B1 may act in concert to produce liver cancers. In a monograph on the molecular biology of cancer, Macdonald \& Ford (2000) asserted that in hepatocellular carcinoma, various mutations of the $p 53$ gene occur regardless of the (known) cause, be it ethnic origin, chronic HBV infection or exposure to aflatoxins. (The p53 gene is a protein which is very important in maintaining the integrity of the genome and much of its function is the repair of damaged DNA. If the structure of $p 53$ itself is changed or damaged, the survival of a cell is also at stake.) HBV can integrate its viral DNA sequences into the host cellular genome on random sites. This integration appears to be a necessary step for the development of subsequent DNA events leading to carcinoma, and "is clearly the major cause of HCC in regions where the virus is endemic and as such may alter the expression of genes at the site of this integration [121]." See Kumar (2003) for a description of the pathogenesis [122].

For subjects who have been exposed to aflatoxin B1, the specific p53 mutation most commonly encountered for those who developed HCC is a "G to T transversion at condon-249, altering an arginine to a serine $[123,124]$." It was this molecular "fingerprinting" that led researchers to suspect the carcinogenicity of aflatoxin B1; pathologists believe that this observation strongly supports the notion that molecular fingerprinting of tumours can provide clues to the identity of initiating agents of cancers. In an extensive epidemiological study (Bressec et al., 1991) suggested that "this mutation was specific to countries in which food was contaminated by aflatoxin B1 (but) in contrast, in countries in which contaminated food is not eaten, the rate of p53 mutation in HCC is low [125]." C.C. Harris (1996) suggested that, "aflatoxin-mediated p53 mutations are a second event leading to further genome instability [126]." This is partly supported by the observation that HBV protein may be able to "modulate $p 53$ function in the nucleotide excision repair [127]."

Typically, Aspergillus flavus grows on crops such as peanuts, corn and grains in the hot 
humid climates of sub-Saharan West Africa and South-East Asia. (It should be emphasised that proper storage of crops susceptible to moulds eliminates conditions favourable to their growth.) C.C. Harris (1996) showed a "strong" correlation between the rate of ingestion of aflatoxin B1 and the specific "condon-249-serine" mutation mentioned in the last paragraph. The people of Senegal, Mozambique and of the Chinese provinces of Qidong and Quanxi ingest "high" doses of aflatoxin B1 (more than 80 nanograms $/ \mathrm{kg}$ body weight/day) in their diet and condon-249 mutation was found in more than $50 \%$ of all HCC cases specific to those regions. In Thailand and in Shanghai (China), the intake of aflatoxin B1 was "moderate" and only $20 \%$ of HCC cases involved the mutation. In the USA, Europe and Japan, intake of aflatoxin B1 was "low" and only 5\% of HCC cases involved the mutation. In Western populations, where HBV incidents are relatively low, alcoholism and the rare hereditary condition of hemochromatosis contribute to pathogenesis, but HBV may cause chronic hepatitis and cirrhosis, which in turn may be important factors of the emergence of HCC too [126].

Pitot \& Dragen (2001) presented the epoxidated form of aflatoxin B1 as the "ultimate carcinogen", a term which they defined as "the form which actually interacts with cellular constituents and probably causes the neoplastic transformation [128]". Timbrell (2000) commented on the effect of diet that, "the carcinogenicty of aflatoxin is reduced by protein deficiency, presumably because of reduced metabolic activation to the epoxide intermediate which may be the ultimate carcinogen which binds to DNA." He also noted that, in rats fed with a low protein diet, there is a "marked loss of microsomal enzyme activity" when compared with those with a high protein diet and that "the decline in activity is accompanied by a decline in the level of liver microsomal protein. Both cytochrome P450 content and cytochrome P450 reductase activity are reduced by the (low) protein diet [129]". Montesano \& Kirby (1994) produced a general scheme of Aflatoxin B1 epoxidation [130] in Figure 5.

All the main causative factors of liver cancer mentioned above interact in complex ways and medical research on pathogenesis is continuous. Claims of p53-induced apoptosis initiated by chloroform have not been substantiated. In fact, in vitro studies of $p 53$-induced apoptosis employ chloroform to extract cells from the culture media after the incubation period prescribed by experiment [131]. Had chloroform interfered with the biochemistry of interest in any way, it would never have been used in the first instance.

\section{Nitrosamines as a suspected "life-style" carcinogen.}

Two British scientists, John Barnes and Peter Magee, reported in 1954 that a chemical compound called dimethylnitrosamine $\left(\mathrm{CH}_{3}\right)_{2} \mathrm{~N}-\mathrm{N}=\mathrm{O}$ produced liver tumours in rats $[132,133]$. The discovery was made during routine health screening of proposed solvents for dry cleaning, and their work motivated ongoing worldwide investigations into the possible carcinogenicity of other nitrosamines and $N$-nitroso compounds. The results have shocked the scientific community. Most of the known nitrosamines tested positive for mutagenicity, and some for carcinogenicity in laboratory animals. Most were organ specific. If one accepts the scepticism expressed by Fawell (2002, lecturing in Imperial College) on whether a single compound, namely, $\mathrm{CHCl}_{3}$, could produce many types of ailments [134], then should one 


\section{Macrothink}

also accept the implication that various cancers and birth defects can be caused by a variety of chemical carcinogens, including the organ-specific nitrosamines? The body of evidence pointing to the carcinognecity of nitrosamines to humans has been growing consistently for half a century. Some landmark stories concerning the toxicity of nitrosamines from 1954 to 2007 are retold below, followed by a description of the chemistry of formation of nitrosamines as a product of reaction between nitrites and secondary amines.
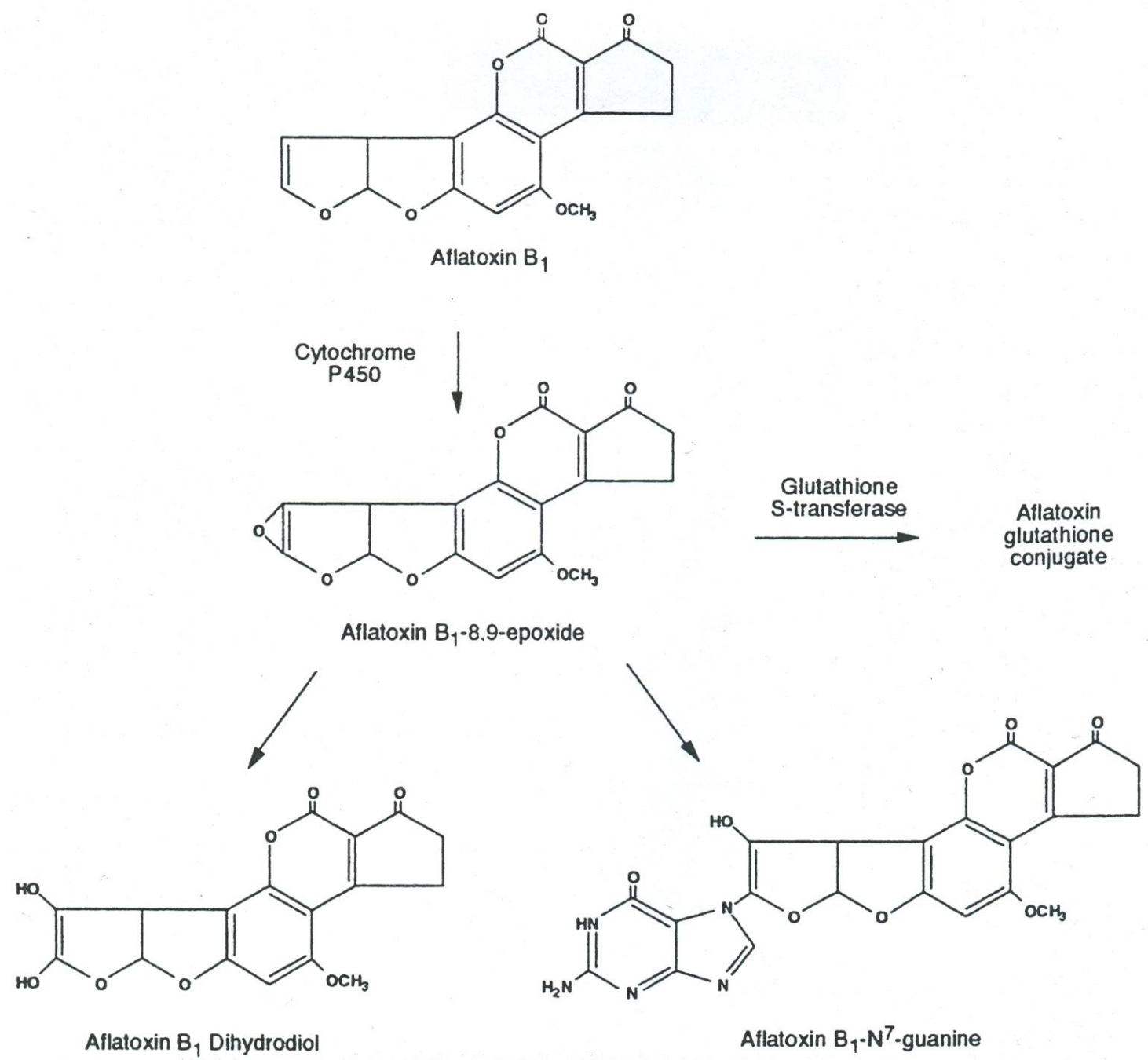

Aflatoxin $\mathrm{B}_{1} \cdot \mathrm{N}^{7}$-guanine

Figure 5. Epoxidation of aflatoxin B1 leading to the formation of a DNA adduct [130].

In 1960, shortly after Barnes \& Magee alerted the world to the harm that nitrosamines can inflict $[132,133]$, it so happened that processing plants in Norway could not produce herring fishmeal fast enough to satisfy demand, and preserved their stock-pile of unprocessed herring with sodium nitrite. Mink fed with the nitrite-preserved herring developed lesions in liver tissues $[135,136]$. It soon dawned on scientists that fish contain amines (e.g., trimethylamine, which is responsible for the odor of fish), which may have reacted with the nitrite to form nitrosamines. It was believed at the time that humans were likely to develop cancer if 
exposed to nitrosamines, and the "First International Evaluation of the Risks associated with the Ingestion of Nitrite" was conducted by the Joint FAO/WHO Expert Committee on Food Additives (JECFA) in 1961 [137]. Soon after, ruminants whose fodder contained nitrite-processed fish also developed liver problems [138,139]. Ender et al. (1964) isolated the toxic dimethylnitrosamine from fishmeals [140], the same compound suspected of causing liver tumours in rats by Barnes \& Magee [132,133]. Sen et al. (1972) investigated a large number of mink deaths in Canada by analyzing their fishmeal for nitrosamines, discovering significant amounts of dimethylnitrosamine in some meal, but without finding nitrites [141]. This does not, however, negate the role that nitrites play in producing nitrosamines, for the simple reason that nitrites might have been the limiting reactant in these particular circumstances. It depends on the quantity of nitrites applied on any one occasion.

Montesano \& Kirby (1994) has summed up the research on the suspected carcinogenicity of nitrosamines well [130]. By 1994, the publication date of their review in Primary Liver Cancer: Etiology and Progression Factors, the scientific community is in no doubt of the role that nitrosamine plays in inducing liver carcinogenicity in rats, but "there is as yet no epidemiological evidence clearly linking nitrosamines to human cancer. This lack of evidence is most probably due to the low (albeit widespread) exposure of humans to nitrosamines and the lack of sensitivity of epidemiological approaches". Montesano \& Kirby (1994) then cited three pieces of "strong indirect evidence" from Singer (1990) to suggest that nitrosamines might be human carcinogens [142]:

Point 1. Widespread exposure of humans to nitrosamines.

Point 2. DNA adducts (the most important one being $\mathrm{O}^{6}$-akyl guanine, abbreviated to $\mathrm{O}^{6}$-akylG in literature) in human (my emphasis) tissues that are attributable to nitrosamines, the alkylating agents, were identified. Montesano \& Kirby (1994) suggested a pathway whereby a nitrosamine is metabolised into a carbocation (electrophile) that is able to interact with DNA and modify it, potentially initiating cancer, Figure 6. 


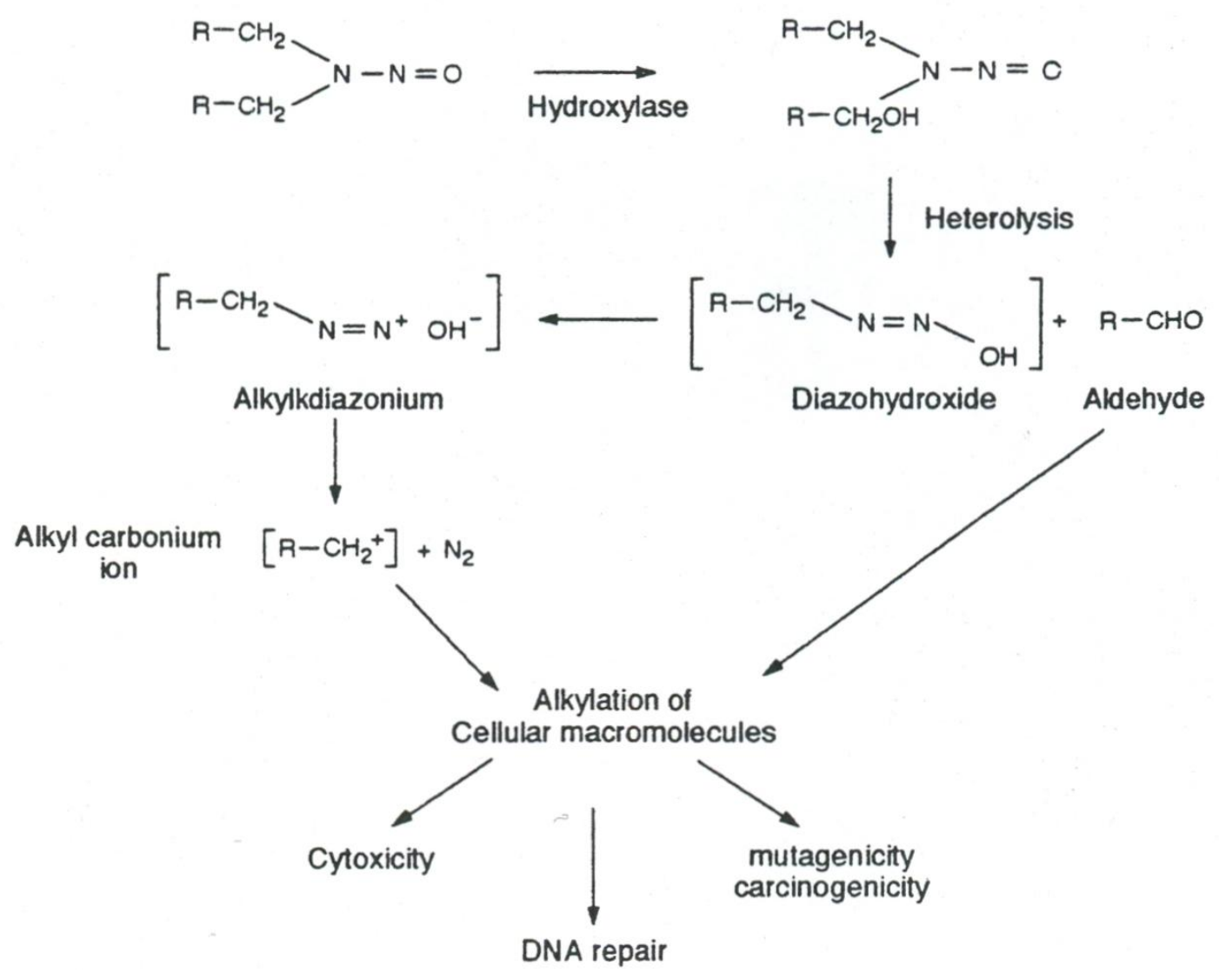

Figure 6. In vivo metabolism of nitrosamines [130].

Point 3. There are similarities between humans and rodents in the metabolism of nitrosamines, in DNA repair mechanisms, and in the processing of DNA alkylation damage which are relevant (my emphasis) to the mechanisms of nitrosamine-induced carcinogenesis.

The three points made above warrant further comment. Point 1 is problematic. Montesano \& Kirby (1994), citing Singer (1990), seemed to have said that, because the general public received widespread exposure to low doses of nitrosamines, the exposure "must" have given rise to "some" cases of cancer, but unfortunately for the research worker, epidemiological methods of detection at the time were not sensitive enough to recognise the resulting low incidences. In that respect, Montesano \& Kirby (1994) appeared to have asserted that the criterion of "widespread exposure" alone is "strong indirect evidence" of carcinogenicity. Four issues must be addressed here:

(1) The Scientific Method. As much as a scientist is allowed the intellectual freedom to hypothesise the existence of any physico-chemical phenomenon, there accompanies this freedom the moral obligation to accept that the proposed scenario may not actually exist, or exist only under rare circumstances not easy to observe or detect. To assert that a situation is definitely "out there" without preliminary evidence to support the claim does not enhance its verisimilitude. The claim must then remain a hypothesis.

(3) Detection of rare cancers. "Rare cancers" in the general public are defined as those with an incidence of less than 6 in 100,000 persons (or 60 in a population of a million) per year 
[143]. Knowledge of rare cancers worldwide already existed well before 1994. Other than a handful of well-known carcinogens incurred during occupational exposures such as those in the dye industries, the causes of most rare cancers are unknown, and yet it is clear that rare cancers are detectable and reported in literature. Lynge et al. (2005) discussed two rare cancers discovered before 1994 [144]:

(i) vaginal adenocarcinoma (cancer of epithelia originating in glandular tissue) developed in daughters exposed to diethylstilbestrol in utero. Diethylstilbestrol (Figure 7) was dispensed to pregnant mothers in the USA (pre-1975) in the erroneous belief that it would reduce the chances of adverse pregnancy outcomes in women with a history of miscarriage. Approved for use by the U.S. FDA on September 19, 1941, the drug was officially withdrawn by the U.S. FDA on Feb 18, 1975 [145].

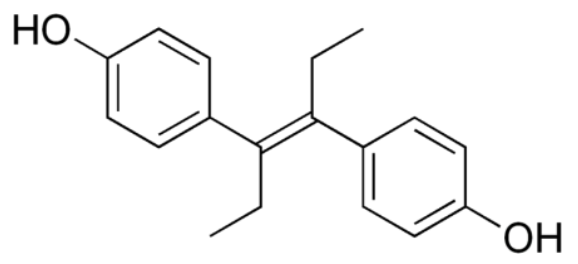

Figure 7. The diethylstilbestrol molecule

Herbst et al. [146,147] reported 7 cases of vaginal cancer that they ascribed to diethylstilbestrol. The population of the U.S.A. in 1971 was 207,660,677 (Pearson Institute, Boston, MA, USA). 7 cases in a population of $207,660,677$ is $3.37 \times 10^{-8}$, which is far less than $6.0 \times 10^{-5}$ (defined criteria for a rare cancer type). (History timeline: Richard Nixon was president in 1971, to be re-elected the following year. In April 1971, the Chinese table tennis team invited their American counterparts to visit China. In July of the same year, U.S. Secretary of State Dr. Henry Kissinger also visited China and arranged for a visit by the First Lady. Nixon finally set foot in China in February 1972.)

(ii) retinoblastoma (cancer of the retina, the light-detecting tissue of the eye) in children due to mutation of chromosome 13, the so-called RB1 gene, which may be inherited from either parent, i.e., the cancer is hereditary. J.L. Young et al. (1999) reported 300 new diagnosis of the cancer per year in the U.S.A. (predominantly in children and young adults under 20) from 1975 to 1995 [148]. The population of the U.S.A. in 1975 was 215,973,199 (Pearson Institute, Boston, MA, USA). 300 cases in $215,973,199$ is $1.38 \times 10^{-6}$, which is an order of magnitude less than $6.0 \times 10^{-5}$. Retinoblastoma is therefore a rare cancer. See also [149,150]. (History timeline: the Vietnam War ended in April, 1975.)

The exceedingly rare cases of "angiosarcoma" identified in four workers of a PVC manufacturing plant in Kentucky [198] was discussed earlier in this work.

(4) Doses and the dose-response relationship. In saying that some cancers must have developed by exposure of the population to "low" doses of nitrosamines, were Montesano \& Kirby (1994) and Singer (1990) assuming that the linear, no-threshold, dose-response model for carcinogenicity is accurate for low doses? Or perhaps only certain individuals 
(a miniscule fraction of the population) are susceptible to nitrosamines? Furthermore, if a substantial proportion of the population consumes fried bacon at breakfast, some possibly for a lifetime, then surely the accumulative dose is not "low" and "insignificant"?

In their description of the developmental history of curing meats, Sindelar \& Houser (2009) cited no less than half-a-dozen pre-1994 papers and reports which addressed the "great challenge" facing the meat industry from the 1970's onwards, i.e., the challenge to eliminate nitrosamines from bacon [150]. Perhaps Montesano \& Kirby (1994) could have quantified doses received by a sample population. The exposure of the U.S. population to nitrosamines via food and beverages, pre-1981, was estimated to be approximately $1 \mu \mathrm{g}$ per person, per day [151]. Scanlan (2000) proposed a figure of $0.1 \mu \mathrm{g}$ to reflect the efforts to minimise nitrosamines in foodstuffs for a good two decades in the U.S. [152], while Griesenbeck et al. (2010) suggested a figure of $0.4 \mu \mathrm{g}$ for the contemporary U.S. population [153]. The inquiry is about how the human body responds to these dose rates.

Montesano \& Kirby (1994) developed Points 2 and 3 much more convincingly than Point 1, and these are discussed below.

Point 2. On DNA adducts, Montesano \& Kirby quoted earlier work (1990) and stated that:

(a) Levels of the DNA repair enzyme methyltransferase (MGMT) for $\mathrm{O}^{6}$-methylguanine and for $\mathrm{O}^{4}$-methylthymidine are "higher in the liver than in other tissues, and humans consistently show higher activity than other species [154]."

(b) Human liver cells increase MGMT levels when exposed to methylating agents. MGMT is the human 06-methylguanine-DNA methyltransferase protein from HeLa M cells [206].

(c) "There is some evidence that methylpurine glycosylase levels are higher in smokers than non-smokers [155]". Methylpurine glycosylase is also a DNA repair enzyme, but cigarette smoke contains certain nitrosamines that have been alleged to cause lung cancer.

Point 3. Similarities between humans \& rodents metabolism of nitrosamine were noted. Montesano \& Kirby (1994) stated that "The majority of known nitrosamines are metabolically activated by cytochrome P450 monooxygenases to several genotoxic and mutagenic alkyldiazonium ions and aldehydes which can react with nucleophilic sites, including exo-oxygen atoms of bases in DNA and other cellular macromolecules (see Fig. 6). For example, cytochrome P450-(II)E1 is very efficient in the metabolic activation of nitrosamines and is inducible by various chemicals including ethanol. Human liver slices are able to metabolize dimethylnitrosamine $(\mathrm{DMN})$ to the same degree as rodent liver via various forms of P450 [see 142,156,157,158]."

Vollhardt \& Schore (2007) also speculated that nitrosamines are likely to cause liver cancer in humans. They expressed their concerns over the presence in human diets of nitrite $\mathrm{NO}_{2}{ }^{-}$ions because they may be a precursor of nitrosamine formation. They comprehensively summed up the state of knowledge, " $N$-Nitrosodialkanamines are notoriously potent carcinogens in a variety of animals. Although there is no direct evidence, they are suspected of causing cancer in humans as well. Most nitrosamines appear to cause liver cancer, but certain of them are very organ specific in their carcinogenic potential (bladder, lungs, esophagus, nasal cavity, 
etc.) [159]". The latter point regarding organ specificity refers to rats, not humans. While nitrosamines have been detected in a variety of cured meats, such as smoked fish, frankfurters ( $N$-nitrosodimethylamine) and fried bacon (principally $N$-nitrosopyrrolidine, alternatively known as $N$-nitrosoazacyclopentane, and to a lesser extent $N$-nitrosodimethylamine, which concentrate in the fat; well-drained bacon contains fewer nitrosamines), bacon has received the most attention. The high temperatures for frying bacon favour the formation of nitrosamines. The molecular structures of the two nitrosamines in fried bacon are shown on Figure 8.

Knowledge and understanding of the public health implications of consuming fried bacon has advanced since the turn of the century. Larsson et al. (2006) published their findings after 18 years of tracking the direct nitrosamine intake and cancer development of 61,433 Swedish women (enrolled in the Swedish Mammography Cohort). The study examined only processed meats, including bacon or side pork, sausages or hotdogs, ham or salami. The results were alarming: 156 cases of stomach cancer were identified, i.e., $0.25 \%$ of the cohort, or 1 in 400 women, developed stomach cancer! This is a very high incidence rate. Larsson et al. (2006) commented on these results, "High consumption of processed meat, but not of other meats (i.e., red meat, fish and poultry), was associated with a statistically significant increased risk of stomach cancer" and that "Stomach cancer risk was two-fold higher among women in the top quintile of $\mathrm{N}$-nitrosodimethylamine intake when compared with those in the bottom quintile. Our findings suggest that high consumption of processed meat may increase the risk of stomach cancer. Dietary nitrosamines might be responsible for the positive association [162]".
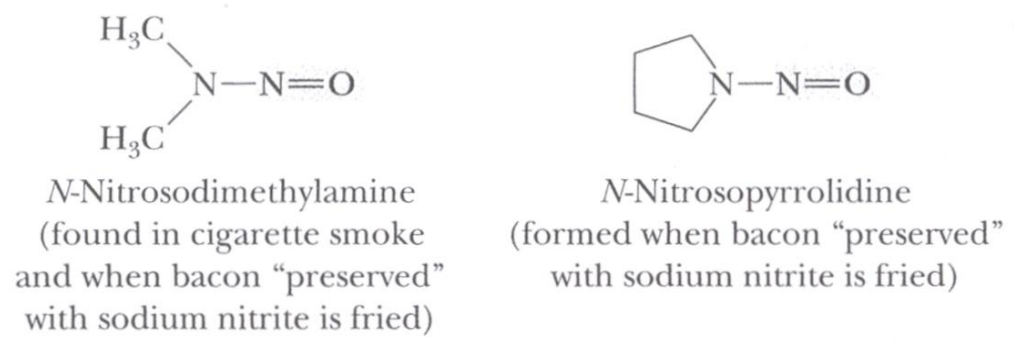

Figure 8. Two nitrosamines found in cigarette smoke and in fried bacon [160].

Other amines found in tobacco smoke are dimethylamine, methylethylamine and the secondary amine pyrrolidine, Figure 9.

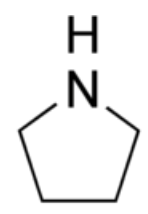

Figure 9. Pyrrolidine, found in cigarette smoke [161]. 
Michaud et al. (2006) published their study of 2 cohorts (47,422 men, 88,471 women) over 22 years and found that 808 of all participants developed bladder cancer, i.e., $0.59 \%$ of either cohorts combined, or 1 in 167 people, developed bladder cancer! Michaud et al. (2006) wrote, "In these 2 cohorts combined, frequent consumption of bacon was associated with an elevated risk of bladder cancer", and that "persons consuming $\geq 5$ servings of bacon/week had a higher risk of bladder cancer than did those who ate no bacon [163]". Michaud et al. (2009) also investigated possible links between glioma (a type of tumour that starts in the brain or spine) and intake of processed meats [164], and fortunately for Homo sapiens, found no association.

It is necessary to describe meat curing. Curing is a process used for centuries to preserve meat. Initially, such treatment was based on salting with $\mathrm{NaCl}$, the effect of which was direct or indirect (through drying) prevention of bacteria growth. Near the turn of the $20^{\text {th }}$ century, salting with sodium nitrate $\mathrm{NaNO}_{3}$ was found to have the desirable effect of producing an appetizing pink colouration and special flavour in meat so treated. Later, the origin of this effect was traced to sodium nitrite $\mathrm{NaNO}_{2}$, produced from $\mathrm{NaNO}_{3}$ by bacterial action during processing. $\mathrm{NaNO}_{2}$ is still used for curing because it inhibits the growth of Clostridium botulinum, the bacteria responsible for the production of an extremely poisonous toxin which causes botulism (a rare form of paralysis), retards development of rancidity and off-odours during storage, and preserves the flavour of added spices and smoke (if the meat is smoked). Again, it is absolutely necessary to eliminate a real risk, namely, botulism. The benefits of such a preventive measure far outweigh the risks.

Consumer groups in the U.S. wanted to ban sodium nitrite because of its potential hazards, but the meat packaging industry did their own research and resisted. Then, scientists found that nitrite is produced by bacterial reduction of nitrate in the normal human intestine, and also in the buccal cavity, implying that ingested nitrite is in fact compatible with normal human physiology. The author of this paper suggests that cancer researchers should investigate the thermodynamics and kinetics of nitrosamine formation. If frying bacon at elevated temperatures $\left(\sim 200^{\circ} \mathrm{C}\right.$ for 20 minutes $)$ favours the formation of nitrosamines, will they form in the human intestine where nitrite is produced by bacteria, at the body temperature of $37^{\circ} \mathrm{C}$ ? Do enzymes catalyse the formation of nitrosamines? The amount of nitrosamines formed in both scenarios should be quantified and compared to estimate the risk posed by fried bacon.

The formidable ethical dilemma which faced nutritionists, health officials and food regulators such as the U.S. Food and Drug Administration in the late 1970's was whether or not to terminate the use of $\mathrm{NaNO}_{2}$ as a food preservative, an action which might prevent the formation of nitrosamines, but increase the risk of botulism. After weighing the arguments, the FDA chose not to implement a total ban. Instead, it recommended a controlling strategy, limiting the addition of $\mathrm{NaNO}_{2}$ to around $120 \mathrm{ppm}$, the lowest level known at the time to control the growth of Clostridium botulinum. The latest allowable mass fractions of $\mathrm{NaNO}_{2}$ in foodstuffs were published by the U.S. FDA on $1^{\text {st }}$ April 2016, quoted here per verbatim [165]: 
- As a color fixative in smoked cured tuna fish products so that the level of sodium nitrite does not exceed 10 parts per million ( 0.001 percent) in the finished product.

- As a preservative and color fixative, with or without sodium nitrate, in smoked, cured sablefish, smoked, cured salmon, and smoked, cured shad so that the level of sodium nitrite does not exceed 200 parts per million and the level of sodium nitrate does not exceed 500 parts per million in the finished product.

- As a preservative and color fixative, with sodium nitrate, in meat-curing preparations for the home curing of meat and meat products (including poultry and wild game), with directions for use which limit the amount of sodium nitrite to not more than 200 parts per million in the finished meat product, and the amount of sodium nitrate to not more than 500 parts per million in the finished meat product.

In Canada, similar regulations for allowable potassium and sodium nitrites in food processing and foodstuffs were published on $21^{\text {st }}$ October, 2016 [166]. The latest UK regulations were also published in October 2016 [167].

Since 1999, Vollhardt \& Schore [168] have urged the public "to place these facts into perspective (since) less than $10 \%$ of nitrate/nitrite intake is on average from cured meats. The remainder comes from natural sources - namely, vegetables such as spinach, beets, radishes, celery, and cabbages." In addition, nitrates in fertilizers are reduced to nitrites in the human body and in some plants, and will also contribute to the nitrite intake budget.

Nitrosamines have been involved in other controversies. Fox \& Whitesell (2004) documented the case of "Alar", a synthetic compound that inhibits the apple enzyme that causes ripening and ultimately rotting. "Alar" can be transformed to 1,1-dimethylhydrazine in the human body, which is then oxidised to a nitrosamine, which has tested positive for carcinogenicity in laboratory animals [169]. The sequence of chemical transformations of these compounds can be represented in Figure 10.

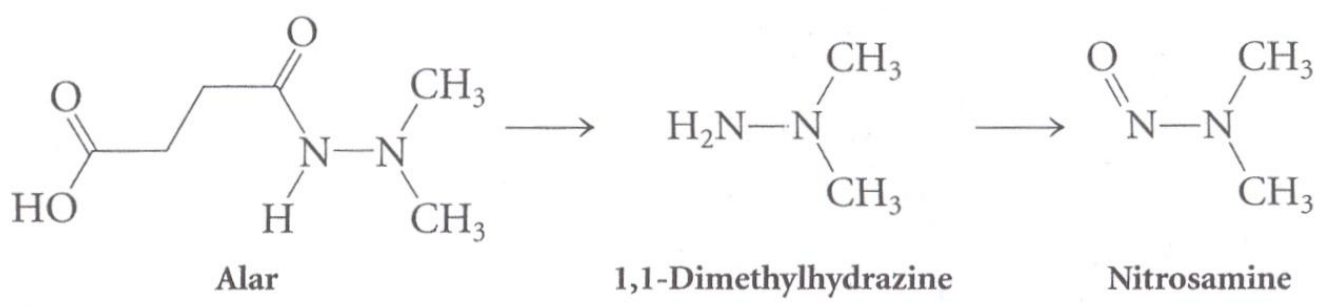

Figure 10. Metabolism of "Alar" into a nitrosamine [169].

As a result, millions of US dollars worth of apples that had been treated by "Alar" was destroyed. This instigated Fox \& Whitesell (2004) to question the Health and Safety strategy of "erring on the side of caution", asking the philosophical question: Does Natural mean good and Synthetic mean bad? They certainly cast doubt on the wisdom of banning "Alar" since "the action was based on only a limited knowledge of the facts: one ordinary mushroom contains ten times as much 1,1-dimethylhydrazine as two apples treated with Alar [169]". Should health authorities ban consumption of mushrooms? The nitrosamine story is interesting in that the alleged risk of cancer is weighed against benefit, i.e., the ability to 
preserve foods and render the public free from toxic effects of food spoilage, over which opinions differ. This scenario is reminiscent of the story of disinfection by-products (DBPs) in drinking water, but only to a small degree.

Nitrites have been suspected to cause Chronic Obstructive Pulmonary Disease (COPD). The disease is characterised by chronic inflammation of alveoli leading to excessive mucus production, excessive fibrous connective tissue development (fibrosis), and degradation of proteins (proteolysis); unfortunately, no cure has been found. It is interesting to note that research at Columbia University reported that $10 \%$ of people who die from COPD, the No. 4 cause of death worldwide, are said to have never smoked in their lives, a statistic significant enough to hint that other causative factors are at play. One such factor may be nitrites in cured meat, Professor R. Graham Barr and his co-worker Rui Jiang so proposed (Jiang et al., 2007). They established from literature review of animal studies that nitrites are transformed to compounds that can damage lungs, causing changes in lung tissues akin to those of emphysema. In their epidemiological work, they employed data from the Third National Health and Nutritional Examination Survey (NHANES, 1988-1994) on 7,581 participants over the age of 44, from which information was available on diet and lung function. The group was representative of the U.S. population of that age group. After adjusting for age, sex, ethnic group and smoking habits, the data show that people who ate cured meat at least 14 times a month had significantly more lung obstruction than those who never ate it at all. Jiang et al. (2007) then concluded that subjects who frequently ate cured meat were $71 \%$ more likely to have lung function results suggestive of COPD compared to those who never ate cured meats $[170,171]$.

\section{Chemistry of formation of nitrosamines.}

Nitrous acid $\mathrm{HNO}_{2}$ is unstable in water at room temperature and decomposes rapidly:

$$
2 \mathrm{HNO}_{2}(a q) \rightarrow \mathrm{NO}_{2}(g)+\mathrm{NO}(g)+\mathrm{H}_{2} \mathrm{O}(l) .
$$

The evolving $\mathrm{NO}_{2}$ redissolves in water and disproportionates to give nitric acid:

$$
3 \mathrm{~N}^{(\mathbf{I V})} \mathrm{O}_{2}+\mathrm{H}_{2} \mathrm{O} \rightarrow \mathrm{N}^{(\text {II) }} \mathrm{O}+2 \mathrm{HN}^{(\mathbf{V I I})} \mathrm{O}_{3} \text {. }
$$

Therefore, whenever $\mathrm{HNO}_{2}$ is required in the laboratory, it is prepared in situ by adding hydrochloric or sulfuric acid to sodium nitrite:

$$
\mathrm{NO}_{2}^{-}+\mathrm{H}_{3} \mathrm{O}^{+} \rightarrow \mathrm{HNO}_{2}+\mathrm{H}_{2} \mathrm{O}
$$

The $\mathrm{pK}_{\mathrm{a}}$ of $\mathrm{HNO}_{2}$ is 3.37 [172] at room temperature and the un-dissociated acid molecule can be found in humans since gastric juices contain $\mathrm{HCl}\left(\mathrm{pK}_{\mathrm{a}}=-7\right) . \mathrm{HCl}$ is a much stronger acid than $\mathrm{HNO}_{2}$ and is able to protonate the $\mathrm{NO}_{2}{ }^{-}$ion not just once, but twice [171]. Nitrous acid reacts with amines in many ways, the outcome depending very much on whether the reactant is aliphatic (an alkylamine) or aromatic (an aniline), and whether the amine is primary (2 hydrogens on $\mathrm{N}$ atom), secondary (1 hydrogen on $\mathrm{N}$ atom) or tertiary (no hydrogen on $\mathrm{N}$ atom). These reactions are made possible by the fact that $\mathrm{HNO}_{2}$ can be protonated further (on the oxygen atom of the $-\mathrm{OH}$ group) with subsequent elimination of $\mathrm{H}_{2} \mathrm{O}$, to furnish the electrophile $\mathrm{NO}^{+}$, known as the nitrosyl ion (which must be distinguished from the nitronium 
ion $\mathrm{NO}_{2}{ }^{+}$, the species believed to be responsible for the nitration of benzene.) The nitrosyl ion is a resonance hybrid of two contributing structures, Figure 11.

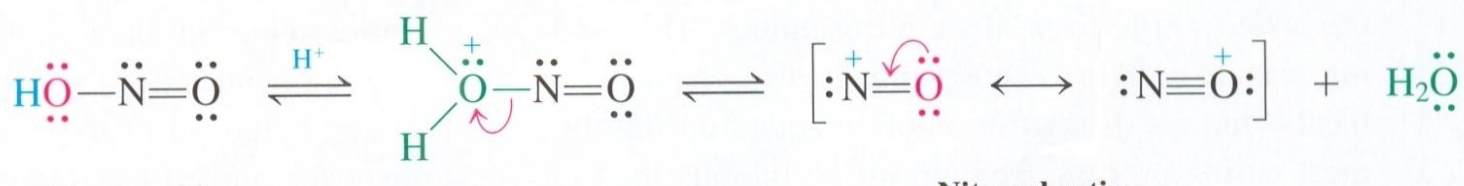

Nitrous acid

Nitrosyl cation

Figure 11. The resonance hydribs of the NO+ ion $[159,173]$.

The nitrosyl ion $\mathrm{NO}^{+}$is an electrophile. The nitrogen atom of an amine donates its lone pair of (non-bonding) electrons to the nitrogen atom of $\mathrm{NO}^{+}$, forming the single bond $\mathrm{N}-\mathrm{N}$, e.g.,

$$
\mathbf{R}_{1} \mathbf{R}_{2} \mathbf{R}_{3}-\mathrm{N}:+(\mathrm{N}=\mathrm{O})^{+} \rightarrow\left(\mathbf{R}_{1} \mathbf{R}_{2} \mathbf{R}_{3}-\mathrm{N}-\mathrm{N}=\mathrm{O}\right)^{+} .
$$

A secondary amine has one hydrogen atom bonded to nitrogen, and it detaches according to:

$$
\left(\mathrm{CH}_{3}\right)_{2} \mathrm{NH}+(\mathrm{N}=\mathrm{O})^{+} \rightarrow\left(\mathrm{CH}_{3}\right)_{2} \mathrm{~N}-\mathrm{N}=\mathrm{O}+\mathbf{H}^{+} .
$$

The proton is hydrated to form $\mathrm{H}_{3} \mathrm{O}^{+}$. The organic product formed in this case is the already-mentioned $\mathrm{N}$-nitrosodimethylamine detected in both frankfurters and fried bacon. It is the secondary aliphatic and aromatic amines which cause concern for public health because they react with nitrous acid to give $N$-nitrosamines and $N$-nitrosodialkanamies, the most notorious animal carcinogens. Jones (1997) proposed a different mechanism involving a protonated nitrous acid species, a cation, as shown below in Fig. 12, but the formation of the carcinogen $N$-nitrosodialkalamines as the main product proceeds unaltered (with a $90 \%$ yield). This is also shown in Figure 12.

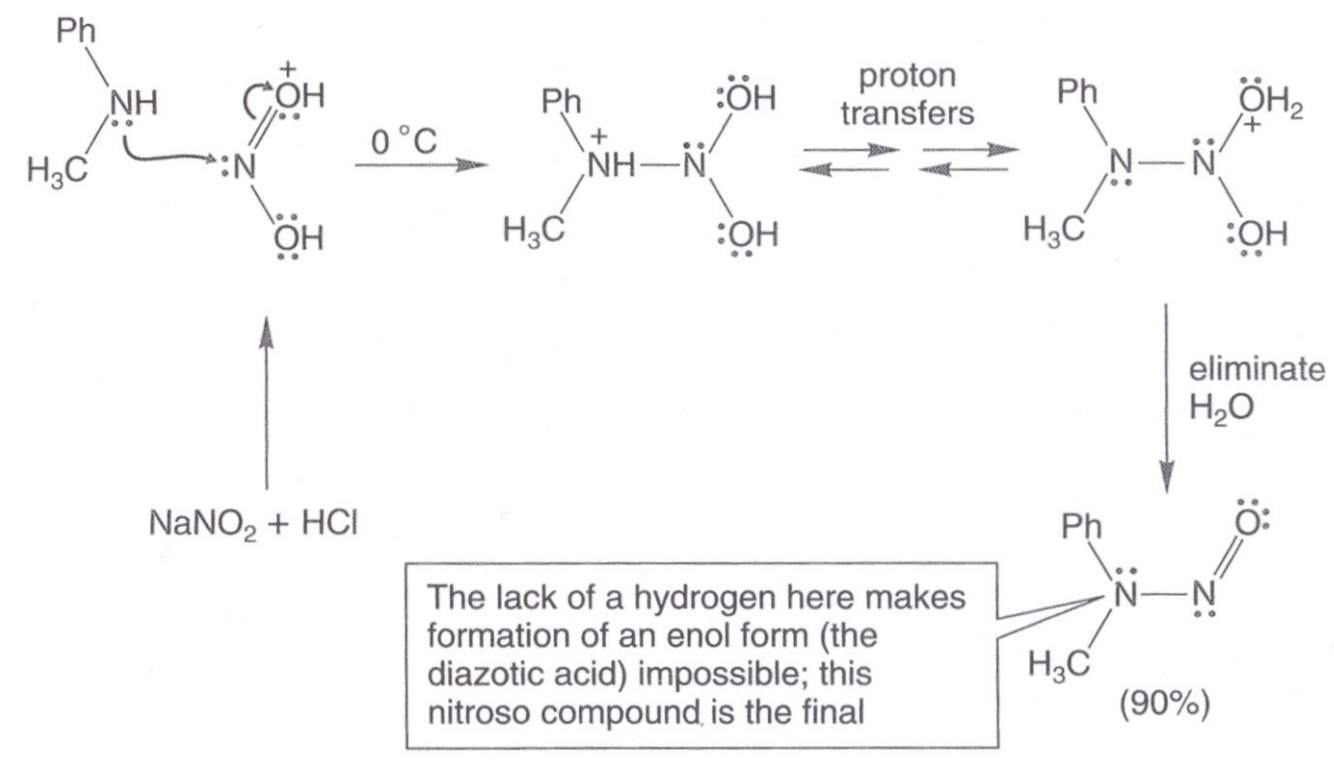

Figure 12. Proposed pathway for the reaction between 2o amines and HNO2 [173]. 
Their mode of carcinogenic action appears to begin with enzymic oxidation of one of the alpha-positions, which allows eventual formation of an unstable monoalkyl-N-nitrosamine. This compound then decomposes to a carbocation $\mathrm{R}^{+}$that, as a powerful electrophile, is thought to attack one of the bases in DNA to inflict the kind of genetic damage that seems to lead to cancerous cell behaviour.

\subsubsection{Birth Defects}

It is interesting to note that chloroform has been the suspected agent responsible for adverse birth outcomes since early Victorian times. During her reign, substances had been suggested to Victoria to ease her pain during childbirth. At the birth of her eighth child, Prince Leopold (the Duke of Albany) on $7^{\text {th }}$ April 1853, chloroform was administered to her as an anaesthetic, by her personal physician Dr. John Snow [174], the same man who, some sixteen months later, would remove the handle of the infamous pump on Broad Street in London during the 1854 cholera epidemic. (The anaesthetic property of chloroform was discovered by the Scottish obstetrician Dr. James Simpson in 1847.)

Prince Leopold endured many serious illnesses from birth. He married at age twenty-nine but died a few years later from the blood-clotting disease now known as haemophilia. Rather than induced by chloroform, haemophilia is now known to be a manifestation of genetic mutation, "one that was to reappear in many of Victoria's descendants although it had never been witnessed in the Royal Family before [175]." Although Victoria's personal physicians made no public announcement of their use of anaesthesia, the news surfaced. Immediately after his birth, the use of anaesthesia to facilitate the birth process caused social controversy, including amongst clerics, who perceived as "unnatural" the application of the relatively unknown substance to subdue pain associated with the natural act of childbirth. Thomas Wakley, the founding editor of Lancet, wrote a scathing editorial $\left(14^{\text {th }}\right.$ May, 1953 , published five weeks after the birth of Leopold) criticising John Snow (although not by name) for "even having considered anaesthesia, endangering the monarchy, and setting a bad example for the rest of the country [176]." Neither Queen Victoria nor her doctors responded publicly to these criticisms.

The prevalent opinion in the $19^{\text {th }}$ century was that the post-natal ailments of Leopold were due to chloroform. Victoria ignored these sentiments, giving birth to her ninth child Princess Beatrice on $14^{\text {th }}$ April 1857, under the anaesthesia of chloroform, administered again by Snow, during the delivery by the attending physician Dr. Charles Locock [174]. Snow was satisfied that the Queen's recovery was "very favourable". Chloroform has long ceased to be an anaesthetic after a few cases of lethal overdose. The connection between chloroform and haemophilia was never proven.

\subsubsection{Disinfection by-products (DBPs) in Swimming Pools}

Nieuwenhuijsen et al. (2000) reviewed the literature available on the subject of adverse reproductive outcomes. They reported that little is known of the following alleged adverse reproductive effects of DBPs: low birth weight, preterm delivery, spontaneous abortions, still birth, and birth defects in the cardiovascular, respiratory and central nervous systems. They 
also stated that the evidence to support the hypothetical cause-effect relationship between trihalomethanes (THMs) and low birth weights is "inconclusive and inconsistent", but pointed to the presence of chloroform in swimming pools as a possible causative agent for these birth effects [177].

On $4^{\text {th }}$ April, 2002, the Medical Editor of The Daily Telegraph (UK national newspaper), Celia Hall, reported the polemics between Nieuwenhuijsen et al. [177] and the Chief Executive of the National Children's Trust, Belinda Phipps [178]. In the article, Phipps commented on the alleged effects of THMs in swimming pools: "For a vast number of pregnant women in the United Kingdom, swimming and aqua exercise programmes are a very enjoyable and beneficial part of their pregnancy. It is critically important to stress that this paper does not attempt to link swimming in indoor pools to miscarriage or birth defects. It does, however, highlight an area of potential risk to pregnant women and offers a simple solution to limit chemical levels in swimming pool water by reducing the amount of chlorine used, a measure in which the National Children Trust would strongly support [178]." The U.S. EPA (1998) reviewed a few epidemiological studies on the subject but reported that there was no convincing evidence that DBPs cause adverse birth outcomes [179]. Kogevinas et al. (2010) looked for biomarkers for potential cancinogenecity in swimmers, but concluded that chloroform is non-mutagenic and that "only brominated THMs were associated with higher genotoxicity; chloroform was not [180]."

In a lecture delivered at Imperial College (London, U.K.), John K. Fawell OBE (2002), advisor to WHO on setting the upper limits of disinfection by-products in drinking water, commented that the epidemiological studies he had reviewed were all of limited value due to difficulties in determining exposures, and that the associations between DBPs and adverse birth outcomes are only weak to moderate. More importantly from the perspective of scientific methodology, because the reported birth defects (and therefore the end points of alleged effect) were different in every study, present epidemiological data is still considered to be inconsistent [134].

In the same lecture, Fawell (2002) casted doubt on the validity of toxicological studies of animals such as rodents because these laboratory animals had been fed with very high doses of disinfection products. In fact, these doses were much higher than those consumed by humans. It was speculated that there was deliberate intention of inducing cancer in the laboratory animals under observation. However, biochemical mechanisms appeared largely non-genotoxic, and living cells were damaged in these experiments by very high doses of halogenated species before any genotoxicity had an opportunity to manifest itself, i.e., animal cells were killed before they had a chance to develop cancer. He emphasised that interpretation of the data from these studies cannot be extrapolated to humans directly. Positive turmourigenicity in the liver, kidney and large intestines of these animals were thought to be induced by a number of halogenated organic compounds including chloroform, bromodichloromethane, bromoform, dichloroacetic acid, trichloroacetic acid, chloral, chloropicrin and "MX", short for "Mutagen X". The IUPAC name for "MX" is 3-chloro-4-(dichloromethyl)-5-hydroxy-2(5H)-furanone, Fig. 13. Humans, however, are only exposed to a minute fraction of these animal doses in everyday life, and Fawell legitimately 
questioned whether any biological action is plausible at such low doses. Some animal studies called into question the alleged biological action of chloroform because even when high doses of chloroform were administered there had been no observed effect [134].

Much interest has been expressed over the mutagenecity of "MX" and its potential impact on public health. "MX" has no commercial applications and not known to exist in nature. It is synthesized in small quantities (and sold by Sigma Aldrich) for research purposes as a DBP. Daniel et al. (1993) reviewed the subject [181] and was satisfied that "MX" is formed by the reaction of chlorine and humic acids in raw water. "Although present only at nanogram/litre levels (in drinking water), its high mutagenecity of more than 1 millionfold greater than the THMs makes MX potentially a far more serious reaction product than THMs, accounting for an estimated 15 to $60 \%$ of the total mutagenecity of chlorinated waters. One problem with MX is that it is non-volatile and therefore not easily measured [181]". (See [207] on the scientific position of WHO on MX.)<smiles>O=C1OC(O)C(C(Cl)Cl)=C1Cl</smiles>

Figure 13. Molecular structure of "Mutagen X" [207].

\subsubsection{Pharmaceutical Drugs and Birth Defects}

Day (2004) summarised some developments in medical research regarding possible links between birth defects and prescribed drugs for pregnant women such as sodium valproate $\left(\mathrm{CH}_{3} \mathrm{CH}_{2} \mathrm{CH}_{2}\right)_{2} \mathrm{CHCOO}^{-} \mathrm{Na}^{+}$(a drug that controls epileptic seizures and is believed to be the worst teratogenic drug amongst other agents of epileptic treatment), progesterone (a hormone that reduces the risk of miscarriage) and a number of antibiotics. The findings and opinions of a number of scientists were listed in Day's review [182].

1. Professor Michael Bracken (Professor of epidemiology, obstetrics and gynaecology at Yale Medical School who headed the survey of 82,000 pregnant British women between 1991-1999) commented that many of the drugs were prescribed unnecessarily. "Some of these women were being given hormones like progesterone to reduce their risk of miscarriage, although there is little evidence that this works, and they were being given the hormones at just the time — during the first trimester — when the fears of birth defects are the greatest". His results were presented at a meeting of the International Society of Pharmacovigilance at Bourdeaux.

2. Dr. Mayur Lakhani (spokesman on professional standards at the Royal College of General Practitioners) was quoted as saying, "I'm concerned to find that these drugs were prescribed at the level they were" and that doctors "hadn't considered the possibility" that the female patient may be pregnant. 
3. Professor John Duncan (Professor of Neurology at the National Hospital for Neurology in London and Medical Director of the National Society for Epilepsy) was quoted saying that, " $7 \%$ of children born to mothers taking this drug (sodium vaproate) would have severe birth defects, such as malformed kidneys and heart problems. Many more were at risk of other defects such as facial abnormalities and cleft palates".

Day's (2004) article ended by noting that "the National Institute for Clinical Excellence, which assesses treatment effectiveness, is expected to recommend shortly that prescriptions for epilepsy are reviewed every year [182]".

\subsubsection{Parasites on Domestic Pets}

Another causative factor for birth defects is parasites from domestic felines. In their tome entitled Toxoplasma: Molecular and Cellular Biology, Ajioka and Soldati (2007) described how some congenital birth defects in humans may be caused by a parasite of the domestic cat, the toxoplasma gondii (a relative of the malaria bug Plasmodium), which they believed has infected more than a quarter of the world's population. They believe that toxoplasma is a pathogen in its own right [183].

\section{Addressing Risks in a Structured Way}

Rodricks (2007) developed a rigorous approach towards analysing large bodies of epidemiological data and subjecting results to an unbiased, systematic and multi-perspectival scrutiny. Using a linear, no-threshold model (i.e., any dose of chloroform received poses a cancerous risk, no matter how minute the dose), the U.S. EPA calculated that 8 out of a million people with an intake of $0.0014 \mathrm{mg} \mathrm{CHCl}_{3}$ per $\mathrm{kg}$ body weight, each day for a full lifetime of 70 years, will develop cancer. Rodricks (2007) argued that this risk (extra lifetime probability of cancer) is accurate if and only if the following are correct [208]:

(1) Chloroform is a human carcinogen.

Comments: The World Health Organization (WHO) in collaboration with many research institutions spent the last quarter of the $20^{\text {th }}$ century to elucidate the carcinogenicity of chloroform at the levels in drinking water and concluded that direct evidence is, at best, "sparse". Many medical practitioners and biochemists cannot commit themselves to listing chloroform as a carcinogen, although its narcotic properties are well known.

(2) The animal carcinogenicity data provide an accurate picture of human response, both in the nature of the response (cancer) and its quantitative aspects (potency).

Comments: A series of studies from 1985 to 2001 show that dosing drinking water with chloroform did not induce cancer in rodents [77, 78, 210 to 213]. This has already been discussed earlier this work. If one insists on using data obtained from animals, then one must also accept that drinking tap water will not cause cancer in humans. The difference in the family members of cytochrome P450 between humans and rodents has also been discussed [77].

(3) The linear, no-threshold, dose-response model is accurate for very low exposures.

Comments: The World Health Organization has rejected this approach followed by the U.S. EPA and Health Canada as a result of a tremendous amount of research [e.g., 77, 78, 
210 to 213$]$.

(4) The quantitative relation between administered dose and target site dose is the same at all doses.

Comments: The physiological status of a living organism changes with time (e.g., metabolic rates do vary in the same organ, depending on many factors) and so will the quantitative relationship between administered doses and effective doses received.

(5) People actually achieve the estimated level of ingestion every day for a lifetime.

Comments: Epidemiologists agree that this is most difficult to establish. The daily habit of individuals does change during a lifetime at different stages of their lives.

The estimated risk will be greater than the actual human risk if and only if one or more of the following is correct:

(1) Chloroform does not increase cancer risk in humans under any conditions (in which case actual risk will be zero).

(2) The experimental animal model is more sensitive to chloroform-induced carcinogenicity than are human beings.

(3) There is a threshold in the dose-response curve, or the curve drops towards risk more quickly than is suggested by the linear model.

(4) The human body is able to rid itself of carcinogenic chloroform metabolites more efficiently at very low doses than it can at high doses.

(5) Exposure does not persist for a full lifetime or is otherwise less than that indicated.

The estimated risk will be less than the actual human risk if:

(1) Human beings are more sensitive to the carcinogenic effects of chloroform than are experimental animals used for hazard and dose-response modelling.

(2) The actual dose-response curve falls toward zero risk more slowly than is indicated by the linear model (it is a so-called super-linear model).

(3) The body cannot rid itself of carcinogenic metabolites of chloroform as efficiently at low doses as it can in high doses.

(4) Exposures are actually higher for some people because they are consistently exposed to water concentrations that exceed the average level.

Rodricks (2007) commented on his own set of criteria for discernment, "Most scientists would hold that these unknowns and uncertainties in the regulatory risk assessment model would tend to favour risk overestimation rather than underestimation or accurate prediction. While this view seems correct, it must be admitted that there is no epidemiological method available to test hypothesis of an extra lifetime cancer risk of about 8 per million from chloroform in drinking water. The same conclusion holds for most environmental carcinogens [208].”

Well into the $21^{\text {st }}$ century, Hrudey \& Charrois (2011) lamented the lack of progress in professional education: "The fact that chloroform is not considered a carcinogen at drinking 
water concentrations has been known for over a quarter of a century now, yet the current literature (Chowdhury \& Hall, 2010 [220]; Chowdhury et al., 2011 [221]) and conference presentations are still all too often showing examples of water professionals not knowing or understanding the evidence about chloroform [222]." The paper written by Chowdhury \& Hall in 2010 has since been retracted [220].

\section{Inorganic Compounds in Drinking Water}

Both organic and inorganic compounds exist in natural bodies of water. Although very few of these have actually shown to cause adverse health effects in humans, Fawell (1993) pointed out that the following are known to have caused real harm [184]:

\subsection{Compounds of Arsenic}

Arsenic may be contained in water that flowed through rocks rich in the element. More than 20 inorganic and organic compounds of arsenic have been identified in the As(III) and As(V) state, in water and food of all sorts and the inorganic ones are very toxic. Although the body readily eliminates organic arsenic, without doubt drinking water poses the greatest threat to public health from arsenic. "Immediate symptoms on an acute poisoning typically include vomiting, oesophageal and abdominal pain, and bloody 'rice water' diarrhea. Long-term exposure to arsenic via drinking-water causes cancer of the skin, lungs, urinary bladder, and kidney, as well as other skin changes such as pigmentation changes and thickening (hyperkeratosis), [however] the symptoms and signs that arsenic causes, appear to differ between individuals, population groups and geographic areas [185]." Fawell (1993), "The most commonly manifested disease so far is skin lesions. In the first decade of the $21^{\text {st }}$ century, skin and internal cancers are likely to become the principal human health concern arising from arsenic [184]." The top priority for any water management programme is to remove arsenic from drinking water. The current recommended limit of arsenic in drinking-water is $10 \mu \mathrm{g} /$ litre (0.13 $\mu \mathrm{M}$ with respect to arsenic atoms), (WHO, 2016, [186]).

\subsection{Compounds of Selenium (a micronutrient, but harmful in excess).}

Selenium is an essential micro-nutrient in the human body but people consuming food containing excessive selenium suffered from brittle hair and nails, skin lesions, mottled teeth and changes in peripheral nerves. China has experienced both selenium deficiency and toxicity problems [219]. Treated drinking water usually contains less than $10 \mu \mathrm{g} /$ litre $(0.12$ $\mu \mathrm{M}$ with respect to Se atoms), but in areas where there are rocks containing selenium, the concentrations may be as high as several hundred micrograms per litre. Health Canada (2015, [187]) limits the concentration in drinking water to $0.05 \mathrm{mg} / \mathrm{litre}(0.67 \mu \mathrm{M}$ with respect to selenium atoms).

\subsection{Compounds of Lead}

Of all the so-called "heavy" metals of concern to public health practitioners, lead seems to have received the most attention. Lead levels in drinking water are likely to be highest if houses and buildings are fitted with (1) faucets and fittings of brass which contains some lead; (2) lead pipe water systems; (3) copper pipes with solder. Water with low (acidic) pH helps to 
dissolve away the pipes and contaminate drinking water with $\mathrm{Pb}^{2+}$ ions. While young children and pregnant women are at the greatest risk of lead poisoning, adults of all ages are not exempted. The U.S.A. banned all use of lead materials in drinking water systems, although this did not totally eliminate lead contamination within existing plumbing. A public health scare hit Hong Kong in 2015, when it was found that lead was present in drinking water at a level above that recommended by WHO. The contamination originated from lead solder for water pipes. Hong Kong sets its standard for lead identical to that of WHO, EU, New Zealand and Canada (2014, [187]) at $10 \mu \mathrm{g} / \mathrm{litre}$, which is the same as $0.01 \mathrm{mg} / \mathrm{litre}$, or $0.01 \mathrm{ppm}$, (i.e., $0.048 \mu \mathrm{M}$ with respect to $\mathrm{Pb}$ atoms).

\subsection{Fluorides}

Fluorine occurs naturally in the minerals fluospar, cryolite and fluorapatite. Artificial fluoridation of drinking water is done by adding sodium fluoride, sodium silicofluoride or hydrofluosilic acid. Low concentrations (not higher than $1 \mathrm{ppm}$ ) of fluoride ions in drinking water are known to provide excellent protection against dental caries, but long-term exposures to higher concentrations are known to have caused crippling skeletal fluorosis and deformation of the skeleton in some people. At $50 \mathrm{ppm}$, toxic effects become evident. Canada sets the maximum acceptable concentration (MAC) for fluoride in drinking water to be $1.5 \mathrm{mg} / \mathrm{litre}$, or $79 \mu \mathrm{M}$ with respect to $\mathrm{F}$ atoms (2011, [188]).

\subsection{Nitrates}

The main source of nitrate $\left(\mathrm{NO}_{3}{ }^{-}\right)$in drinking water is agricultural activity. Much has been written on the effects of nitrate on human health. The most famous effect is Methaemoglobinaemia, better known as the Blue Baby Syndrome, caused by the decreased ability of blood to carry oxygen around the body. One of the most common causes is nitrate in drinking water. In Canada, the maximum acceptable concentration (MAC) for nitrate in drinking water is set at $45 \mathrm{mg} /$ litre, equivalent to $10 \mathrm{mg} /$ litre measured as nitrate-nitrogen. The MAC for nitrite is $3 \mathrm{mg} /$ litre, equivalent to $1 \mathrm{mg} /$ litre measured as nitrite-nitrogen [189]. See also Dabrowski \& Sikorski (2005), [190].

\section{Conclusions}

- Potable water and effective sanitation is essential to the continuation of life but the lack of these provisions is still a reality for millions around the world, and many perish as a result. Homo sapiens have struggled against waterborne diseases for as long as they existed, but nowadays some may have disregarded that disinfection of water by chlorination at the beginning of the 20th century greatly reduces these sufferings and changed the course of human history forever.

- Chlorination of natural waters produces disinfection by-products (DBPs), which are organic compounds with chlorine atoms as constituents, but many of these compounds also have natural origins.

- Intense research carried out by the World Health Organization in the last quarter of the 20th century concluded that a definitive cause-and-effect relationship cannot be 
established between chloroform found in drinking water for humans and hypothetical risks of gastrointestinal cancers and birth defects.

- The failure to chlorinate water intended for human activities had resulted in pandemics of cholera and many waterborne diseases across the continents. Failure to provide clean water for cooking also means malnutrition for millions around the world, with devastating consequences. The World Health Organization asserts that the first priority must be that of providing clean, inexpensive drinking water, recognising that the benefits of chlorination far outweigh any hypothetical risks of carcinogenecity. The World Health Organization recommends and fully supports chlorination as the means of disinfecting water.

- The profile and specificity of cytochrome P450 enzymes in humans and smaller mammals such as rodents are dissimilar, and therefore the metabolic pathways for the metabolism of xenobiotics will be different. Consequently, it is difficult to extrapolate toxicological data obtained from rodents to humans, and to infer that they will exhibit the same dose-response relationship towards the same xenobiotic.

- Known causes of liver cancer are chronic hepatitis and chemical agents such as aflatoxin B1 and nitrosamines. Azo dyes are currently believed to contribute to bladder cancer as an occupational hazard, and that the hereditary causes of colorectal cancer are well known. Congenital birth defects are complicated clinical cases. Some of the latest research indicates strongly that some pharmaceutical drugs for the prevention of epileptic seizures, progesterone (to prevent miscarriage), and some antibiotics prescribed to pregnant women may cause birth defects. It is recommended that epidemiologists attempting to link cancers and birth defects to disinfection by-products in drinking water take all these other causative factors into account and investigate the possibility of synergy between them.

- The paucity of cogent evidence connecting miniscule amounts of chloroform in drinking water to gastrointestinal cancers and birth defects is apparent. Until in vivo molecular mechanisms of pathogenesis are demonstrated convincingly, public health officials must remain sceptical of claims of the hypothetical risks of chlorination. This review concludes by asserting that this is the only sensible position to take.

\section{References}

Ajioka J. A., \& Soldati, D. (Eds.) (2007). Toxoplasma: Molecular and Cellular Biology; Horizon Bioscience: Wymondham, UK, 2007.

Anderson C. (1991). Cholera Epidemic Traced to Risk Miscalculation. Nature, 1991, 354(29), pp. 255.

Ausubel J. H., Meyer, P.S., \& Wernick, I. K. (2001). Death and the Human Environment: the United States in the $20^{\text {th }}$ Century. Technology in Society, 2001, 23(2), pp. 131-146.

Baker M. N. (1949). The Quest for Pure Water: the History of Water Purification from the Earliest Records to the Twentieth Century, American Water Works Association Inc.: New 
York, 1949.

Barnes, J. M., \& Magee, P. N. (1954). Some Toxic Properties of Dimethylnitrosamine. British Journal of Industrial Medicine, 11, 167-174.

Barnes, J. M., \& Magee, P. N. (1956). Some Toxic Properties of Dimethylnitrosamine. British Journal of Cancer, 10, 114-122.

Basu, A. (2000). Vibrio cholerae O139 in Calcutta, 1992-1998 : Incidence, Antibiograms, and Genotypes. Emerging Infectious Diseases, 6 (2, Mar-Apr.), 139 - 147.

Batram, J. (2001). WHO Guidelines for Drinking Water Quality Training Pack. World Health Organization, Water and Sanitation for Health Unit: Geneva, Switzerland, 2001.

Bauld, N. L. (2001). Alkyl Halides. Teaching material produced by Professor N.L. Bauld at University of Texas at Austin. Available at: http://research.cm.utexas.edu/nbauld/teach/halides.html. Accessed on 1st Dec., 2016.

Beasley R. P., Hwang L.Y., Lin C. C., \& Chien C. S. (1981). Hepatocellular Carcinoma and Hepatitis B Virus: A Prospective Study of 22,707 Men in Taiwan. Lancet, 318(2), 1129 1133.

Bentivoglio M., \& Pacini P. (1995). Filippo Pacini: A Determined Observer. Brain Research Bulletin, 38(2), 161-165.

Bernard B. (2016). Chloroform: A profile in Risk Management. Water Quality \& Health, 2016. Available at: http://www.waterandhealth.org/chloroform-profile-risk-management/. Accessed: March 31, 2017.

Best M., \& Neuhauser, D. (2004). Ignaz Semmelweis and the Birth of Infection Control. Quality and Safety in Health Care, 13(3), 233 - 234.

Black R. E. (1998). Diseases Spread by Food and Water. Chap. 10, section on Cholera, in Maxcy-Rosenau-Last Public Health and Preventive Medicine; Wallace, R.B., Ed.; $14^{\text {th }}$ ed.; Appleton and Lange, 240.

Black R. E. (1998). Diseases Spread by Food And Water. Chap. 10, section on Cholera, in Maxcy-Rosenau-Last Public Health and Preventive Medicine; Wallace, R.B., Ed.; $14^{\text {th }}$ ed.; Appleton and Lange, 240.

Böhler N. (1960). En Ondartet Leversykdom hos Mink. (Translation: A Malignant Liver Disease in Mink). Norsk Pelsdyrblad, 34, 104 - 106.

Böhler, N. (1962). Ondartet Leversykdom hos Pelsdyr i Norge (Translation: Malignant Liver Disease in Fur Animals in Norway). Proceedings, IX Nordic Veterinary Congress, Copenhagen, II, $774-776$.

Brent, J. A., \& Rumack, B. H. (1993). Mechanisms: Role of Free Radicals in Toxic Hepatic Injury. I. Free Radical Biochemistry. Journal of Toxicology: Clinical Toxicology, 31(1), 139 171. 
Brent, J. A., \& Rumack, B. H. (1993). Role of Free Radicals in Toxic Hepatic Injury. II: Are Free Radicals The Cause Of Toxin-Induced Liver Injury? Journal of Toxicology: Clinical Toxicology, 31(1), $173-196$.

Bressac, B. et al. (28 authors), 1991. p53 Mutation in Hepatocellular Carcinoma after Aflatoxin Exposure. Lancet, 338(8779, Nov. 30), 1356 - 1359.

Bressec, B., Kew, M., Wands, J., \& Ozturk, M. (1991). Selective G to T mutations of p53 Gene in Hepatocellular Carcinoma from Southern Africa. Letters to Nature. Nature, 350 (April 4), $429-431$.

Brock, T. D. (1999). Consolidation and Transition. Chap. 19 in Robert Koch: a Life in Medicine and Bacteriology, ASM Press: Washington DC, 230 - 231.

Brown, W. H., \& Foote, C. S. (1989). Amines. Chap. 21 in Organic Chemistry, $2^{\text {nd }}$ ed., Saunders College Publishing, 859.

Brown, W. H., \& Foote, C. S. (1989). Amines. Chap. 21 in Organic Chemistry, $2^{\text {nd }}$ ed., Saunders College Publishing, 1989, 859.

Brukner, J. V., \& Warren, D. A. (2001). Toxic Effects of Solvents and Vapours. Chap. 24 in Casarett \& Doull's Toxicology: the basic science of poisons; Klaassen, C.D., Ed.; McGraw Hill, 887 - 889 .

Brukner, J. V., \& Warren, D. A. (2001). Toxic Effects of Solvents and Vapours. Chap. 24 in Casarett \& Doull's Toxicology: the basic science of poisons; Klaassen, C.D., Ed.; McGraw Hill 2001, pp. $887-889$.

Bull, R. J., Brown, J. M., Meierhenry, E. A., Jorgensen, T. A., Robinson, M., \& Stober, J. A. (1986). Enhancement of the hepatotoxicity of chloroform B6C3F1 mice by corn oil: implications for chloroform carcinogenesis. Environmental Health Perspectives, 69, 49 - 58.

Carter, R. L., \& Neville, A. M. (1978). The Aetiology of Human Cancers. Chap. 3 in Oncology for Nurses and Health Care Professionals: Pathology, Diagnosis and Treatment; Tiffany, Robert, Ed.; Harper and Row Beaconsfield, 1, 38.

Chamulitrat, W., Jordan, S. J., \& Mason, R. P. (1994). Nitric oxide production during endotoxic shock in carbon tetrachloride-treated rats. Journal of Molecular Pharmacology, 46(2), 391-397.

Chlorine Chemistry Council vs. E.P.A., 206 F.3d 1286 (2000). Available at:https://www.ravellaw.com/opinions/d4d08c4125e4cdffa4d0405982c37c28. Accessed: Dec. 9, 2016.

Chowdhury, S. et al. (2011). Disinfection by-products in Canadian provinces. Journal of Hazardous Materials, 187(1-3), 574 - 584.

Chowdhury, S., \& Hall, K. (2010). Human health risk assessment from trihalomethanes in Canadian cities. Environmental International, 36(5), 453 - 460. (RETRACTED).

Cohn, D. V. (1996). Professor of Biochemistry, University of Louisville Schools of Medicine 
and Dentistry delivers the lecture: The Life and Times of Louis Pasteur. Keynote address, Centennial Celebration of the death of Pasteur sponsored jointly by the University of Louisville, the Pasteur Institute of Paris, and the Alliance Française de Louisville. School of Dentistry, University of Louisville, Feb. 11, 1996. Available at: http://pyramid.spd.louisville.edu/ eri/fos/interest1.html. Accessed: March 31, 2017.

Coman, J. (2004). Derrida, philosophy's father of 'deconstruction', dies at 74. Daily Telegraph, October $2004 . \quad$ Available at: http://www.telegraph.co.uk/news/worldnews/europe/france/1473821/Derrida-philosophys-fat her-of-deconstruction-dies-at-74.html. Accessed: March 31, 2017.

Cotran, R. S., Kumar, V., \& Collins T. (1999). Primary Carcinoma of the Liver, in Chap. 19: The liver and the biliary tract, Robbins' Pathologic Basis of Disease, $6^{\text {th }}$ ed.; WB Saunders: Philadelphia, PA, USA, 1999, p. 888.

Cotran, R.S., Kumar, V., \& Collins, T. (1999). Hepatitis B Virus. In Chap. 8: Neoplasia, Robbins' Pathologic Basis of Disease, $6^{\text {th }}$ ed.; WB Saunders: Philadelphia, PA, USA, 1999, pp. 314.

Critchley, D. R., Streuli, C. H., Kellie, S., Ansell, S., \& Patel, B. (1982). Characterization of the Cholera Toxin Receptor on Balb/c 3T3 Cells as a Ganglioside Similar to, or Identical With, Ganglioside GM1. No Evidence for Galactoprotein with Receptor Activity. Biochemical Journal, 204(1), 209 - 219.

Dabrowski, W. M., Sikorski, Z. E., Eds. Heavy Metals. Chap. 10 in Toxins in Food, CRC Press, Inc., 2005.

Daniel, F. B., Meier, J. R., \& Deangelo, A. B. (1993). Advances in Research on Carcinogenic and Genotoxic By-Products of Chlorine Disinfection: Chlorinated Hydroxyfuranones and Chlorinated Acetic Acids. Annali dell'Istituto Superiore di Sanità, 29(2), 279 - 291.

Davies, K. J. A. (2000). Oxidative Stress, Antioxidant Defenses, and Damage Removal, Repair and Replacement Systems. International Union of Biochemistry and Molecular Biology (IUBMB) Life, 50, 279 - 289.

Davy, J. S. (1898). The Local Government Board, Borough of Maidstone. Epidemic of Typhoid Fever, 1897. Report of Inquiry and Appendices. HMSO: London, 1898.

Day, M. Prescribed Drugs Pose Birth Defect Risk to Thousands (news report). Daily Telegraph, September 12, 2004, p. 6. Available at: http://www.telegraph.co.uk/news/uknews/1471543/Prescribed-drugs-pose-birth-defect-risk-to -thousands.html. Accessed: March 31, 2017.

Devitt, T. (2010). Broad Street pump, cholera and Dr. John Snow. Soho Memories, March 25, 2010. Available at: http://www.sohomemories.org.uk/page_id_6_path_0p3p.aspx. Accessed: March 31, 2017.

Ellis, R. H. (1994). The Case Books of Dr. John Snow. Medical History Supplement, No. 14, The Welcome Trust Centre for the History of Medicine, UCL: London, 1994, p. 271. 
Emsley, J. (2004). Germ Warfare. Chap. 4 in Vanity, Vitality and Virility: The Science Behind the Products You Love to Buy (bk), Oxford University Press: Oxford, 2004, p. 123.

Ender, F., Havre, G., Helgebostad, A., Koppang N., Madsen R., \& Ceh L. (1964). Isolation and Identification of a Hepatotoxic Factor in Herring Meal Produced from Sodium Nitrite Preserved Herring. Die Naturwissenschaften, 51(24), 637-8.

Environment and Climate Change Canada (2008). Threats to Sources of Drinking Water and Aquatic Ecosystem Health in Canada. Part 1: Waterborne pathogens.Available at: https://www.ec.gc.ca/inre-nwri/default.asp?lang=En\&n=235D11EB-1\&offset=2\&toc=hide.

Accessed: March 31, 2017.

Environment Canada \& Health Canada (1999). Environmental Protection Act, 1999. Priority Substances List Assessment Report for Chloroform. Minister of Public Works and Government Services Canada, February 2001.

Environment Canada \& Health Canada (2001). Environmental Protection Act, 1999. Priority Substances List Assessment Report for Chloroform. Minister of Public Works and Government Services Canada, February 2001.

FAO/WHO (Food and Agriculture Organisation of the United Nations/World Health Organization). Evaluation of the Toxicity of a Number of Antimicrobials and Antioxidants (Sixth report of the Joint FAO/WHO Expert Committee on Food Additives). Food and Agriculture Organisation of the United Nations (FAO) Nutrition Meetings Report Series, No. 31, 1962; World Health Organization (WHO) Technical Report Series No. 228, 1962, pp. $69-75$.

Fawell, J. K. (OBE). Water pollution and Epidemiology. Lecture delivered at the Huxley School of Environmental and Earth Sciences, Imperial College, London, Spring 2002.

Fawell, J. K. (OBE). (1993).The Impact of Inorganic Chemicals on Water Quality and Health. Annali dell'Istituto Superiore di Sanità, 2, 293 - 303.

Fenwick, A. (2010). Neglected Tropical Diseases: Can We Take the 'Neglected' Out of the Name? A Global Village: International Affairs Journal, Imperial College: Model United

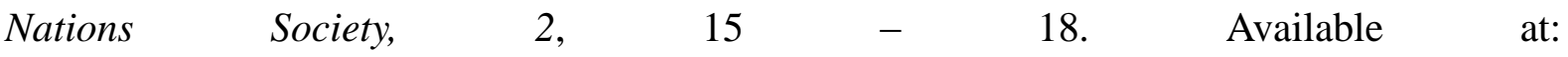
http://www.aglobalvillage.org/journal/issue2/fenwick/. Accessed: March 31, 2017.

Fintel, B., Samaras, A. T., \& Carias E. (2009). The Thalidomide Tragedy: Lessons for Drug Safety and Regulation. The Helix, North Western University, July 28, 2009. Available at: https://helix.northwestern.edu/article/thalidomide-tragedy-lessons-drug-safety-and-regulation. Accessed: March 31, 2017.

Food and Drug Administration. (1975). "Certain estrogens for oral use. Notice of withdrawal of approval of new drug applications", Federal Register, 40(25), 5384, FDA, 1975.

Fox, M. A., \& Whitesell, J. K. (2004). Chap. 18. Organic Chemistry, $3^{\text {rd }}$ ed. Jones and Bartlett Publishers, 2004, 18 - 25. 
Franklin, J. (2010). What Science Knows and How it Knows it, Encounter Books, 2010.

Garner A. Dr. Anthony Garner, Lecturer in Biochemistry, Brunel University, UK. Personal Communications, 2004 to 2007.

Gavin, H. (1848). Sanitary Ramblings: Being Sketches And Illustrations Of Bethnal Green, A Type Of The Condition Of The Metropolis And Other Large Towns. John Churchill: London, $1848,42-55$.

Geske, F. J., Nelson, A. C., Lieberman, R., Strange, R., Sun, T., \& Gerschenson, L. E. (2000). DNA Repair is Activated in Early Stages of p53-Induced Apoptosis. Cell Death and Differentiation, 7(4, Apr.), 393 - 401.

Gibbons, J., \& Laha, S. (1999). Water Purification Systems: A Comparative Analysis Based on the Occurrence of Disinfection By-products. Environmental Pollution, 106(3), 425 - 428.

Golden, R. J., Holm, S. E., Robinson, D., Julkunun, P. H., \& Reese, E. A. (1997). Chloroform mode of action: implications for cancer risk assessment. Regulatory Toxicology and Pharmacology, 26, $142-155$.

Goodman, C. C., Fuller, K. S., \& Boissonnault, W. G. (2003). Adenocarcinoma (etiologic and risk factors) in The Gastrointestinal System. Chap. 15 in Pathology: implications for the physical therapist, $2^{\text {nd }}$ ed. Saunders, 2003, p. 654.

Government of Canada (2011). Guidelines for Canadian Drinking Water Quality: Guideline Technical Document - Fluoride. Available at: http://healthycanadians.gc.ca/publications/healthy-living-vie-saine/water-fluoride-fluorure-ea u/index-eng.php?page=2\#part1. Accessed: March 31, 2017.

Government of Canada (2014). Guidelines for Canadian Drinking Water Quality: Guideline Technical Document - Nitrate and Nitrite. Available at: http://healthycanadians.gc.ca/publications/healthy-living-vie-saine/water-nitrate-nitrite-eau/in dex-eng.php?page=2\#part1. Accessed: March 31, 2017.

Greenwood, D., Slack, R. C. B., Peutherer, J. F., \& Barer, M. R. (2007). Medical Microbiology: A Guide to Microbial Infections: Pathogenesis, Immunity, Laboratory Diagnosis and Control. $17^{\text {th }}$ ed., Churchill Livingston (Elsevier), 2007, p. 30.

Gribble, G. W. (1994). Natural Organohalogens: More Than You Think! Journal of Chemical Education, 71(11), 907 - 911.

Griesenbeck, J. S. et al. (10 authors), 2010. Maternal Characteristics associated with the Dietary Intake of Nitrates, Nitrites, and Nitrosamines in Women of Child-Bearing Age: A Cross-Sectional Study (National Birth Defects Prevention Study), Environmental Health, 9(19), 10.

Guengerich, F. P. (1995). Human Cytochrome P450 Enzymes (a review paper with 472 references). Chap. 14 in Cytochrome P450: Structure, Mechanism and Biochemistry, $2^{\text {nd }}$ ed., Ortiz de Montellano, P.R., Ed., Plenum Press: New York, 1995, 473 - 535. 
Hall, C., \& Phipps, B. (2002). Chemicals in pools linked to miscarriages, The Daily Telegraph (United Kingdom newspaper), $4^{\text {th }}$ April 4, 2002. Available at: http://www.telegraph.co.uk/news/science/science-news/3293191/Chemicals-in-pools-linked-t o-miscarriages.html. Accessed: March 31, 2017.

Hall J. et al. (10 authors). (1993). Alkylation and oxidative-DNA damage repair activity in blood leukocytes of smokers and non-smokers. International Journal of Cancer, 1993, 54 (5), pp. $728-733$.

Halliwell, B., \& Gutteridge, J. (1998). Chloroform and bromotrichloromethane. Section 8.3.1 of Free Radicals in Biology and Medicine, $3^{\text {rd }}$ ed., Oxford University Press, 1998, pp. 144.

Halliwell, B., \& Gutteridge, J. (2015). Chapter 9.3, Section 9.3.1: Chloroform and bromotrichloromethane. In: Free Radicals in Biology and Medicine (bk), $5^{\text {th }}$ ed., Oxford University Press, 2015, pp. 469.

Hanrahan, M. (2010). Deconstruction Today. UCL videotaped lecture, January 26, 2010. Available at: https://www.youtube.com/watch?v=R8WMLHZVUZQ. Accessed: March 31, 2017.

Hansen, M. A. (1964). An Outbreak of Toxic Liver Injury in Ruminants. Nordisk Veterinaer Medicine, 16, 323 - 342 .

Harris, C. C. (1996). The 1995 Walter Hubert Lecture - molecular epidemiology of human cancer: insights from the mutational analysis of the p53 tumour-suppressor gene (Review). British Journal of Cancer, 73(3), 261 - 269.

Havezov, I., \& Tsekulov, E. (2010). Arsenic Species Isoformation --- a key problem for water purification. In: Water Treatment Technologies for the Removal of High-Toxicity Pollutants (bk), Ed. Miroslava Václavíková, Ksenija Vitale, G.P. Gallios, Lucia Ivanicová, Springer, 2010, pp. 119.

Hazell, L. J., Arnold, L., Flowers, D., Waeg, G., Malle, E., \& Stocke, R. (1996). Presence of Hypochlorite-Modified Proteins in Human Atherosclerotic Lesions. Journal of Clinical Investigation, 97(6), 1535 - 1544.

Hazen, S. L., Hsu, F. F., Mueller, D. M., Crowley, J. R., \& Heinecke, J. W. (1996). Human Neutrophils Employ Chlorine Gas as an Oxidant during Phagocytosis. Journal of Clinical Investigation, 98(6), $1283-1289$.

Health Canada (2015). Guidelines for Canadian Drinking Water Quality. Available at: http://www.hc-sc.gc.ca/ewh-semt/pubs/water-eau/sum_guide-res_recom/index-eng.php.

Accessed: March 31, 2017.

Health Canada (2016). Guidelines for Canadian Drinking Water Quality. Ottawa, Canada, November 21, 2003. (Updated to 2016). Available at: http://www.hc-sc.gc.ca/ewh-semt/pubs/water-eau/index-eng.php. Accessed: March 31, 2017. 
Health Canada (2016). List of Permitted Preservatives. Available at: http://www.hc-sc.gc.ca/fn-an/securit/addit/list/11-preserv-conserv-eng.php. Accessed: March 31, 2017.

Herbst, A. L., \& Scully, R. E. (1970). Adenocarcinoma of the Vagina in Adolescence. A Report of 7 Cases including 6 Clear-Cell Carcinomas (so-called Mesonephromas). Cancer, 25(4), $745-757$.

Herbst, A. L., Ulfelder, H., \& Poskanzer, D. C. (1971) Adenocarcinoma of the Vagina. Association of Maternal Stilbestrol Therapy with Tumor Appearance In Young Women. New England Journal of Medicine, 284(15), 878 - 881.

Howard-Jones, N. (1984). Robert Koch and the cholera vibrio: a centenary. British Medical Journal (Clinical Research Edition), 288(4), 379 - 381.

Hrudey, S. E., \& Charrois, J. W. A. (2011). Chapter 1, Disinfection by-products (DBPs) as a public health issues. In: Disinfection by-products and human health (bk.), Australian Water Association, IWA Publishing (London, U.K.), pp. 8.

Hsu, I. C., Metcalf, R. A., Sun, T., Welsh, J. A., Wang, N. J., \& Harris, C. C. (1991). Mutational Hotspot in the p53 Gene in Human Hepatocellular Carcinomas. Nature, 350, 427 $-428$.

Hudgens, J. W., Johnson, R. D., Timonen, R. S., Seetula, J. A., \& Gutman, D. (1991). Kinetics of the reaction $\mathrm{Br}_{2}+\mathrm{CCl}_{3}$, and the thermochemistry of the $\mathrm{CCl}_{3}$ radical and cation. $J$. Phys. Chem., 95, 4400.

Hudson, R. P. (1983). Specific Prevention. Chap. 9 in Disease and its Control: the Shaping of Modern Thought; Contributions in Medical History, No. 12; Greenwood Press: Westport, CT, USA, 1983, p. 177.

Hunter, P. R., Colford, J. M., LeChevallier, M. W., Binder, S., \& Berger, P.S. (2001). Waterborne Diseases. Conference Panel Summaries, Emerging Confectious Diseases Conference in Atlanta, Georgia, USA, 2000, Emerging Infectious Diseases, 7(3, Supplement), $544-545$.

International Agency for Research on Cancer, IARC (1991). Chlorinated Drinking-Water, Chlorination By-Products, some other Halogenated Compounds; Cobalt and Cobalt Compounds. IARC Monographs on the Evaluation of Carcinogenic Risks to Humans, Vol. 52, World Health Organization, Lyon, France, 1991, pp. 128.

Jarvis, W.R . (1994). Handwashing — the Semmelweis Lesson Forgotten? Lancet, 344 (Nov. 12), $1311-1312$.

Jefford, C. E., \& Irminger-Finger, I. (2006). Mechanisms of Chromosome Instability in Cancers. Critical Reviews in Oncology/Hematology, 59(1), 1 - 14. (Note: review paper with 142 references).

Jena, S. (2007). Cholera Kills 80 in Indian State: Health officials in the eastern Indian state of 
Orissa say 80 people have died from an outbreak of cholera in three tribal districts in the past 15 days. BBC News, Aug. 27, 2007.

Jiang, R., Paik, D. C., Hankinson, J. L., \& Barr, R. G. (2007). Cured Meat Consumption, Lung Function and Chronic Obstructive Pulmonary Disease among United States Adults. American Journal of Respiratory and Critical Care Medicine, 175, 798 - 804.

Johansson, S. L., \& Cohen, S. M. (1997). Epidemiology and Etiology of Bladder Cancer. Seminars in Surgical Oncology, 13(5), 291 - 298.

Jones, M. (1997). Organic Chemistry, W.W. Norton \& Co., 1997, p. 1098.

Jones, S. (1997). Death or Resurrection. Chap. 6 in In the Blood: God, Genes and Destiny (bk), Flamingo, 1997, 252.

Jorgensen, T. A., Meierhenry, J. R., Rushbook, C. J., Bull, R. J., \& Robinson, M. (1985). Carcinogenecity in drinking water to male Osborne-Mendel rats and female B6C3F1 mice. Fundamental and Applied Toxicology, 22, 90 - 102.

Kew, M. C. (2003). Hepatitis B Virus in the Etiology of Hepatocellular Carcinoma. In Viruses and Liver Cancer, Tabor, E., Ed.; Perspectives in Medical Virology 6; Zuckerman, A.J., Mushahwar, I.K., Eds.; Elsevier Science B.V., 2003, pp. 17 -30.

Knudson, A. G. Hereditary Cancers Disclosed a Class of Cancer Genes. Cancer, 1989, 63, pp. $1888-1891$.

Kogevinas, M. et al. (13 authors). (2010). Genotoxic Effects in Swimmers Exposed to Disinfection By-products in Indoor Swimming Pools. Environmental Health Perspectives, $118(11$, Nov.), $1531-1537$.

Koike, K., \& Moriya, K. (2003). Role of Hepatitis C Virus in Hepatocarcinogenesis: Oxidative Stress in the Absence of Inflammation. In Frontiers in Hepatology 5: HCV/Oxidative Stress and Liver Disease; Yamaguchi Symposium on Liver Disease; Okita, K., Ed.; Springer-Verlag: Tokyo, 2003, pp. 48 - 57.

Koppang, N. (1964). An outbreak of toxic liver injury in ruminants: Case reports, pathological-anatomical investigations and feeding experiments. Nordisk Veterincer Medicine, $16,305-322$.

Kumar, P., \& Clark, M. (2005). Clinical Medicine. $6^{\text {th }}$ ed., Elsevier Saunders, 2005, p. 332.

Kumar, V. (2003). Primary Carcinoma of the Liver. Chap. 16: The Liver and the Biliary Tract, in Robbins' Basic Pathology, $7^{\text {th }}$ ed.; Robbins, S.L., Cotran, R.S., Eds.; W.B. Saunders Company, 2003, pp. 626.

Lahti, K., \& Hiisvirta, L. (1995). Causes of Waterborne Outbreaks in Community Water Systems in Finland: 1980-1992. Water Science and Technology, 31(5-6), 33-36.

Larson, J. L., Wolf, D. C., \& Butterworth, B. E. (1994). Induced Cytotoxicity and Cell Proliferation in the Hepatocarcinogenicity of Chloroform in Female B6C $3 F_{1}$ Mice: 
Comparison of Administration by Gavage in Corn Oil vs ad Libitum in Drinking Water. Fundamental and Applied Toxicology, 1994, 22 (1), pp. 90 - 102.

Larson, J. L., Wolf, D. C., Morgan, M. K., \& Butterworth, B. E. (1995). Toxicity and cell proliferation in the liver, kidneys and nasal passages of female F-344 rats induced by chloroform administered by gavage. Food and Chemical Toxicology, 33(6), 443 - 456.

Larsson, S. C., Bergkvist, L., \& Wolk, A. (2006) Processed meat consumption, dietary nitrosamines and stomach cancer risk in a cohort of Swedish women. International Journal of Cancer, 119 (4), 915 - 919.

Laval, F., \& Laval, J. (1984). Adaptive Response in Mammalian Cells: Crossreactivity of Different Pre-treatments on Cytotoxicity as contrasted to Mutagenicity. Proceedings of the National Academy of Sciences of the U.S.A., 81(4), 1062 - 1066.

Lewis, D. F. V. (2001). Guide to Cytochrome P450 Structure and Function, Oxford University Press, 2001.

Lewis, D. F. V., Ioannides, C., \& Parke, D. V. (1998). Cytochromes P450 and Species Differences in Xenobiotic Metabolism and Activation of Carcinogen. Environmental Health Perspectives, 106(10), $633-641$.

Li, X. X., Zheng, Q. C., Wang, Y., \& Zhang, H. X. (2014). Theoretical insights into the reductive metabolism of $\mathrm{CCl}_{4}$ by cytochrome $\mathrm{P} 450$ enzymes and the $\mathrm{CCl}_{4}$-dependent suicidal inactivation of P450. Dalton Transactions, 43(39), 14833-40.

Lilienfeld, D. E., \& Engin, M. S. (1991). The Silence: the Asbestos Industry and Early Occupational Cancer Research --- a case study. American Journal of Public Health, 81(6), 791-800. Available at: https://www.ncbi.nlm.nih.gov/pmc/articles/PMC1405162/pdf/amjph00206-0121.pdf. Accessed: March 31, 2017.

Lipinski, B. (2011). Hydroxyl Radical and Its Scavengers in Health and Disease. Oxidative Medicine and Cellular Longevity, Volume 2011 (2011), Article ID 809696, 9 pages.

Longmate, N. (1966). News of Cholera. Chap. 1 in King Cholera: the Biography of a Disease, Hamish Hamilton: London UK, June 1966, p. 2.

Lynge, E. et al. (13 authors) European Multi-Centre Case-Control Study on Risk Factors for Rare Cancers of Unknown Aetiology. European Journal of Cancer, 41(4), 601 - 612.

Macdonald, F., \& Ford, C. H. J. (1997). Hepatocellular Carcinoma. Section 7.4.1 of Chap. 7: Gastrointestinal Cancers in Molecular Biology of Cancer, Bios Scientific Publishers, 1997, pp. 112.

Mádai, L. (1970). Semmelweis and Statistical Science. Orvostörteneti Közlemények, Communicationes de historia artis medicinae. Budapest, Hungary, 55-56, 157 - 174 (in English).

Manno, M., King, L. J., \& De Matteis, F. (1989). The degradation of haem by carbon 
tetrachloride: Metabolic activation requires a free axial coordination site on the haem iron and electron donation. Xenobiotica, 19(9), 1023-35.

McArdle, C. S., Kerr, D. J., \& Boyle, P. (2000). Introduction. Chap. 1 in Colorectal Cancer, Isis Medical Media Ltd., Oxford, 2000, pp. $1-2$.

McCulloch, A. (2003). Chloroform in the Environment: Occurrence, Sources, Sinks and Effects. Chemosphere, 50(10), $1291-1308$.

Mendelsohn, J., Howley, P. M., Israel, M. A., Gray, J. W., \& Thompson C. B. (2001). Viruses and Liver Cancer. In The Molecular Basis of Cancer, $3^{\text {rd }}$ ed., Saunders Elsevier: Philadephia, $2001,78-81$.

Michaud, D. S., Holick, C. N., Batchelor, T. T., Giovannucci, E., \& Hunter, D. J. (2009). Prospective Study of Meat Intake and Dietary Nitrates, Nitrites, and Nitrosamines and Risk of Adult Glioma. American Journal of Clinical Nutrition, 90 (3, Sept.), 570-577.

Michaud, D. S., Holick, C. N., Giovannucci, E., \& Stampfer, M. J. (2006). Meat Intake and Bladder Cancer Risk in 2 Prospective Cohort Studies. American Journal of Clinical Nutrition, 84(5), $1177-1183$.

Miller, H., \& Conko, G. (2001). The Perils of Precaution: Why Regulators' 'Precautionary Principle' Is Doing More Harm Than Good. Policy Review (Hoover Institution, Stanford University), no. 107, June/July 2001.

Montesano, R. (1981). Alkylation of DNA and Tissue Specificity in Nitrosamine Carcinogenesis. Journal of Supramolecular Structure and Cellular Biochemistry, 17(3), 259 273.

Montesano, R. (1990). Alkylation Repair in Human Tissues. In: DNA damage and Repair in Human Tissues; Sutherland B.M., Woodhead A.D., Eds.; Plenum Press: New York, 1990, pp. 437.

Montesano, R., \& Kirby, G. M. (1994). Chemical Carcinogens in Human Liver Cancer. Chap. 6 in Primary Liver Cancer: Etiology and Progression Factors, Bréchot, C., Ed., CRC Press, 1994.

Montesano, R., \& Magee, P. N. (1970) Metabolism of Dimethylnitrosamine by Human Liver Slices in Vitro. Letters to Nature, Nature, 228 (Oct. 10), 173 - 174.

Mostafa, M. H., Sheweita, S. A., \& O’Connor, P. J. (1999). Relationship Between Schistosomiasis and Bladder Cancer. Clinical Microbiology Reviews, 12(1), 97 - 111.

Munoz, N., \& Linsell, A. (1982). Epidemiology of primary liver cancer. In Epidemiology of Cancer of the Digestive Tract; Correa, P., Haenszel H., Eds.; Martinus Nijhoff: The Hague, 1982, pp. $161-195$.

Nakajima, T., Elovaara, E., Okino, T., Gelboin, H. V., Klockars, M., Riihimaki, V., Aoyama, T., \& Vainio H. (1995). Different Contributions of Cytochrome p450 2E1 and p450 2B1/2 to Chloroform Hepatotoxicity in Rat. Toxicology and Applied Pharmacology, 133(2), 215 - 
222.

National Academy of Sciences. (1981). N-nitroso Compounds: Environmental Distribution and Exposure in Humans. The Health Effects of Nitrate, Nitrite, and N-nitroso Compounds. National Academies Press: Washington D.C., 1981, pp. 3 - 51.

National Cancer Institute (1976). Report on the Carcinogenesis Bioassay of Chloroform. CAS 67-66-3, March 1, 1976. Available at: http://ntp.niehs.nih.gov/ntp/htdocs/lt_rpts/trchloroform.pdf. Accessed: March 31, 2017.

Neidleman, S. L., \& Geigert, J. (1986). Introduction. Chap. 1 in Biohalogenation: Principles, Basic Roles and Applications; Ellis Horwood Series in Organic Chemistry; Ellis Horwood Ltd.: Chichester, 1986.

Nieuwenhuijsen, M. J., Toledano, M. B., Eaton, N. E., Fawell, J., \& Elliott, P. (2000). Chlorination Disinfection By-products in Water and their Association with Adverse Reproductive Outcomes: A Review. Occupational and Environmental Medicine, 57, 73 - 85.

Nieuwenhuijsen, M. J., Toledano, M. B., \& Elliott, P. (2000). Uptake of Chlorination Disinfection By-Products; A Review and a Discussion of its Implications for Exposure Assessment in Epidemiological Studies. Journal of Exposure Analysis and Environmental Epidemiology, 10 (6, Pt. 1, Nov.-Dec.), 586 - 599.

Nuland, S. B. (1979). The Enigma of Semmelweis - an Interpretation. Journal of the History of Medicine and Allied Sciences (a Quarterly), 34(3), 255 - 272.

O’Connor D. R. (Justice, the Honorary, 2000) Introduction, in Chap. 1 of "Part 1, Report of the Walkerton Inquiry: The Events of May 2000 and Related Issues". Report of the Walkerton Commission of Inquiry: The Events of May 2000 and Related Issues, Parts 1 and 2, Ministry of the Attorney General, Ottawa, Canada, January 8, 2002. Ministry of the Attorney General: Ontario, January 14, 2002, pp. 14.

Pan American Health Organization, PAHO (1995). Cholera in the Americas. Epidemiological Bulletin, 1995, 16(2), pp. $11-12$.

Parker, S. L., Tong, T., Bolden S., \& Wingo, P. A. (1996) Cancer Statistics, 1996. CA - a Cancer Journal for Clinicians (American Cancer Society), 46(1), 5 - 27.

Pearce, F. (2003). Arsenic's Fatal Legacy Grows. New Scientist, 2407 (Aug. 9), 4 - 5.

Pereira, M. A., \& Grothaus, M. (1997). Chloroform in Drinking Water Prevents Hepatic Cell Proliferation Induced by Chloroform Administered by Gavage in Corn Oil to Mice. Fundamental and Applied Toxicology, 37(1), 82 - 87.

Pitot, H. C., Dragen, Y. P. Mechanisms of Chemical Carcinogenesis. Chap. 8: Chemical Carcinogenesis in Casarett and Doull's Toxicology: The Basic Science Of Poisons, $6^{\text {th }}$ ed.; Klaassen, C.D., Ed.; McGraw Hill, 2001, pp. 252.

Race, J. (1918). Historical Aspects. Chap. 1 in Chlorination of Water, John Wiley \& Sons Inc., New York, 1918, p. 8. Note: Joseph Race F.I.C., a Canadian, accredited the 
chlorination process to Houston and McGowen after reviewing The Royal Commision $5^{\text {th }}$ Report on Sewage Disposal, HMSO, 1908.

Rapport, M. (2008). 1848: Year of Revolution (bk). Little \& Brown: London, 2008, p. 35.

Robbins, S. L., Cotran, R. S., Kumar, V., \& Collins, T. (1996). Pocket Companion to Robbins' Pathologic Basis of Disease, $6^{\text {th }}$ ed., WB Saunders Co.: Philadelphia, PA, 1999, p. 206.

Rodricks, J. V. (2007). Calculated Risks: The Toxicity and Human Health Risks of Chemicals in our Environment, $2^{\text {nd }}$ ed., Cambridge University Press, 2007, Chap. 8, Risk Assessment II: Applications, pp. $245-246$.

Rodricks, J. V. (2007). Calculated Risks: The Toxicity and Human Health Risks of Chemicals in our Environment, $2^{\text {nd }}$ ed., Cambridge University Press, 2007, Prologue, p. 4.

Ryan, K. J., Ray, C. G., Ahmad, N., Drew, W. L., \& Plorde, J. J. (2010). Sherris' Medical Microbiology: An Introduction to Infectious Diseases. McGraw-Hill, 2010, p. 567.

Sánchez, J. L., \& Taylor, D. N. (1997). C Cholera. The Lancet Seminars, the Lancet, 349 (no. 9068), $1825-1830$.

Scanlan, R. A. (2000). Nitrosamines and Cancer (2000). The Linus Pauling Institute Newsletter, 2000, Fall/Winter, Oregon State University: The Linus Pauling Institute, 2000.

Schwartz, D. J. (2014). Policy and the Transparency of Values in Science. Environmental Health Perspectives, 122(11), A291.

Seetula, J. A. (1996). Kinetics and thermochemistry of the $\mathrm{R}+\mathrm{HBr} \rightleftharpoons \mathrm{RH}+\mathrm{Br}$ equilibrium. J. Chem. Soc., Faraday Trans., 1996, 92, 3069.

Semmelweis, I. P. (1862). On the Origin and Prevention of Puerperal Fever. General Correspondence, Medical Times and Gazette (London), 1, $601-602$.

Sen, N. P., Schwinghamer, L. A., Donaldson, B. A., \& Miles, W. F. (1972). N-Nitrosodimethylamine in Fish Meal. Journal of Agricultural and Food Chemistry, 20(6), $1280-1281$.

Seyhan, N. E. (1989). Organic Chemistry: Structure and Reactivity, $2^{\text {nd }}$ ed., D.C. Heath \& Co., 1989, pp. 910.

Sigma Aldrich (2016). Information sheet on Adenosine 5'-diphosphoribose (sodium salt). Available at: http://www.sigmaaldrich.com/catalog/product/sigma/a0752?lang=en\&region=CA. Accessed: March 31, 2017.

Simonetti, J., Bulkow, L., McMahon, B. J., Homan, C., Snowball, M., Negus, S., Williams, J., \& Livingston, S. E. (2010). Clearance of Hepatitis B antigen and risk of hepatocellular carcinoma in a cohort chronically infected with hepatitis B virus. Hepatology, 51(5), 1531 1537. 
Simonetti, R.G., Cammà C., Fiorello F., Politi F, D’Amico G. Pagliaro L. (1991). Hepatocellular Carcinoma: A Worldwide Problem and the Major Risk Factors. Digestive Diseases and Sciences, 1991, 36 (7), pp. 962 - 972 (conference report).

Sindelar, J. J., \& Houser, T. A. (2009) Alternative Curing Systems. Chap. 15, Ingredients in Meat Products: Properties, Functionality and Applications, Tarté, R., Ed., Springer: New York, 2009, pp. 379 - 405. (Chapter 15: Alternative Curing Systems, Ingredients in meat products: properties, functionality and applications, R. Tarté, Ed., Springer, 2009, pp. 389 - 390.)

Singer, B. (1990). Alkylation, Mutagenesis and Repair. Mutation Research, 233(1-2), 235 245.

Slater, T. F. (1972). Hepatotoxicities of Carbon Tetrachloride. Chaps. $9 \& 10$ of Free Radical Mechanisms in Tissue Injury, Pion Ltd.: London, 1972.

Slater, T. F., \& Sawyer, B. C. (1971). The Stimulatory Effects of Carbon Tetrachloride and other Haologeno-Alkanes on Peroxidative Reactions in Rate Liver Fractions in vitro: General Features of the System Used. Biochemical Journal, 123(5), 805 - 814.

Snow J. (1855). On the Mode of Communication of Cholera, John Churchill: New Burlington Street, London, England, 1855.

Snow J. (1856). Cholera and the Water Supply in the South Districts of London in 1854. Journal of Public Health, 2, 239 - 257.

Stephen L. (1898). Dictionary of National Biography (1898), Volume 53, 1898, editor: Sir Leslie Stephen, Macmillan 1898, Great Britain.

Summers J. (1989). Broad Street Pump Outbreak. Soho - A History of London's Most Colourful Neighbourhood (bk), Bloomsbury Publishing Ltd: London, 113 - 117.

Swerdlow D.L. (1992). Waterborne Transmission of Epidemic Cholera in Trujillo, Peru: Lessons for a Continent at Risk. (Epidemiology), Lancet, 340(8810), 28 - 33.

Tabor E. (Editor). (2003). Preface to Viruses and Liver Cancer, Perspectives in Medical Virology, 6; Zuckerman, A.J., Mushahwar, I.K., Series Eds.; Elsevier, 2003.

Talbot, J. H. (1970). A Biographical History of Medicine: Excerpts and Essays on the Men and their Work, Grune and Stratton, $662-663$.

Teaf C. M. (2000). Properties and Effects of Organic Solvents. Chap. 16 in Principles of Toxicology: Environmental and Industrial Applications, Williams, P.L., James, R.C., Roberts, S.M., Eds.; John Wiley: New York, 2000, p. 396.

The RARECARE Project of the Foundazione IRCCS Instituto Natzionale Dei Tumori [Milan, Italy], was funded by the European Commission [EC] from April 1, 2007 to March 31, 2010, through its Public Health and Consumer Protection Directorate, DG SANCO). Available at http://www.rarecare.eu/rarecancers/rarecancers.asp. Accessed: March 31, 2017.

Thomas Wakley (from the Editorial, The Lancet 453, May 14, 1853). 
Timbrell J. (2000). Factors Affecting Metabolism and Disposition. Chap. 5 in Principles of Biochemical Toxicology, Taylor and Francis, 2000, p. 144.

Trafton A. (2015). New evidence for how a rare form of liver cancer arises. MIT News Office, April 1, 2015. Available at: http://news.mit.edu/2015/vinyl-chloride-liver-cancer-0401. Accessed: March 31, 2017. Chemistry \& Industry (editorial board). DETR: PVC Impact Not Excessive. Chemistry \& Industry, 2, 201.

Triggle N. (2004). In the Time of Cholera. BBC News Channel Report, September 13, 2004. Available at: http://news.bbc.co.uk/1/hi/health/3632856.stm. Accessed on: March 31, 2017.

Tschuikow-Roux, E., \& Paddison, S. (1987). Bond dissociation energies and radical heats of formation in $\mathrm{CH}_{3} \mathrm{Cl}, \mathrm{CH}_{2} \mathrm{Cl}_{2}, \mathrm{CH}_{3} \mathrm{Br}, \mathrm{CH}_{2} \mathrm{Br}_{2}, \mathrm{CH}_{2} \mathrm{FCl}$, and $\mathrm{CHFCl}_{2}$. International Journal of Chemical Kinetics, 19(1), 15-24.

Turner E. (2007). Noam Chomsky, Intellectual Elitism, Po-Mo Gibberish, More Attacks on Deconstruction, and Bad Writing Revisited. Biblioklept, March 14, 2007. Available at: https://biblioklept.org/2007/03/14/noam-chomsky-intellectual-elitism-po-mo-gibberish-moreattacks-on-deconstruction-and-bad-writing-revisited/. Accessed: March 31, 2017.

U.S. Center for Diseases Control (CDC). Angiosarcoma of the Liver Among Polyvinyl Chloride Workers - Kentucky. MMWR, 1974, 23, pp. 49-50 (February 9, 1974). Available at: http://www.cdc.gov/mmwr/preview/mmwrhtml/lmrk103.htm. Accessed: March 31, 2017.

U.S. Centers for Disease Control and Prevention (CDC), 2016. Data files. Available at: http://www.cdc.gov/nchs/nhanes/nhanes3/data_files.htm. Accessed: March 31, 2017.

U.S. Environmental Protection Agency (1998). Panel Report and Recommendations for Conducting Epidemiologic Research on Reproductive and Developmental Effects and Exposure to Disinfected Drinking Water. U.S.EPA., Research Triangle Park, North Carolina, 1998.

U.S. Environmental Protection Agency (2006). Stage 2 Disinfectants and Disinfection By-products Rule (Stage 2 DBPR), 71-FR-388, January 4, 2006, vol. 71, no. 2. Available at: https://nepis.epa.gov/Exe/ZyPDF.cgi?Dockey=P100C8XW.txt. Accessed: March 31, 2017.

U.S. Environmental Protection Agency (2015). Emergency Disinfection of Drinking Water. Available https://www.epa.gov/sites/production/files/2015-11/documents/epa816f15003.pdf.

U.S. Environmental Protection Agency (2016). Dense non-aqueous phase liquids (toxicology). Available

https://cluin.org/contaminantfocus/default.focus/sec/Dense_Nonaqueous_Phase_Liquids_(D NAPLs)/cat/Toxicology/p/2/n/6. Accessed: Dec 9., 2016.

U.S. Food \& Drug Administration (2016). Code of Federal Regulations Title 21. Vol. 31, Part 172 - Food additives permitted for direct addition to food for human consumption. Subpart B--Food Preservatives. Sec. 172.175: Sodium nitrite. Available at:https://www.accessdata.fda.gov/scripts/cdrh/cfdocs/cfcfr/CFRSearch.cfm?fr=172.175. 
Accessed: March 31, 2017.

UK Food Standards Agency (2016). Food Additives Legislation Guidance to Compliance. October 2016. Available at: https://www.food.gov.uk/.../food-additives-legislation-guidance-to-compliance.pdf. Accessed: March 31, 2017.

United Nations (UN) Water. 2014. Agriculture is the biggest water user, with irrigation accounting for $70 \%$ of global water withdrawals. Available at: http://www.unwater.org/statistics/statistics-detail/en/c/246663/. Accessed: March 31, 2017.

United Nations (UN) Water. 2014. Population increase implies increased freshwater demand of about 64 billion cubic metres a year.Available at: http://www.unwater.org/statistics/statistics-detail/en/c/211814/. Accessed: March 31, 2017.

United Nations (UN) Water. 2014. Water Quality. Available at: http://www.unwater.org/statistics/statistics-detail/en/c/260727/. Accessed: March 31, 2017.

United Nations Children's Fund (UNICEF). 2015. Progress on Sanitation and Drinking Water: 2015 Update and MDG Assessment.Available at: https://www.unicef.org/publications/index_82419.html. Accessed: March 31, 2017.

United Nations Education Scientific and Cultural Organization (UNESCO). 2016. The United Nations World Water Development Report (2016): Water and Jobs, pp. 39, 47. UNESCO, 7 , place de Fontenoy, 75352 Paris 07 SP, France. Available at: http://unesdoc.unesco.org/images/0024/002439/243938e.pdf. Accessed: March 31, 2017.

Vollhardt, K. P., \& Schore N. E. (1999). Amines and their Derivatives. Chap. 21 in Organic Chemistry, Structure and Function, $3^{\text {rd }}$ ed., W.H. Freeman: New York, 1999, pp. 959 $-961$.

Vollhardt, K. P., \& Schore N.E. (2007). Amines and their Derivatives. Chap. 21 in Organic Chemistry: Structure \& Function, $5^{\text {th }}$ ed., W.H. Freeman, 2007, pp. 980.

Wang, X. W. et al. (10 authors). (1995). p53 Modulation of TFIIH-associated Nucleotide Excision Repair Activity. Nature Genetics, 10(2), 188 - 195.

Warren, W., Biggs, P. J., El-Baz, M., Ghoneim, M. A., Stratton, M. R., \& Venitt, S. (1995). Mutations in the $p 53$ Gene in Schistosomal Baldder Cancer: A Study of 92 Tumours from Egyptian Patients and a Comparison between Mutational Spectra from Schistosomal and Non-Schistosomal Urothelial Tumours. Carcinogenesis, 16(5), 1181 - 1189.

Water Aid. Annual Report, 2006/07. London, UK, 2007, p. 44.

Weiss R. (2002). Challenges for Humanity: War on Disease. National Geographic, 2002, February, pp. $12-13$.

Whanger, P. D. (1989). China, a Country with both Selenium Deficiency and Toxicity: Some Thoughts and Impressions. Journal of Nutrition, 119(9), 1236-9. 
White, G. C. (1992). The Handbook of Chlorination and Alternative Disinfectants, $3^{\text {rd }}$ ed., Van Nostrad Reinhold: New York, 1992.

Willey, J., Sherwood, L., \& Woolverton, C. (2009). Prescott's Principles of Microbiology, McGraw-Hill, 2009, p. 35.

Wisconsin Department of Health Services (Wisconsin, USA). Chemical Fact Sheets: Chloroform. Last Revised: July 12, 2010. Available at: www.dhs.wisconsin.gov/eh/chemFS/fs/chloroform.htm. Accessed: March 31, 2017.

Wogan, G. N. (1992). Aflatoxins as Risk Factors for Hepatocellular Carcinoma in Humans. Cancer Research, 1992, 52, pp. 2114s - 2118s.

Woodham-Smith C.B., OBE. (1951). Florence Nightingale, 1820-1910. McGraw-Hill: New York, 1951.

World Health Organization (1991). Chlorinated Drinking-Water, Chlorination By-Products, some other Halogenated Compounds; Cobalt and Cobalt Compounds. International Agency for Research on Cancer (IARC) Monographs on the Evaluation of Carcinogenic Risks to Humans, Vol. 52, World Health Organization, Lyon, France, 1991.

World Health Organization (1993). Recommendations for Drinking Water Quality (Training Package), $2^{\text {nd }}$ ed. Vol. 1. WHO: Geneva, December 1993.

World Health Organization (1993). Recommendations for Drinking Water Quality (Training Package), $2^{\text {nd }}$ ed., vol. 1. WHO: Geneva, December 1993.

World Health Organization (1998). The World Health Report 1998-Life in the 21st Century: A Vision for All. WHO: Geneva, 1998.

World Health Organization (1998). The World Health Report 1998 --- Life in the 21st Century: A Vision for All. WHO, Geneva, 1998.

World Health Organization (2000). Health hazards of Poor Water Supply and Sanitation. Box 1.2 in Section 1.1 (Main findings), Chap. 1: The Global Water Supply and Sanitation Assessment 2000, in Global Water Supply and Sanitation Assessment 2000 Report, WHO, 2000.

World Health Organization (2000). Summary of Results on Cancer Studies. Section 5.2.1.4, in Chap. 5, Epidemiological Studies, in Environmental Health Criteria 216: Disinfectants and Disinfectant By-products. International Programme on Chemical Safety, WHO: Geneva, 2000, p. 322. Available at: http://www.inchem.org/documents/ehc/ehc/ehc216.htm. Accessed: March 31, 2017.

World Health Organization (2004). IARC Monographs on the Evaluation of Carcinogenic Risks to Humans, Vol. 84: Some drinking water disinfectants and contaminants, including Arsenic. Lyons, France, 2004, pp. 441.

World Health Organization. (2005). Trihalomethanes in Drinking Water. WHO/SDE/WSH/05.08/64. Available at: 
http://www.who.int/water_sanitation_health/dwq/chemicals/THM200605.pdf.Accessed: March 31, 2017.

World Health Organization. (2005). WHO position paper on Oral Rehydration Salts to reduce mortality from cholera. WHO: Geneva, 2008.

World Health Organization. (2016). Arsenic. Available at: http://www.who.int/mediacentre/factsheets/fs372/en/. Accessed: March 31, 2017.

World Health Organization. (2017). World Water Day, 2017. Why Waste Water? Available at: http://www.who.int/water_sanitation_health/news-events/world-water-day-2017/en/.

Accessed: March 31, 2017.

World Health Organization. (2016). Cholera - United Republic of Tanzania. Available at: http://www.who.int/csr/don/22-april-2016-cholera-tanzania/en/. Accessed: March 31, 2017.

Yamamoto, H., Nagano, T., \& Hirobe, M. (1988). Carbon tetrachloride toexicity on E. coli exacerbated by Superoxide. Journal of Biological Chemistry, 263(25), 12224 - 7.

Yang, C. S., Yoo, J. S., Ishizaki, H., \& Hong, J. Y. (1990). Cytochrome P450 II-El: Roles in Nitrosamine Metabolism and Mechanisms of Regulation. Drug Metabolism Reviews, 22(2), $147-159$.

Young, J. L. Jr., Smith, M. A., Roffers, S. D., Liff, J. M., \& Bunin, G. R. (1999). Retinoblastoma. Chap. 5 in Cancer Incidence and Survival among Children and Adolescents: United States SEER Program 1975-1995; Ries, L.A.G., Smith, M.A., Gurney, J.G., Linet. M., Tamra, T., Young, J.L., Bunin, G.R., Eds.; National Cancer Institute, SEER Program. NIH Pub. No. 99-4649. Bethesda, MD, 1999.

\section{Copyrights}

Copyright for this article is retained by the author(s), with first publication rights granted to the journal.

This is an open-access article distributed under the terms and conditions of the Creative Commons Attribution license (http://creativecommons.org/licenses/by/4.0/) 